\title{
DETERMINAÇÃO DAS CONCENTRAÇÕES SÉRICAS DE $\alpha$ - TOCOFEROL EM PACIENTES PORTADORES E NÃO PORTADORES DE DIABETES MELLITUS DO TIPO 2 DO MUNICÍPIO DE JUNDIAÍ-SP.
}

\section{VANESSA KRISTINNE ILLISON}

Dissertação apresentada ao Departamento de Nutrição da Faculdade de Saúde Pública da Universidade de São Paulo para obtenção do título de Mestre em Saúde Pública.

Área de concentração: Nutrição

Orientador: Prof". Drª ${ }^{2}$. Patrícia Helen de Carvalho Rondó

São Paulo 2006 
DETERMINAÇÃO DAS CONCENTRAÇÕES SÉRICAS DE $\alpha$ TOCOFEROL EM PACIENTES PORTADORES E NÃO PORTADORES DE DIABETES MELLITUS DO TIPO 2 DO MUNICÍPIO DE JUNDIAÍ-SP.

VANESSA KRISTINNE ILLISON

São Paulo

2006 


$$
46840 / 2006 d x
$$

Autorizo, exclusivamente para fins acadêmicos e científicos, a reprodução total ou parcial desta tese, por processos fotocopiadores.

Assinatura:

Data: 
Este trabalho é dedicado a ...

Meus pais Tomi e Eneide que me ensinaram a viver com dignidade e iluminaram os caminhos obscuros com afeto e dedicação para que eu pudesse trilhar sem medo e cheia de esperanca.

Meu amor Celso, que pacientemente me acompanhou nos bons momentos e também nas horas de maior angústia, sempre me incentivando e tornando meus dias melhores.

Aos meus irmãos Jeannie e Richard pelo companheirismo e apoio todos os dias.

A todos os pacientes que gentilmente nos qujuaram, pois sem eles este trabalho nunca teria existido. 


\section{AGRADECIMENTOS}

A realização deste trabalho só foi possivel graças à colaboração de várias pessoas e instituiç̃es, às quais sou grata e registro aqui meus sinceros agradecimentos:

i Prof. Orf. Patricia Helen de Carvalho Rondó, pela orientaşão e confiansa:

i Fundação de Amparo à Pesquisa do Estado de São Paulo (FAPESP) pelo financiamento do projeto:

Ao Conselho Nacional de Desenvolvimento Científico $e$ Tecnológico (CNPq), pelo auxilio concedido através da bolsa de Mestrado:

Ao Or. Ericson Bagatin por ter autorizado a realização do projeto no municipio de Jundiai: 
Ao Or. Homero e Dra. Beatriz por gentilmente terem cedido o banco de dados com os pacientes diabéticos do municipio de Jundiai:

A Solange e Angela, funcionárias do NIS-Jundiai pela atenģão - gentileza:

A técnica de laboratório e amiga Rosana A.S.Manólio, pela indispensável ajuda com seus conhecimentos de Química:

i Andréia M. Oliveira, companheira de trabalho, pelo imprescindivel auxilio em todas as fases de elaboraçäo do projeto:

A Fátima e Kátia pela ajuda indispensável e sobretudo pela amizade verdadeira:

A Joilane, Sheila, Josimara e Jesuana no auxilio na Antropometria: 
A Maria Cecilia Bento, indispensável ma colheita do sangue:

A todos os funcionários das policlínicas do Retiro e Hortolândia que disponibilizaram as dependências para a realização da colheita:

A Yara, Silmara, Erli e Iramaia pela ajuda nas análises estatísticas e pela amizade:

A todas as colegas da FSP, pelo companheirismo e amizade:

Aos funcionários da Comissão de Pós-Graduação, pelo empenho ao curso: 
"Morre lentamente quem näo viaja, quem não ts, quem não ourve música, quem näo encontra graga en si mesmo.

Morre lentamente quem se transforma en escravo do hábito, repetindo todos os dies os mesmos trajetos, quem näo muda de marca, näo se arrisca a vestir ume nova cor ou näo conversa com quem näo conhece.

Morre lentamente quem evita uma paixäo, quem prefere o negro sobre 0 branco e os pontos sobre os "is" em detrimento de um redemointo de emogäes, justamente as que resgatam o brilho dos olhos, coragärs aos tropegos.

Morre lentamente quem näo vira a mesa quando estó infeliz com seu trabalho, quem mão arrisca o certo pelo incerto para ir atrós de um sonho, quern näo se permite pelo menos uma vez na vida fugir dos conselhos sensatos.

Evitemos a morte em doses seaves, recordando sempre que estar vivo exige un esforgo bem maior que o simples fato de respirar". 


\section{RESUMO}

Illison, V.K. Determinação das concentrações séricas de $\alpha$ - tocoferol em pacientes portadores e nžo portadores de diabetes mellitus do tipo 2 do município de Jundiaí SP. São Paulo, 2006. [Tese de Mestrado - Faculdade de Saúde Pública, Universidade de São Paulo]

Objetivo: Este estudo investigou 1) as concentrações séricas de $\alpha$-tocoferol em pacientes com DM2 e em pessoas não diabéticas 2) a relação entre a concentração sérica deste antioxidante e o consumo de vitamina $\mathrm{E}$ da dieta em pacientes com DM2 e em pessoas não diabéticas. Metodologia: Estudo do tipo caso- controle envolvendo 58 pessoas portadoras de DM2 e 58 pessoas não portadoras de DM2 realizado no município de Jundiaí - SP, em Setembro e Outubro de 2005. As concentrações séricas de $\alpha$ - tocoferol foram determinados por HPLC e os níveis plasmáticos de glicose, colesterol total e frações e triglicérides por método enzimático colorimétrico. Foram considerados normais, concentrações séricas de $\alpha$ - tocoferol $>11,6 \mu \mathrm{mol} / \mathrm{L}$ e deficientes $\leq 11,6 \mu \mathrm{mol} / \mathrm{L}$. $O$ consumo de alimentos fonte em vitamina $\mathrm{E}$, foi avaliado por questionário de freqüência alimentar, utilizando-se escores. Análise de ANCOVA foi utilizada na comparação das médias das concentrações séricas de $\alpha$ - tocoferol entre os grupos ajustadas por covariáveis. Análises de regressão linear multivariada investigaram a relação das concentrações séricas de $\alpha$ - tocoferol em pacientes com e sem DM2 ajustadas pelas variáveis de confusão. Resultados: A média de covariância para o $\alpha$ - tocoferol nos pacientes caso foi 13,20 $\mu \mathrm{mol} / \mathrm{L}$ [IC(95\%): $12,16-14,23 \mu \mathrm{mol} / \mathrm{L}]$ e nos pacientes controle foi $13,52 \mu \mathrm{mol} / \mathrm{L}$ [ IC(95\%): $12,48-14,56 \mu \mathrm{mol} / \mathrm{L}]$. Não houve diferença estatística significante entre os grupos na deficiência de $\alpha$ - tocoferol ( $p>0,05 ; p=0,698)$. $O$ modelo final de regressão linear para o grupo caso mostrou associação estatística significante entre concentrações séricas de $\alpha$-tocoferol e colesterol total $(\beta=0,0288 ; p<0,05)$ e triglicérides $(\beta=0,01849$; $p<0,01)$ e entre concentrafões séricas de $\alpha$ - tocoferol e colesterol total plasmático $(\beta=$ $0,04071 ; p<0,05)$ e IMC $(\beta=0,248 ; p<0,05)$ para o grupo controle. Não houve associação estatística entre níveis séricos de $\alpha$ - tocoferol e vitamina $E$ consumida da dieta em nenhum dos grupos $(p>0,05)$. Conclusão: $A$ prevalência de deficiência de $\alpha-$ tocoferol mostrou-se elevada nos dois grupos do estudo, não havendo diferença estatística 
entre os mesmos. O DM2 não acarretou muito impacto nas concentraç̃es de $\alpha$ - tocoferol, provavelmente pelo fato da dieta apresentar baixo consumo para os dois grupos estudados.

Descritores: Diabetes Mellitus 2, estresse oxidativo, $a$ - tocoferol 


\section{SUMMARY}

Illison, V.K. Serum alpha-tocopherol status in diabetes mellitus 2 and healthy patients in Jundiaí city - SP. São Paulo, 2006. [Tese de Mestrado - Faculdade de Saúde Pública, Universidade de São Paulo]

Objectives: This study investigated 1) the serum concentrations of $\alpha$-tocopherol in patients with diabetes mellitus 2 (DM2) and healthy individuals; 2) the relationship between concentrations of vitamin $\mathrm{E}$ in blood and in the diet of patients with DM2 and healthy individuals. Methods: Case- Control study involving 58 DM2 and 58 healthy individuals in Jundiai city - SP, from September to October 2005. The serum $\alpha$-tocopherol concentrations were measured using High Performance Liquid Chromatography. Glucose, total cholesterol and triglycerides were measured by means of an enzymatic assay. Serum vitamin $\mathrm{E}$ concentrations higher than $11,6 \mu \mathrm{mol} / \mathrm{L}$ are considered as normal concentrations. The frequency of ingestion of foods rich in vitamin $\mathrm{E}$ was measured using a questionnaire categorized into scores. ANCOVA analysis was utilized to compare mean concentrations of $\boldsymbol{\alpha}-$ tocopherol between cases and controls, adjusting for several variables. Multivariater linear regression analysis was carried out to evaluate the predictors of the $\alpha$ - tocopherol concentrations adjusting for confounding variables in the DM2 and healthy individuals. Results: The $\alpha$ - tocopherol covariance mean in the case group was $13,20 \mu \mathrm{mol} / \mathrm{L}$ [IC(95\%): $12,16-14,23 \mu \mathrm{mol} / \mathrm{L}]$ and in the control group was 13,52 $\mu \mathrm{mol} / \mathrm{L}$ [ IC(95\%): $12,48-14,56 \mu \mathrm{mol} / \mathrm{L}]$. There was no difference between mean $\alpha$ - tocopherol concentrations in the case and control groups $(p>0,05 ; p=0,698)$. The final multiple linear regression model for $\alpha$-tocopherol in the case group showed statistical association between serum $\alpha$ - tocopherol concentrations and total cholesterol $(\beta=0,0288 ; p<0,05)$ and triglycerides $(\beta=0,01849 ; p<0,01)$. The control group showed statistical association between serum $\alpha$ - tocopherol concentrations and total cholesterol $(\beta=0,04071 ; p<0,05)$ and body mass index (BMI) $(\beta=0,248 ; p<0,05)$. There was no difference between serum $\alpha-$ tocopherol concentration and dietary vitamin $E$ in both groups $(p>0,05)$. Conclusion: The prevalence of low serum $\alpha$-tocopherol concentrations in this study showed higher in both group without statistical difference. The DM2 did not cart many impact in serum $\alpha-$ tocopherol concentrations probably the low dietary intake vitamin $\mathrm{E}$ in both groups.

Descritores: Diabetes Mellitus 2, oxidative stress, $\alpha$ - tocopherol 


\section{ÍNDICE}

1- INTRODUÇÃO

1.1- Radicais Livres e defesas antioxidantes no DM2 13

1.2- Vitamina E 20

2- OBJETIVOS 29

2.1. Objetivo Geral 30

2.2- Objetivos Específicos $\quad 30$

3- CASUÍ́STICA E MÉTOdOS 31

3.1- Delineamento, Seleção dos grupos e População 32

3.2- Amostragem 35

3.3- Variáveis do Estudo $\quad 36$

3.3.1- Variáveis descritivas dos pacientes com e sem DM $2 \quad 35$

3.3.2- Variáveis de interesse para pacientes com DM2 35

3.3.3- Variáveis de interesse para pacientes sem DM2 35

3.3.4- Variáveis antropométricas de pacientes com e sem DM2 36

3.4- Freqüência Alimentar 36

3.5- Testes estatísticos $\quad 37$

3.6- Levantamento dos dados $\quad 38$

3.6.1 Técnica de colheita de dados 38

3.6.2- Colheita de amostras de sangue $\quad 40$

3.6.3- Antioxidantes sanguíneos $\quad 42$

3.6.4- Dosagem de $\alpha$ - tocoferol 43

3.7- Aspectos éticos 45 
4.1- Abrangência do estudo 48

4.1.2- Características sócio-demográficas dos grupos 48

4.1.3- Hábitos de fumar e beber dos grupos 50

4.1.4- Características do grupo caso

4.1.5- Presença de morbidades nos grupos 53

4.1.6- Medicamentos e suplementos vitamínicos dos grupos $\quad 53$

4.1.7- Características antropométricas dos grupos $\quad 54$

4.1.8- Características bioquímicas dos grupos $\quad 57$

4.1.9- Concentração de $\alpha$ - tocoferol sérico nos grupos 59

4.2- Freqüência do consumo de alimentos fonte de $\alpha$-tocoferol 63

5.0- DISCUSSÃO

5.1- Validade do estudo $\quad 68$

5.2- Características gerais dos grupos 69

5.3- Concentrações séricas de $\alpha$ - tocoferol nos grupos 71

6.0- CONCLUSÕES

7.0- CONSIDERAÇÕES FINAIS

8.0- REFERÊNCIAS BIBLIOGRÁFICAS

$\begin{array}{ll}\text { ANEXOS } & 98\end{array}$

Anexo 1 - Termo de consentimento livre e esclarecido 99

Anexo 2- Formulário de entrevista 100

$\begin{array}{ll}\text { Anexo 3- Ficha de avaliação } & 103\end{array}$

$\begin{array}{ll}\text { Anexo 4- Questionário de consumo alimentar } & 104\end{array}$ 
Anexo 5- Comitê de Ética 


\section{LISTA DE TABELAS}

Tabela 1: Taxa de prevalência de DM2 na população de 30 a 69 anos de idade* em municipios de algumas capitais estaduais, Brasil ,1988.

Tabela 4.1.1- Número e percentual de pacientes caso e controle, segundo sexo, escolaridade e renda mensal, Jundiaí - SP, 2005.

Tabela 4.1.2 - Número e percentual de pacientes caso, segundo tempo de DM2, Jundiaí SP, 2005.

Tabela 4.1.3- Média e desvio padrão, de ariáveis antropométricas de pacientes caso e controle, segundo sexo, Jundiaí - SP, 2005.

Tabela 4.1.4- Número, percentual, média e desvio padrão de variáveis bioquímicas, segundo grupo caso e controle, Jundiaí - SP, 2005

Tabela 4.1.5: Médias estimadas, desvio padrão e intervalo de confiança das concentraçð̃es séricas de $\alpha$-tocoferol, segundo grupo caso e controle, Jundiai - SP, 2005.

Tabela 4.1.6: Coeficiente de correlação de Pearson entre $\alpha$-tocoferol e variáveis de interesse clínico, Jundiai - SP, 2005

Tabela 4.1.7: Coeficiente de correlação de Pearson entre $\alpha$-tocoferol e frações lipídicas nos grupos caso e controle, Jundiaí - SP, 2005.

Tabela 4.1.8: Modelo de regressão linear para as concentrações séricas de $\alpha$ - tocoferol dos pacientes do grupo caso, Jundiaí- SP, 2005. 
Tabela 4.1.9: Modelo de regressão linear para as concentrações séricas de $\alpha$ - tocoferol dos pacientes do grupo controle, Jundiaí- SP, 2005.

Tabela 4.2: Freqüência de consumo de alimentos ricos em vitamina $E$, segundo grupo caso e controle, Jundiaí - SP, 2005.

Tabela 4.2.1 : Estatística descritiva dos escores de freqüência de consumo de alimentos fontes de vitamina E, segundo grupos caso e controle, Jundiaí-SP, 2005 


\section{LISTA DE QUADROS E FIGURAS}

Quadro 1- Graus de tolerância a glicose segundo critérios da American Diabetes Association

Quadro 2- Critérios de controle para o DM2 e co-morbidades associadas segundo American Diabetes Association

Quadro 3- Comparação de vitamina E status

Figura 1: Formação de ERMO

Figura 2: Estrutura química da vitamina $E$

Figura 3: Esquema de absorção e transporte de vitamina E no homem

Figura 4 : Mapa da cidade de Jundiaí- SP

Figura 4.1- Percentual de pacientes caso e controle, segundo hábito de fumar

Figura 4.2- Percentual de pacientes caso e controle, segundo hábito de ingerir bebidas alcoólicas

Figura 4.3 - Estado nutricional (IMC) do grupo caso e controle, segundo sexo

Figura 4.4 - Distribuição percentual de paciente caso e controle, segundo concentrações séricas de $\alpha$-tocoferol

Figura 4.5 - Concentrações séricas de $\alpha$-tocoferol nos grupos caso e controle, segundo escores médios de consumo de alimentos ricos em vitamina E, Jundiaí - SP, 2005 
1-Introducão 


\section{INTRODUÇÃo}

O diabetes tipo 2 (DM2) é uma das principais síndromes de evolução crônica que acomete a populacão nos dias atuais sendo considerado como um dos maiores problemas em Saúde Pública, causando alta mortalidade, morbidade e danos econômicos aos seus portadores. Apesar do aumento na prevalência e incidência do DM 2 ter ocorrido globalmente, este quadro tem sido especialmente dramático em sociedades em transição econômica e em países em desenvolvimento. Segundo SOUZA e col. (2003), a prevalência do DM2 vem crescendo significativamente com o processo de industrialização e urbanização populacional dos últimos anos.

BOUCHE (2003) reporta que o custo do DM2 para o indivíduo e para a sociedade, o crescimento do número de casos e as complicaçoes subseqüentes, tornam as medidas de prevenção e controle da doença de extrema importância SARTORELLI \& FRANCO (2003) também mencionam que, pelo fato do DM2 estar associado a altos índices de hospitalizaçð̃es, as maiores necessidades de cuidados médicos e diversas complicações, pode-se prever que isso representará uma grande carga para os sistemas de saúde dos paises latino americanos.

Segundo a OMS (2003) o aumento na prevalência e incidência do DM2 deve ocorrer globalmente e os 150 milhores de casos da doença dobrará até o ano 2025. Nas Américas, o número de indivíduos com diabetes DM2 foi estimado em 35 milhões para o ano 2000 e projetado para 64 milhões em 2025.

O DM2 é uma doença multifatorial, heterogênea e corresponde de 80 a $90 \%$ de todos os casos de diabetes no mundo. Atualmente sabe-se que, pacientes com DM2 apresentam razão de mortalidade maior do que aqueles que não apresentam a doença e que está intimamente relacionada ao aumento na frequêêcia de doenças cardiovasculares (SALLES e col. 2004). 
Em estudo realizado por BARCELÓ \& RAJPATHAK (2001) na América Latina, observou-se uma prevalência para o DM 2 correspondendo a $14,9 \%$ no México, 8,9\% no Paraguai e 7,9\% no Brasil, em indivíduos na faixa etária de 34-64 anos de idade. Mas, conforme estudo do Ministério da Saúde em inquérito amostral realizado em várias capitais Brasileiras, a prevalência de indivíduos com DM2 pode ser visualizada na tabela 1.

Tabela 1: Taxa de prevalência de DM 2 na população de 30 a 69 anos de idade* em municipios de algumas capitais estaduais, Brasil ,1988.

\begin{tabular}{c|c}
\hline Capitais Selecionadas & Prevalência \\
\hline Brasília & 5,2 \\
\hline Belém & $\mathbf{7 , 2}$ \\
\hline Fortaleza & 6,5 \\
\hline João Pessoa & $\mathbf{8 , 0}$ \\
\hline Recife & 6,4 \\
\hline Salvador & $\mathbf{7 , 9}$ \\
\hline Rio de Janeiro & $\mathbf{7 , 5}$ \\
\hline São Paulo & 9,7 \\
\hline Porto Alegre & $\mathbf{8 , 9}$ \\
\hline Total & $\mathbf{7 , 6}$ \\
\hline
\end{tabular}

* Taxa estimada, ajustada por idade

Fonte: Ministério da Saúde/SPS. Estudo Multicêntrico de prevalência do diabetes melittus no Brasil

A glicose é a principal fonte de energia para o funcionamento das células. Em condiç̋̃es normais a insulina, hormônio produzido pelas células $B$ das ilhotas de Langerhans no pâncreas, promove o transporte da glicose para dentro das células, músculos e tecido adiposo. Quando a insulina liga-se aos seus receptores na membrana, aproximadamente $80 \%$ das células do corpo (excetuando-se os neurônios do cérebro), tornam-se permeáveis permitindo a rápida entrada de glicose. A principal forma de transporte de glicose nas células é através de difusão facilitada, com participação de proteinas de membrana especificas. A insulina age no receptor localizado na membrana plasmática, desencadeando uma cascata de sinais 
intracelulares envolvendo principalmente reaçðes de fosforilação citosólica, provocando a translocação das vesículas que captam a glicose circulante para o interior da célula, onde passará a ser substrato para todas as funçôes metabólicas habituais dos carboidratos (PEREIRA e col, 2003).

Grande parte da glicose circulante no estado pós-absortivo é captada por órgãos independentes da insulina como o cérebro (50\%) e órgãos esplâncnicos (25\%), sendo que apenas o restante é utilizado em tecidos dependentes da insulina, principalmente a musculatura esquelética e em segundo lugar o tecido adiposo. Na musculatura esquelética, a maior parte da glicose transportada para as células musculares é armazenada sob a forma de glicogênio, que pode ser posteriormente utilizada pelos músculos para fins energéticos. No tecido adiposo, a insulina inibe a ação da lipase sensivel a hormônios, enzima que causa a hidrólise dos triglicerídeos armazenados nas células adiposas, evitando a liberação dos ácidos graxos para o sangue circulante. Porém, o mais importante, é que a insulina aumenta o transporte e o metabolismo de glicose nos adipócitos formecendo o substrato glicerol-3-fosfato para a síntese de triacilglicerois.(GUYTON \& HALL, 1998).

Logo após a ingestão de uma refeição, cerca de $60 \%$ da glicose é imediatamente armazenada no figado sob a forma de glicogênio hepático pela ação da insulina. Entre as refeições, quando não há alimento disponível e a concentração sanguínea de glicose começa a diminuir, o glicogênio hepático é novamente decomposto em glicose, que volta a ser liberada para o sangue impedindo que a concentração sanguínea de glicose sofra uma diminuição acentuada. $O$ mecanismo pelo qual a insulina causa a captação e o armazenamento da glicose no figado inclui a inativação da fosforilase hepática, enzima que faz o glicogênio hepático se decompor em glicose, o aumento da captação da glicose sanguínea através do aumento da atividade da glicoquinase, enzima que causa a fosforilaça inicial da glicose depois que esta se difunde nas células hepáticas e aumento da atividade das enzimas que promovem a sintese de glicogênio. Quando o nível de glicose sanguínea torna-se baixo entre as refeições, ocorre então a secreção da insulina pelo pâncreas, que reverte o mecanismo de armazenamento da glicose pelo figado (GUYTON \& HALL, 1998). 
A manutença precisa da homeostase da glicose depende quase exclusivamente da apropriada secreção da insulina e da eficácia desta nos tecidos periféricos. Assim, a insulina inibe a gliconeogênese através da reduçăo da quantidade e atividade das enzimas hepáticas e por meio da aceleração da absorção da glicose nos tecidos periféricos (RUHE e cols, 2001).

Em individuos saudáveis, independentemente das calorias ingeridas, as concentraç̃es de glicose no sangue variam entre 87 e $108 \mathrm{mg} / \mathrm{dL}$, conforme estudos realizados por DIAMOND e col. (2003). Mas, segundo a American Diabetes Association citado por HIRAI e col. (2004, p. 85), os graus de tolerância à glicose são definidos de acordo com o quadro abaixo.

Quadro 1. Graus de tolerância à glicose segundo os critérios da American Diabetes Association, (1997).

\begin{tabular}{|l|c|c|}
\hline \multicolumn{1}{|c|}{$\begin{array}{c}\text { Grau de tolerância a } \\
\text { glicose }\end{array}$} & $\begin{array}{c}\text { Glicemia de jejum } \\
(\mathrm{mg} / \mathrm{dl})\end{array}$ & $\begin{array}{c}\text { Glicemia de duas horas p6s- } \\
\text { sobrecarga (mg/dl) }\end{array}$ \\
\hline Normal & $70-100$ & Até 140 \\
\hline Glicemia de jejum alterada & $100-126$ & Até 140 \\
\hline $\begin{array}{l}\text { Tolerância à glicose } \\
\text { diminuída }\end{array}$ & $<126$ & $140-199$ \\
\hline Diabetes mellitus & $>126$ & $>200$ \\
\hline
\end{tabular}

*Individuos com glicemia casual $>200 \mathrm{mg} / \mathrm{dl}$ são considerados diabéticos.

Qualquer desequilibrio na captação da glicose periférica pode levar à intolerância à glicose ou mesmo ao diabetes mellitus. A intolerância a glicose é definida como um estágio intermediário entre a homeostase normal da glicose e o diabetes (ADA, 1997). Assim, a tolerância à glicose é mantida normal pela relação inversa entre a sensibilidade e a secreção da insulina, isto é, quanto maior a sensibilidade à insulina, menor a produção desta pelas células B do pâncreas (DAVIDSON, 1995). 
Quando há uma menor utilização de glicose pelas células, o pâncreas procura compensar a reduzida entrada de glicose, aumentando a produção de insulina, o que pode provocar a elevação dos niveis circulantes desse hormônio (hiperinsulinemia). A sensibilidade à insulina significa uma diminuição na capacidade da insulina em estimular a utilização da glicose, seja com deficiência no receptor de insulina ou com defeito em algum mecanismo pós-receptor durante sua utilização (KIM e col. 1996; ADA, 1997). A hipótese metabólica sugerida por FELBER e col. (1993) para o surgimento da sensibilidade à insulina é o aumento na oxidação lipídica, condição geralmente observada em pessoas com diabetes e obesidade. A sensibilidade à insulina é baseada em mecanismos fisiológicos que incluem uma série de retroalimentaçð̃es negativas como a inibição da função do ciclo de glicogênio devido a consequaente diminuição da utilização da glicose resultando no aumento da oxidação lipídica.

A sensibilidade à insulina é denominada de fase pré-hiperglicêmica do DM2 e a deficiência na secreção caracteriza a fase hiperglicêmica da doença ( GORDEN, 1997).

O DM2 é originado por uma disfunção na homeostase da glicose e é causado tanto pela inabilidade dos tecidos periféricos em responder aos estímulos da insulina, como também por uma dimimuiçăo da sensibilidade das células $B$ do pâncreas à estimulação da glicose (AHMAD e cols., 2003).

A hiperglicemia crônica pode provocar glicotoxicidade e falência das células $\beta$ das ilhotas de Langerhans sem que haja um aumento na sintese destas células, resultando em deficiência na secreção de insulina. A hiperglicemia crônica também poderia levar a várias alteraç̋es como: redução dos transportadores de glicose localizados nas células $\beta$, redução da quantidade de transportadores nos tecidos musculares esqueléticos ou da capacidade de cada transportador carrear glicose, ou ainda de uma glicação de algumas proteínas ou enzimas envolvidas no metabolismo da glicose, 
como a glicoquinase, localizada nas células $\beta$, que age como "sensor de glicose" nestas células (PEREIRA e col, 2003).

O DM2 pode estar associado a outras morbidades que podem aumentar o risco de desenvolvimento de doenças cardiovasculares como infarto do miocárdio e acidente vascular cerebral AVC). Assim, vários estudos observaram a estreita relação entre intolerância à glicose e hiperglicemia a hipertrigliceridemia, colesterol HDL baixo, hipertensão e obesidade, caracterizando a síndrome metabólica (DEEDWANIA, 2004; NINOMIYA e col. 2004; MARROQUIN e col. 2004)

A sindrome metabolica em adultos, na Europa afeta cerca de 10 milhóes de pessoas e nos Estados Unidos afeta aproximadamente 47 milhőes de pessoas, sendo que 7\% da prevalencia encontra-se na faixa etária de 20 a 29 anos e $40 \%$ encontra-se na faixa de 60 anos ou mais, e a tendência é que a prevalência continue aumentando devido ao aumento dos casos de obesidade e envelhecimento da populaçăo (CHRIST e col. 2003; KIP e col. 2004).

Segundo DEEDWANIA (2004) a sensibilidade à insulina é a alteração primária que mais contribui para as modificaçøes encontradas na síndrome metabólica, sendo a obesidade (principalmente obesidade abdominal) um fator de risco importante para seu desenvolvimento. Mas, deve-se considerar também que um aumento no estresse oxidativo, a diminuição na fibrinólise, microalbuminúria, anormalidades na regulação autonômica e ativação do sistema renina-angiotensina-aldosterona também contribuem no contexto fisiopatológico da síndrome metabólica (MARROQUIN e col, 2004, CHRIST e col. 2004, NINOMIYA e col. 2004).

A intolerância a glicose, sensibilidade à insulina e o DM2 tem sido descrito por vários pesquisadores como resultante de interações entre fatores genéticos e ambientais. Dentre os fatores ambientais podem ser citados alteraços nas dietas e hábitos alimentares que aliados à inatividade fisica contribuem para 0 desenvolvimento da obesidade, o uso de certos medicamentos, o baixo peso ao 
nascer, infecçðes, citotoxicidade ou outras lesð̃es nas células $\beta$. Alguns estudos relacionam a obesidade à sensibilidade à insulina, mudanças no peso, duração do sobrepeso e obesidade com a incidência de DM2, diabetes materno e riscos de futuro desenvolvimento de diabetes e obesidade e comportamentos que elevam o risco de desenvolvimento de obesidade. (CERIELLO e col., 1998; HAFFNER e col., 1999; SKRHA e col., 1999; WANNAMETHEE e col. 1999; DABELEA e col. 2000; MONTEIRO e col. 2000; SMITH e col. 2000, SEGHROUCHNI e col. 2002; SENTINELLI e col. 2002; HU e col. 2001\& 2003).

De acordo com a OMS (2003), a associaçăo entre o ganho de peso e distribuição da gordura corporal com as disfunç̋̃es ligadas à obesidade, sensibilidade à insulina e DM2 são convincentes, pois o aumento no índice de massa corporal e circunferência da cintura refletem o ganho de peso e acúmulo de adiposidade central (abdominal), que parece estar mais intimamente relacionada ao desenvolvimento de anormalidades no perfil lipídico e glicídico do que adiposidade inferior (femoral).

GIMENO e col. (2000) no estudo com a comunidade Nipo-Brasileira encontraram maiores índices de massa corporal (IMC) e maior relação cintura-quadril em pessoas adultas portadoras de distúrbios da glicose, lípides e hipertensão que tiveram ganho de peso a curto prazo, verificando que o risco de desenvolvimento de distúrbios na tolerância à glicose aumentou de $2 \%$ a $15 \%$ isoladamente ou associado à hipertensão e à obesidade abdominal, por unidade percentual de ganho de peso, quando comparados com indivíduos que mantiveram o peso estável.

A perda de peso tem sido extensivamente investigada como um fator preventivo na evoluçăo das disfunções relacionadas à glicemia (HENRY e col. 1986; WING e col.1987). No estudo realizado durante 12 anos em homens e mulheres com idades entre 40-59 anos que apresentavam doenças cardiovasculares no Reino Unido, WANNAMETHEE e col. (1999) demonstraram que ganhos substanciais no peso (>10\%) aumentam significantemente o risco de desenvolvimento de intolerância à glicose, resistência à insulina e DM2. A redução de peso também demonstrou a 
melhoria na pressão sanguínea, perfil lipídico, tolerância à glicose, sensibilidade à insulina e produziu uma significativa melhora nos níveis sanguineos de hemoglobina glicosilada Em concordância com o estudo realizado no Reino Unido, COLDITZ e col.(1995) analisaram os dados obtidos no Nurse Health Study e demonstraram que a perda de peso em mulheres com IMC $>27 \mathrm{~kg} / \mathrm{m}^{2}$ estava associada com uma redução de $30 \%$ no desenvolvimento de diabetes quando comparadas às mulheres que não tiveram mudanças no peso.

A relação entre diabetes gestacional com o desenvolvimento de DM2 e obesidade também tem sido muito investigada. DONHORST e col. (1998), usando fatores de risco modificáveis como obesidade persistente, ganho de peso e subseqüente gravidez e fatores de risco não modificáveis como etnia, peso antes da gravidez, idade, paridade, histórico familiar de diabetes, grau de hiperglicemia durante a gravidez e após o parto, no estudo de risco e prevenção de diabetes, demonstrou que mulheres com histórico de diabetes gestacional apresentaram aumento no risco futuro de desenvolvimento de obesidade e DM2, assim como seus filhos. $O$ estudo de DABELEA e col (2000), também demonstrou a relação entre a exposição intrauterina a diabetes e a alta prevalência de intolerância à glicose em adolescentes e 0 excesso de obesidade especialmente nos primeiros 20 anos de vida.

A hipertensão arterial também figura entre os fatores de maior risco relacionado ao desenvolvimento de enfermidades cardiovasculares e a associação destas patologias multiplica o risco de morbidade cardiovascular em relação ao risco de um não diabético em pelo menos 2 vezes, uma vez que, a hipertensão precede em vários anos a apariçăo do diabetes mellitus. Metabolicamente, a obesidade gera resistência à insulina, e conseqüentemente hiperinsulinemia. $\mathbf{A}$ insulina reduz a excreção renal de sódio fazendo com que o volume extracelular e sanguíneo se eleve, aumentando também o esforço cardíaco e a resistência periférica, que são os principais reguladores da pressão arterial. A hiperinsulinemia ainda altera os íons intracelulares fazendo com que haja uma retenção de $\mathrm{Na}^{+} \mathrm{e} \mathrm{Ca}^{2+}$ aumentando a reatividade vascular e a proliferação celular (GUYTON \& HALL, 1998). 
No estudo realizado por HUBERT (1993) com a população de Framinghan observou-se que, para cada $10 \%$ de elevação no peso à pressão arterial aumentou 6,5 mmHg. A redução da pressão arterial em pacientes diabéticos com alto risco cardiovascular produz redução da mortalidade total dos óbitos por AVC, dos eventos cardiovasculares e do infarto do miocárdio e diminui a progressão da doença renal associada ao diabetes.

As dislipidemias atingem de $30-60 \%$ da população diabética e constituem um importante fator de risco aterosclerótico. As dislipidemias são as alterações metabólicas lipídicas decorrentes de distúrbios em qualquer fase do metabolismo lipídico, que ocasionem repercussão nos níveis séricos das lipoproteínas. Quando a dislipidemia é resultado de açðes medicamentosas ou conseqüência de alguma doença é chamada de dislipidemia secundária, e por exclusão todas as outras formas de dislipidemia são consideradas primárias (GURRUCHAGA, 1997).

As pessoas com maior quantidade de tecido adiposo concentrado na região abdominal apresentam hipertrigliceridemia, aumento de colesterol total e diminuição de colesterol HDL devido a menor atividade da lipoproteína lipase (LPL), fazendo com que o catabolismo dos quilomicrons e VLDL diminua. Ainda, em presença de valores limites a normais de colesterol LDL, pessoas com diabetes apresentam partículas de LDL menores, devido à oxidação causada pela glicose fazendo com que o papel aterogênico destas lipoproteínas aumentem (GURRUCHAGA, 1997).

Além do fator ambiental, fatores genéticos também estão claramente implicados na etiologia da doença sendo que o DM2 está mais firmemente vinculado ao fator hereditário do que o DM1. Em algumas populaçðes podem ser encontradas altas prevalências da doença, como no estudo com os índios Pima nos Estados Unidos onde cerca de $50 \%$ dos indivíduos adultos apresentam a doença assim como em estudos com a comunidade Nipo-Brasileira onde $22,6 \%$ apresentaram DM 2. Em concordância com o obtido em outros estudos, IVES e col. (1997) também mencionam que a prevalência do DM2 é maior em grupos de pessoas que 
apresentam histórico familiar da doença, obesidade e em grupos raciais conhecidos como grupos de alto risco para a doença (Americanos Nativos, Hispânicos e Americanos Africanos). Assim, apesar da contribuição genética ser bem reconhecida, os genes que conferem susceptibilidade à doença ainda não foram identificados na maioria dos casos e supze-se que o comportamento do diabetes mellitus seja complexo, sendo necessário a presença simultânea de vários genes alterados e diferentes combinações de defeitos gênicos para o desenvolvimento da doença (HIRAI e col, 2004).

Para o adequado controle de diabetes e co-morbidades associadas a American Diabetes Association (1997), propõe com a finalidade de reduzir o risco cardiovascular e prevenir a glicotoxicidade e complicações relacionadas, os critérios descritos a seguir (Quadro 2).

Quadro 2: Critérios de controle para o DM 2 e co-morbidades associadas segundo American Diabetes Association, (1997).

\begin{tabular}{|l|c|}
\hline Pressåo Arterial & $\begin{array}{c}\leq 130 \mathrm{mmHg} \text { de PAS* } \\
\leq 85 \mathrm{mmHg} \text { de PAD ** }\end{array}$ \\
\hline Glicemia & $\leq 110 \mathrm{mg} / \mathrm{dl}$ \\
\hline Triglicérides & $\leq 150 \mathrm{mg} / \mathrm{dl}$. \\
\hline Circunferência abdominal & $<102 \mathrm{~cm} \mathrm{em} \mathrm{homens}$ \\
& $<88 \mathrm{~cm} \mathrm{em} \mathrm{mulheres}$ \\
\hline HDL colesterol & $>40 \mathrm{mg} / \mathrm{dl} \mathrm{em} \mathrm{homens.}$ \\
& $>50 \mathrm{mg} / \mathrm{dl} \mathrm{em} \mathrm{mulheres}$ \\
\hline
\end{tabular}

Pressão arterial sistólica: ** Pressão arterial diastólica

O reconhecimento da existência de diferentes formas de diabetes em pessoas adultas torna-se necessário para reconsiderar a estratégia de identificação do diabetes mellitus e sua correta classificação. 
O LADA (Latent Autoimmune Diabetes in Adults) é uma forma especial de diabetes com fenótipo similar ao DM2, mas com positividade para autoanticorpos pancreáticos. Difere do DM 1, pois o processo de destruição autoimune das células $\beta$ do pâncreas é muito lenta (ZHOU, 2003).

Segundo FALORNI (2003), a coexistência de resistência à insulina e defeitos na secreção de insulina suportam a hipótese que o LADA pode resultar da interação entre a predisposição genética para autoimunidade das ilhotas e predisposição genética para o DM2. A presença de autoanticorpos para células de ilhotas (ICA) e autoanticorpos para ácido glutâmico descarboxilase (GAD65Ab) identificam os pacientes com características clínicas muito similares àquelas encontradas em pessoas com a forma progressiva do DM 1. Em contrapartida, a presença de baixos niveis de GAD65AB e a ausência de ICA ou outros marcadores imunológicos, caracteriza um subgrupo de pacientes com características clínicas quase indistinguiveis daquelas encontradas em pacientes com DM2.

A frequêencia de LADA em pacientes diagnosticados com DM2 varia entre 6-50\%, sendo elevada em jovens diagnosticados com DM2 antes dos 35 anos e subestimada em idosos. O estudo realizado por LI e col. (2003) com pacientes LADA que apresentaram ou não sindrome metabólica, demonstrou que ambos grupos tiveram características similares à forma clássica do DM1 como baixo peso, tendência ao desenvolvimento de cetoacidose e intolerância nas funçðes das ilhotas de Langerhans, necessitando de estratégias terapêuticas diferentes das utilizadas no tratamento do DM2.

Importantes fatores podem ser considerados na identificação clínica do LADA em pacientes diagnosticados com DM2. A ineficiência de tratamentos com hipoglicemiantes orais com aumento de risco para desenvolvimento de deficiência de insulina, 60 a $80 \%$ dos casos evoluindo para tratamentos com insulina exógena dentro de 5 a 6 anos e a presença de pacientes com baixo IMC na data do diagnóstico são úteis na identificação do LADA (BEHME e col. 2003; FALORNI, 2003). Em 
estudo realizado para caracterizar pacientes com LADA observou-se que a maior parte dos pacientes que apresentava a doença era do sexo feminino, com um IMC médio de $17,2 \mathrm{~kg} / \mathrm{m}^{2}$, diagnosticadas com DM2 na terceira década de vida e tomando-se dependente de tratamento com insulina após uma média de 2.5 anos (TAN e col. 2001).

Aspectos clínicos como idade, severidade dos sintomas e IMC podem ser parâmetros limitados para a identificação dos pacientes com LADA, pois o IMC tende a aumentar com a idade (LANDIN-OLSSON, 2002).

Apesar da obesidade e da inatividade fisica serem conhecidas como fatores de risco para o DM2, recentes evidências indicam que algumas das complicaçð̃es da doença estão associadas ao aumento da atividade de radicais livres à oxidação lipidica e ao estresse oxidativo (NOUROOZ-ZADEH e col. 1997; PALANDUZ 2001; AHMAD e col. 2003, MONTONEN e col, 2004).

\section{1- Radicais Livres e defesas antioxidantes no DM2}

$\mathrm{O}$ termo radical livre refere-se a átomo ou molécula que contém número ímpar de elétrons em sua última camada eletrônica formados a partir de reaçð̃es de óxidoreduç̋̃es. Nas moléculas, os elétrons em geral se reúnem em pares. Quando dois elétrons ocupam um mesmo orbital dizemos que seus spins estão emparelhados. Os elétrons com spins emparelhados tem números quânticos magnéticos de spins com sinais opostos. $\mathrm{O}$ não emparelhamento de elétrons da última camada confere alta reatividade a esses átomos ou moléculas (FERREIRA e MATSUBARA, 1997; HALLIWELL e GUTTERIDGE, 1999)

A maior parte dos radicais livres são derivados do metabolismo celular aeróbio $\left(\mathrm{O}_{2}\right)$, sendo portanto, chamados de "espécies reativas do metabolismo do oxigênio" (ERMO). Em condições físiológicas do metabolismo celular aeróbio, $\circ \mathrm{O}_{2}$ sofre redução tetravalente com aceitação de quatro elétrons, resultando na formaçăo de 
$\mathrm{H}_{2} \mathrm{O}$ e intermediários reativos, como os radicais superóxido $\left(\mathrm{O}_{2}^{-}\right)$, hidroperoxila $\left(\mathrm{HO}_{2}\right)$ e hidroxila $(\mathrm{OH})$, e o peróxido de hidrogênio $\left(\mathrm{H}_{2} \mathrm{O}_{2}\right)$. A redução completa do $\mathrm{O}_{2}$ ocorre na mitocôndria e a reatividade das ERMO é neutralizada com a entrada dos quatro elétrons (FERREIRA e MATSUBARA, 1997).

O termo ERMO é mais apropriado para designar os agentes reativos patogênicos do que o termo radical livre, pois alguns radicais livres não apresentam elétrons desemparelhados em sua última camada (FERREIRA e MATSUBARA, 1997). As principais ERMO são:

Radical supenóxido $\left(\mathrm{O}_{2}\right)$ : formado após a primeira redução do $\mathrm{O}_{2}$ em quase todas as células aeróbicas e produzido durante a ativação máxima de neutrófilos, monócitos, macrófagos e eosinófilos (HALLIWELL e GUTTERIDGE, 1999).

$$
\mathbf{O}_{2}+\mathbf{e}^{-} \rightarrow \mathbf{O}_{2}
$$

Radical hidroperoxila $\left(\mathrm{HO}_{2}\right.$ ): forma protonada do radical superóxido, ou seja possui o próton hidrogênio, sendo mais reativo que o radical superóxido, por sua facilidade em iniciar a destruição de membranas biológicas (HALLIWELL e GUTTERIDGE, 1999).

Radical hidroxila (OH): é considerada a ERMO mais reativa em sistemas biológicos e reage rapidamente com inúmeras biomoléculas, danificando o alvo mais próximo do local. Sua formação in vivo pode estar relacionada com a decomposição do peroxinitrito, do peróxido de hidrogênio ou superóxido, e com a presença ou não da ação catalítica de metais de transição (ferro), conhecidas como reaçôes de Fenton e Haber-Weiss, conforme esquema abaixo (HALLIWELL e GUTTERIDGE, 1999):

Reaçăo de Fenton:

$$
\begin{aligned}
& \mathrm{Fe}^{++}+\mathrm{O}_{2} \leftrightarrow \mathrm{Fe}^{+++}+\mathrm{O}_{2}^{-} \\
& 2 \mathrm{O}_{2}^{-+}+2 \mathrm{H}^{+} \rightarrow \mathrm{O}_{2}+\mathrm{H}_{2} \mathrm{O}_{2} \\
& \mathrm{Fe}^{++}+\mathrm{H}_{2} \mathrm{O}_{2} \rightarrow \mathrm{Fe}^{+++}+\mathrm{OH}^{-}+\mathrm{OH}^{\circ}
\end{aligned}
$$


Reactio de Haber-Weiss:

$$
\begin{aligned}
& \mathrm{Fe}^{+++}+\mathrm{O}_{2}^{-*} \leftrightarrow \mathrm{Fe}^{++}+\mathrm{O}_{2} \\
& \mathrm{Fe}^{++}+\mathrm{H}_{2} \mathrm{O}_{2} \rightarrow \mathrm{Fe}^{+++}+\mathrm{OH}^{+}+\mathrm{OH} \\
& \mathrm{O}_{2}^{-+}+\mathrm{H}_{2} \mathrm{O}_{2} \rightarrow \mathrm{O}_{2}+\mathrm{OH}+\mathrm{OH}
\end{aligned}
$$

Peróxido de hidrogênio $\left(\mathrm{H}_{2} \mathrm{O}_{2}\right)$ : apesar de não apresentar características de radical livre pela ausência de elétrons desemparelhados na última camada esta espécie é extremamente deletéria e toma-se importante porque participa da reação que produz - OH e atravessa camadas lipídicas, reagindo com membranas eritrocitárias e com proteinas ligadas ao $\mathrm{Fe}^{++3}$ (FERREIRA e MATSUBARA, 1997; HALLIWELL e GUTTERIDGE, 1999).

$$
\mathrm{O}_{2}+2 \mathrm{e}^{-}+2 \mathrm{H}^{+} \rightarrow \mathrm{H}_{2} \mathrm{O}_{2}
$$

Oxigênio singlet $\left({ }^{1} \mathrm{O}_{2}\right)$ : é a forma excitada do oxigênio molecular e não possui elétrons desemparelhados em sua última camada. $\mathrm{O}^{1} \mathrm{O}_{2}$ possui uma alta reatividade, sendo um poderoso agente oxidante. Tem importância em certos eventos biológicos, mas poucas doenças foram relacionadas à sua presença (FERREIRA e MATSUBARA, 1997).

As ERMO demonstram importante papel no desenvolvimento de danos teciduais em humanos e são responsáveis por desencadear o processo de envelhecimento e mais de 50 doenças crônicas não transmissíveis como: aterosclerose, diabetes, câncer, doença de Parkinson, doença de Alzheimer. A reação de ERMO com biomoléculas tais como lipídios de membranas, proteínas e ácido desoxiribonucléico (DNA), pode provocar modificaçðes irreversíveis nas suas estruturas (ABDALLA, 2000).

Também existem as "espécies reativas do metabolismo de nitrogênio" (ERN), como o óxido nítrico e peroxinitrito.

Oxido nítrico (NO): é gerado in vivo a partir do aminoácido arginina, possui potencial tóxico e está relacionado à formação de outras espécies altamente reativas, como o radical hidroxila e o peroxinitrito (HALLIWELL e GUTTERIDGE, 1999). 
Peroxinitrito (ONOO): é uma espécie altamente tóxica, agindo diretamente sobre moléculas biológicas que sofrem protonação em pH fisiológico e pode se decompor, gerando radical hidroxila e dióxido de nitrogênio em uma quebra homolítica dessa molécula, conforme esquema abaixo (HALLIWELL e GUTTERIDGE, 1999):

$$
\mathrm{ONOO}^{-}+\mathrm{H}^{+} \rightarrow \mathrm{OH}+\mathrm{NO}_{2}
$$

Vale ressaltar, que nem sempre as ERMO e as ERN estão envolvidas em processos biológicos indesejáveis. Por exemplo, o ânion superóxido possui um papel importante no combate de infeç̧⿸尸es provocadas por bactérias, auxiliando os neutrófilos na destruição dos microorganismos. Outro exemplo é que o óxido nítrico contribui no controle da pressão e fluxo sanguíneo do sistema cardiovascular (BAST e col., 1991; MONCADA e HIGGS, 1993).

A formação de ERMO é mostrada na figura 1.

Figura 1: Formação de ERMO (PóvOA, 1995)

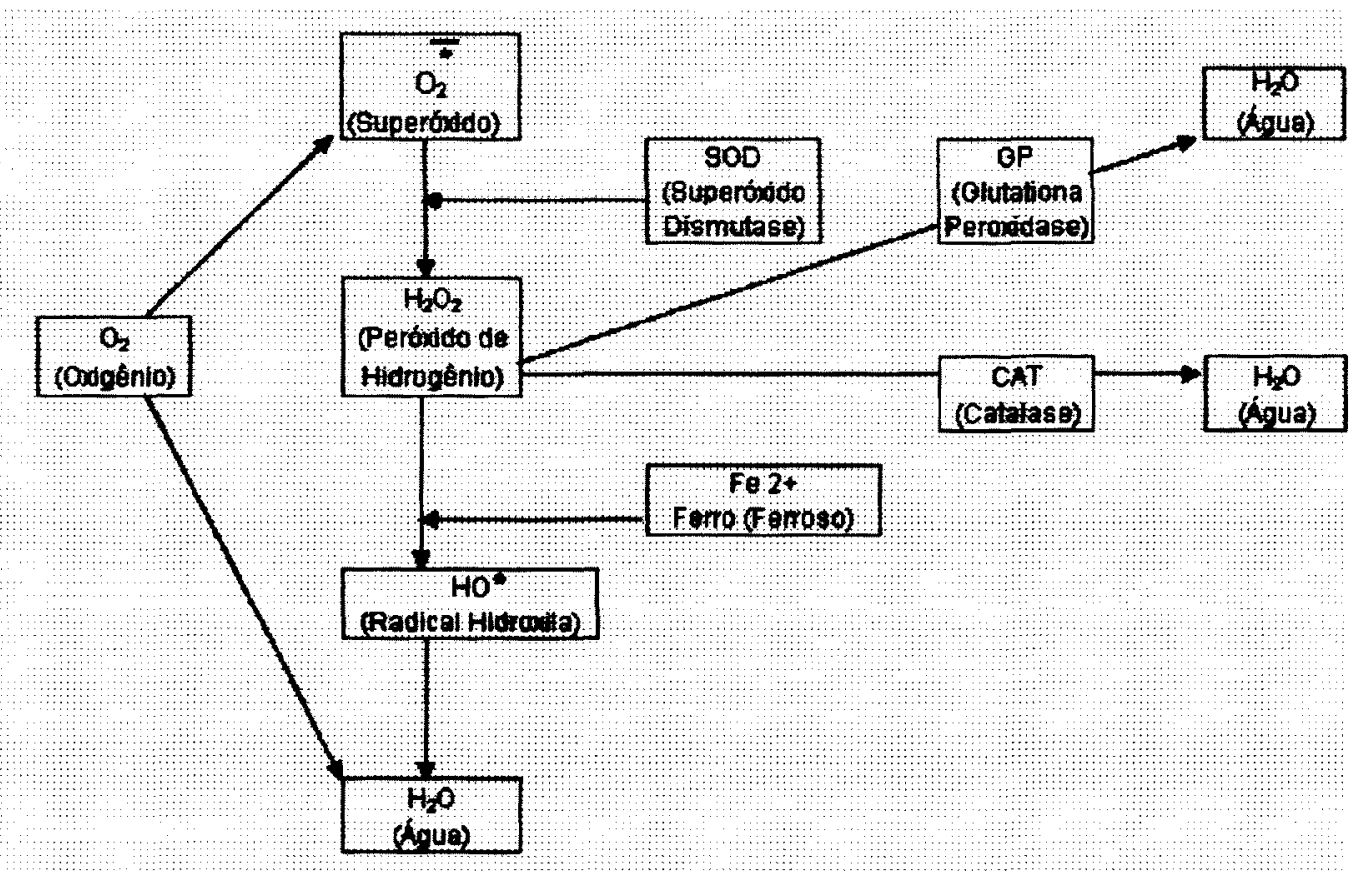


Todos os componentes celulares são susceptiveis a ação das ERMO, porém a membrana é un dos mais atingidos em decorrência da oxidação lipídica. A oxidação lipídica acarreta modificações na estrutura e permeabilidade das membranas celulares com conseqüente perda da seletividade na troca iônica e liberacão do conteúdo de organelas, como as enzimas hidrolíticas dos lisossomos, e formação de produtos citotóxicos (como o malonaldeído), culminando com a morte celular (HERSHKO, 1989).

A oxidação lipídica é uma reação em cadeia iniciada freqüentemente pelo radical hidroxila $(\mathrm{OH})$, representada pelas etapas de iniciação, propagação e terminação (GARDÈS-ALBERT e col, 1991). Estas etapas estão apresentadas nas reações seguintes, onde $\mathrm{L}$ representa o lipidio:

$$
\begin{aligned}
& \mathrm{LH}+\mathrm{OH}(\mathrm{ou} \mathrm{LO}) \rightarrow \mathrm{L}^{\circ}+\mathrm{H}_{2} \mathrm{O}(\mathrm{ou} \mathrm{LOH}) \text { - Iniciação } \\
& \mathrm{L}^{\cdot}+\mathrm{O}_{2} \rightarrow \mathrm{LOO}^{\circ} \\
& \mathrm{LH}+\mathrm{LOO}^{\circ} \rightarrow \mathrm{L}^{\circ}+\mathrm{LOOH} \text { Propagação } \\
& \mathrm{LOO}^{\circ}+\mathrm{L}^{\circ} \rightarrow \mathrm{LOOL}+\mathrm{LOO}^{\circ} \rightarrow \mathrm{LOOL}+\mathrm{O}_{2}-\text { Terminação }
\end{aligned}
$$

A reaçăo de oxidação lipídica inicia-se com o sequestro do hidrogênio do ácido graxo polinsaturado (LH) da membrana celular pelo $\mathrm{OH}$ (radical hidroxila) ou pelo LO (radical alcoxila) com conseqüente formação de radical lipídico (L). Na propagacăo $\circ \mathrm{L}$. reage rapidamente com $0 \mathrm{O}_{2}$, resultando em radical peroxila (LOO'), que por sua vez seqüestra novo hidrogênio do ácido graxo polinsaturado, formando novamente $o L$ na segunda equação de propagação. $O$ término da 
lipoperoxidação ocorre quando os radicais ( $\mathrm{L}^{-}$E LOO) produzidos nas etapas anteriores propagam-se até destruírem-se a si próprios (FERREIRA e MATSUBARA, 1997).

Os principais produtos finais da oxidação lipídica compreendem os derivados da decomposição de hidroperóxidos, como álcoois, aldeídos, cetonas, ésteres e outros hidrocarbonetos. $\mathrm{O}$ malonaldeído é o maior produto secundário da oxidacăo lipídica, apresentando efeito citotóxico, carcinogênico, mutagênico (FERREIRA e MATSUBARA, 1997).

Os danos causados às biomoléculas pelas ERMO e ERN são controlados pelo complexo sistema de defesa antioxidante sintetizado pelo organismo.

Os antioxidantes são substâncias que quando presentes em baixas concentraçð̃es em relação ao substrato oxidável, retardam ou previnem a oxidação de um substrato, removem os radicais livres ou outras espécies reativas de oxigênio e nitrogênio e minimizam a disponibilidade de substâncias pró-oxidantes como os íons de ferro e cobre. (HALLIWELL \& GUTTERIDGE, 1999). Do ponto de vista biológico, podemos conceituar antioxidantes como substâncias que protegem biomoléculas e estruturas celulares contra os efeitos potencialmente danosos de processos ou reaç⿸es que promovem a oxidaça (ABDALLA, 2000).

YUN-ZHONG (2002) relata que o sistema de defesa antioxidante exerce ação sinérgica contra os radicais livres e pode ser dividido em duas categorias: a das enzimas como a superóxido dismutase (SOD), catalase, glutationa redutase (GR), glutationa peroxidase (GSH-Px), metionina sulfóxido redutase e a NADH quinona redutase e a dos micronutrientes antioxidantes como a arginina, citrulina, taurina, creatina, selênio, zinco, vitamina $E$, vitamina $C$, vitamina $A$ e os polifenóis (OPARA 2002; WIERNSPERGER 2003). 
A glutationa-redutase, superóxido-dismutase (SOD), catalase, glutationa-peroxidase (GSH-Px) e a vitamina $\mathrm{E}$ atuam na célula como detoxificadores do agente causador de lesðes, enquanto que a vitamina $\mathrm{C}$ e a glutationa-redutase, atuam como reparadores da lesão ocorrida Com exceção da vitamina $E$, que é um antioxidante da membrana, a maior parte dos agentes antioxidantes está no meio intracelular (FERREIRA \& MATSUBARA, 1997).

Em sistemas aeróbicos é fundamental o equilibrio entre os agentes óxido-redutores e o sistema de defesa antioxidante, visto que, esses agentes são gerados endogenamente como consequéncia direta do metabolismo de $\mathrm{O}_{2}$ e também em situaç̃es não-fisiológicas como a exposição das células a xenobióticos (FERREIRA \& MATSUBARA, 1997).

O DM2 causa um aumento na geração de produtos derivados da glicooxidação quando associado ao estresse oxidativo, exercendo um efeito adverso no metabolismo da glicose. Assim, a presença de altas concentraçōes de glicose eleva a peroxidaçăo lipídica, aumenta o risco associado ds doenças ateroscleróticas e cardiovasculares e favorece o desenvolvimento de inúmeras complicaçð̋es (PEREIRA e col, 2003).

A maior causa de incapacidade e morte associada ao diabetes são as complicaçðes envolvendo pequenos e grandes vasos sangǘneos que podem ser ocasionados pela oxidação dos radicais livres às células contribuindo no desenvolvimento de macroangiopatias e microangiopatias. RUHE e cols, (2001) acrescentam que, dentre as complicaç̋̃es crônicas debilitantes que comprometem seriamente a qualidade de vida e que se associam à evolução do DM 2 destacam-se as doenças cerebrovasculares e complicą̧ひes microvasculares como neuropatias, doenças renais e retinopatia. Em indivíduos diabéticos, complicações como a retinopatia são 25 vezes mais frequientes do que em indivíduos não diabéticos, e um terço dos portadores da doença desenvolvem nefropatia com evolução para insuficiência renal crônica (HIRAI e col., 2004). Observa-se ainda que, pacientes com DM2 apresentam 
um aumento de três a sete vezes na incidência de doenças vasculares quando comparadas aos grupos não-diabéticos, tomando as doenças cardiovasculares as maiores causas de morte entre os diabéticos (FARVID et col. 2004).

O papel dos antioxidantes e seu potencial como inibidores da oxidação causada pelos radicais livres, como agentes preventivos e terapêuticos nas doenças arteriais coronarianas e cardiovasculares, na melhoria da açăo da insulina em pacientes diabéticos bem como das suas complicaç̃es, tem sido muito relatado em estudos atuais, havendo no entanto, controvérsia quanto à capacidade destes antioxidantes em retardar ou reverter os danos já causados pelas doenças. (SINGH e col. 1995; HASANAIN, 2002, DIERCKX, 2003 ).

\section{2-Vitamina E}

Desde a descoberta da vitamina E em 1922 sua função no corpo humano tem sido extensivamente investigada. Atualmente, é conhecida como possuidora de um papel fundamental no metabolismo normal de todas as células (MAHAN e col, 2002).

Segundo SCHWEDHELM (2003), a vitamina E refere-se ao grupo de oito compostos sendo, quatro tocoferóis e quatro tocotrienóis denominados de alfa, beta, gama e delta e diferenciados por atividade. Todos os oito compostos possuem em sua estrutura um anel 6- cromanol e uma cadeia lateral sendo que, os tocóis possuem uma cadeia lateral fitol, três carbonos assimétricos na posição 2 do anel e nas posições 4' e 8' da cadeia lateral, enquanto os trienóis possuem a mesma estrutura com ligaçðes duplas nas posiçð̋es 3', 7' e 11' da cadeia lateral. Ambos ocorrem com uma grande variedade de isômeros que diferem entre si pelo número e posição dos grupos metil no anel cromanol (Fig. 2). 
Figura 2: Estrutura química da vitamina $E$.

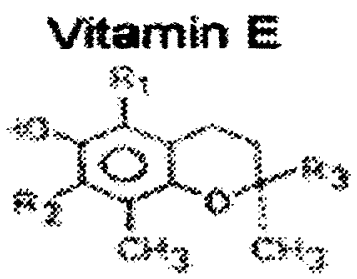

As propriedades químicas da vitamina $\mathrm{E}$ incluem a insolubilidade em água e a completa solubilidade em óleos, gorduras, acetona, álcool, clorofórmio, éter, benzeno e outros solventes lipossolúveis. É estável ao calor e álcalis na ausência de oxigênio e não é afetada por ácidos em temperaturas superiores a $100^{\circ} \mathrm{C}$. Entretanto, pode ser lentamente oxidada pelo oxigênio atmosférico e ter sua oxidação acelerada pela exposição à luz, calor e álcalis na presença de ferro e sais de cobre (MACHLIN, 1991).

Os tocoferois e tocotrienóis são amplamente distribuidos in natura e o a-tocoferol é o composto mais abundante e biologicamente ativo dentre todos. A ingestão dietética usual é estimada em 7 a $11 \mathrm{mg} /$ dia, sendo a RDA (Recommended Dietary Allowance) para o a-tocoferol de $15 \mathrm{mg} /$ dia para pessoas acima de 15 anos de idade (SARUBIN, 2000).

A vitamina E é sintetizada por plantas e encontrada principalmente nos produtos de origem vegetal. Boas fontes são os óleos vegetais, margarinas, gérmen de trigo, sementes e nozes. Também pode ser encontrada em pequenas quantidades em tecidos de origem animal, como os tecidos gordurosos. (O'CONNELL, 2001; MAHAN e col, 2002).

Conforme SCHWEDHELM (2003), devido à vitamina E ser um composto lipossolúvel, sua absorção depende inteiramente da presença de gordura da dieta e 
das funçð̃es pancreática e biliar. As lipases pancreáticas e esterases são necessárias à hidrólise de triglicérides e quebra dos ésteres de tocoferol, forma comum da vitamina E em suplementos dietéticos. Na ausência das secreç̃es biliares ou pancreáticas a absorçăo e secreção no sistema linfático são prejudicadas, e na ausência de ambas somente quantidades insignificantes da vitamina são absorvidas (TRABER, 2002).

A absorção da vitamina $E$ dá-se na porção superior do intestino delgado onde é capturada pelos quilomicrons na circulacão linfática e levada ao figado onde será incorporada ao VLDL e dividida em lipoproteinas de alta densidade (HDL) (MAHAN e col, 2002).

Figura 3: Esquema de absorção e transporte de vitamina E no homem.

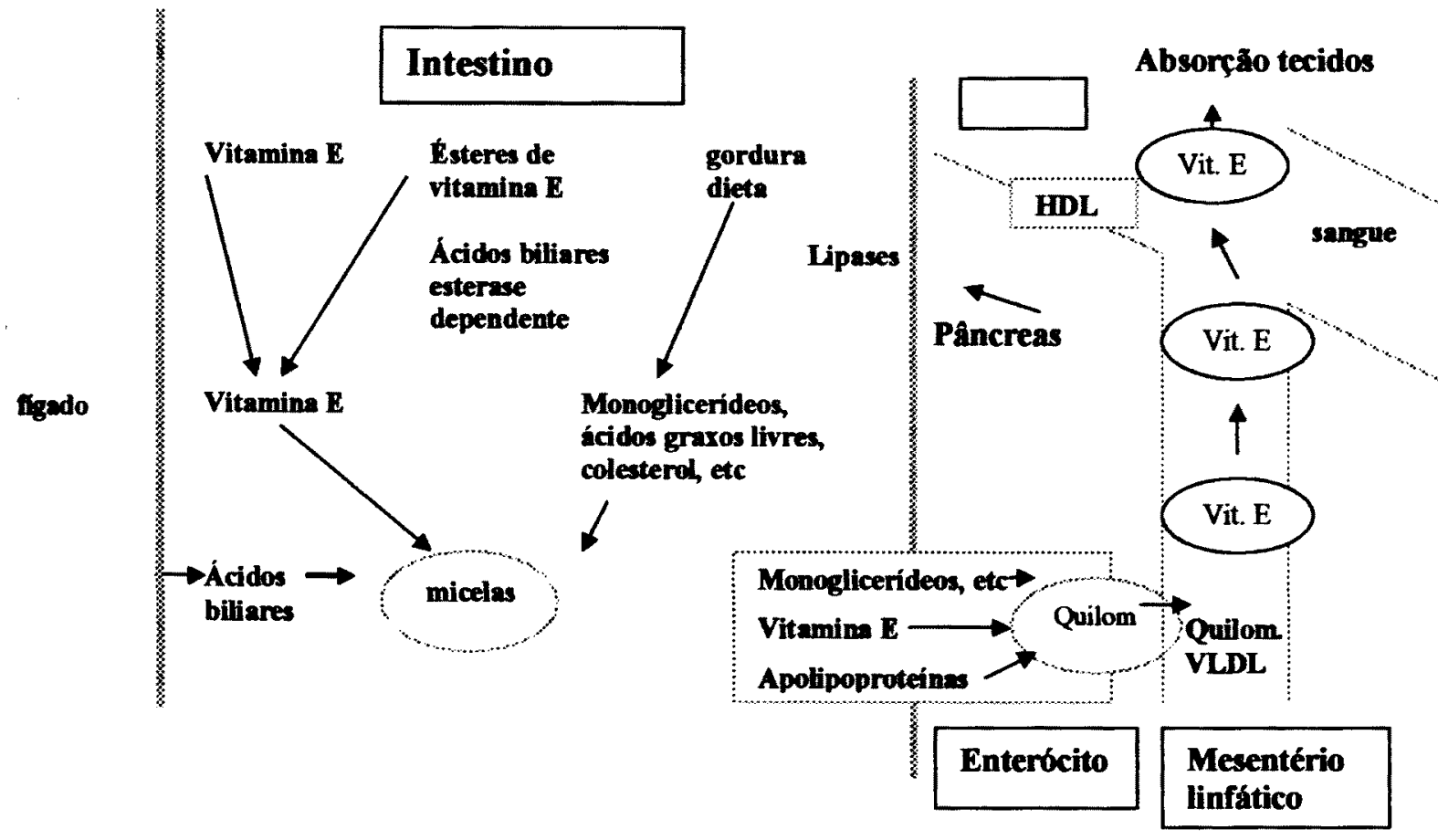

As lipoproteínas săo transportadoras de lipídios no plasma e consistem de um centro hidrofóbico contendo triacilglicerol e éster de colesterol e uma superficie abrangendo colesterol não esterificado, fosfolipídios e uma grande variedade de apoliproproteínas. São heterogêneas em tamanho, composição química e função e devido a diferenças na densidade são divididas em quatro grandes classes: 
quilomicrons, lipoproteína de densidade muito baixa (VLDL), lipoproteína de baixa densidade (LDL) e lipoproteína de alta densidade (HDL). São consideradas estruturas dinâmicas capazes de transferir moléculas entre o centro e a superfície das lipoproteínas, entre lipoproteínas e entre lipoproteínas e tecidos. São sintetizadas principalmente no intestino (quilomicrons e HDL), figado (VLDL e HDL) ou formadas no plasma (HDL e LDL) durante o metabolismo do triacilglicerol. A maioria das apolipoproteinas são sintetizadas no figado e intestino e regulam diferentes enzimas envolvidas no metabolismo das lipoproteinas (DREVON, 1993).

BEHRENS e col. 1982, mostraram que o VLDL tem grande capacidade para transportar o $a$ - tocoferol, mas como está presente em pequenas quantidades, esta lipoproteína não pode ser vista como quantitativamente importante no transporte da vitamina em estados de abstenção. Em geral, o LDL transporta duas vezes a concentraça de $a$ - tocoferol observada no HDL, sugerindo assim, que o LDL e 0 HDL são as lipoproteinas mais importantes no transporte do $\alpha$-tocoferol no plasma humano. Entretanto, no mesmo estudo foram encontradas diferenças significativas entre homens e mulheres em relaça ao transporte de $\alpha$ - tocoferol demonstrando que, em homens o LDL está mais relacionado ao transporte do $\alpha$ - tocoferol do que o $\mathrm{HDL}$, enquanto nas mulheres o oposto foi relatado, diferença atribuída aos maiores niveis de HDL em mulheres.

Alteraçð̃es nos níveis de lipoproteinas como: elevaçðes nas concentraçðes de VLDL, redução nas concentrações de $\mathrm{HDL}$, aumento da susceptibilidade do $\mathrm{LDL}$ às modificações causadas pela oxidaçăo in vitro e a predominante presença de partículas pequenas de LDL tem sido verificada em pacientes com DM2 (YOSHIDA, 1997).

Os eritrócitos também podem armazenar vitamina $\mathrm{E}$ e a concentração nessas células chega a $20 \%$. Nos tecidos os niveis de vitamina E variam consideravelmente, encontrando-se altas concentraçōes nas glândulas adrenais e pituitária testículos e fraç⿸尸es celulares ricas em membranas como mitocôndrias e microssomos, sendo que, 
- tecido adiposo, figado e músculos são os tecidos que apresentam maior armazenamento (MACHLIN, 1991).

A vitamina $\mathrm{E}$ é um potente antioxidante lipossolúvel, possui um papel fundamental no metabolismo normal de todas as células e sua deficiência pode afetar vários sistemas orgânicos diferentes. A deficiência de vitamina $\mathrm{E}$ pode predispor as células vermelhas sanguíneas ao aumento da hemólise oxidativa in vitro e produzir diminuição no tempo de vida das células vermelhas in vivo. Assim, a concentração plasmática normal de vitamina $\mathrm{E}$ é de $23.2 \mu \mathrm{mol} / \mathrm{L}(1 \mathrm{mg} / \mathrm{dL})$, variando entre 11.6 a $30.8 \mathrm{umol} / \mathrm{L}(0.5-1.6 \mathrm{mg} / \mathrm{dL})$. Quando o valor plasmático de vitamina E está inferior a $11.6 \mu \mathrm{mol} / \mathrm{L}$ o estado de deficiência é caracterizado (MEYDANI, 1995). A comparação do status da vitamina $\mathrm{E}$ no soro ou plasma são demonstrados no quadro 3.

Quadro 3: Comparação vitamina E status (baseado em MEYDANI, 1995).

\begin{tabular}{ll|cc}
\hline Vitamina E (mg/dL) no soro ou & Deficiente & Adequado \\
$\begin{array}{l}\text { plasma (Todas as idades) } \\
\text { Vitamina } \mathbf{E} \text { ( } \mu \text { mol/L) no soro ou }\end{array}$ & $<0.5$ & $>0.5-1.6$ \\
plasma (Todas as idades) & & $<11.6$ & $>11.6-30.8$ \\
\hline
\end{tabular}

Os mais comuns estados de má-absorção que causam deficiência de vitamina $\mathrm{E}$ são obstrução biliar, doenças crônicas do figado, cirrose biliar, pancreatite, fibrose cística em crianças prematuras, pacientes que receberam nutrição parenteral, bem como, em condiçōes que interfiram na digestão normal, absorçăo ou transporte de gorduras da dieta. Quadros de deficiência severa ou crônica podem progredir para síndromes neurológicas caracterizadas por neuropatia, alteração de reflexos, equilibrio e coordenação, ataxia e perda sensorial nas pernas e braços. A deficiência de vitamina E também está vinculada ao desenvolvimento de displasias broncopulmonares, 
hemorragias intraventriculares no cérebro, fibroplasia retrolental, anemia em crianças prematuras, desenvolvimento de certas formas de câncer, doenças cardiovasculares $e$ efeitos na função imune. Em nível celular a deficiência de vitamina $\mathrm{E}$ está associada ao aumento na peroxidacăo lipídica da membrana celular e maior risco de lesð̃es e necroses (DREVON, 1993; LANDVIK e col, 2002).

O mecanismo de açăo da vitamina E é atuar neutralizando os radicais livres produzidos durante o metabolismo celular normal e proteger as membranas celulares e lipoproteínas, particularmente o LDL da oxidação, podendo interagir também com antioxidantes hidrossolúveis tal como a glutationa. Possui um importante papel na prevenção e tratamento das complicações causadas pelo DM2 como doenças cardiovasculares, neuropatias e nefropatias diminuindo a glicação das proteinas a oxidação dos lipídios e inibição da adesão e agregação de placas (CERILLO e col. 1991, REAVEN e col. 1995, TUTUNCU e col. 1998, BURSELL e col. 1999, ANDREW e col. 2000, DEVARAJ e col. 2000).

Assim, quando as espécies altamente reativas atacam o íntimo da membrana lipídica ou das lipoproteinas, a vitamina $\mathrm{E}$ reduz esses radicais a metabólitos não prejudiciais quebrando essa cadeia de reaç̃es e inibindo a oxidação dos lipídios. Portanto, juntamente com outros nutrientes e fatores endógenos tem a funcăo de proteger o sistema de defesa antioxidante do organismo dos radicais livres e espécies reativas de oxigênio e nitrogênio (HALLIWELL 2002; LANDVIK e col, 2002).

Evidências epidemiológicas sugerem que o hábito de fumar também contribui na geraçăo de radicais livres e causa depleçðes nos antioxidantes do plasma e danos às proteínas e lipídios. Em um estudo conduzido por HANDELMAN e col. (1996) demonstrou-se que pessoas com o hábito de fumar apresentaram após exposição prolongada de 9 horas a fumaça do cigarro, diminuiçores significativas de até $70 \%$ nos níveis plasmáticos de $\alpha$-tocoferol quando comparadas às não fumantes, aumentando assim, os riscos de desenvolvimento de doenças pulmonares e cardiovasculares, intimamente relacionadas às complicaç̃es do DM2. 
A vitamina E é muito utilizada em certas doenças por seu alto poder antioxidante natural. A ação benéfica do $\alpha$-tocoferol está relacionada a um grande número de processos patológicos como doenças coronárias e do coração, câncer, catarata, DM2 e doença de Alzheimer. FEKI et col.(2000) no estudo do tipo caso-controle, demonstrou que pacientes com doenças coronárias apresentavam concentraçð̃es séricas de vitamina $\mathrm{E}(19.90 \pm 5.83 \mu \mathrm{mol} / \mathrm{L})$ menores quando comparados aos pacientes que não apresentavam doenças coronarianas $(21.69 \pm 5.24 \mu \mathrm{mol} / \mathrm{L})$ e uma correlação inversa entre vitamina $\mathrm{E}$ e mortalidade causada por doenças isquêmicas do coração, corroborando a hipótese do efeito protetor da vitamina Desta maneira, o efeito protetor contra aterogênese pode ser atribuída à capacidade da vitamina $E$ em inibir a oxidação e melhorar a resistência antioxidativa do LDL.

Diversos autores sugerem que baixos níveis de vitamina $\mathrm{E}$ ( $\alpha$ - tocoferol), estão associados ao aumento na incidência de DM2 e de suas complicaç̋es e diminuição nos níveis de antioxidantes, devido ao aumento na produção de radicais livres causados pela hiperglicemia. $\mathbf{O} \alpha$-tocoferol tem demonstrado um efeito favorável no controle glicêmico, resistência à insulina, no bloqueio da peroxidação lipídica, atividade proaterogênica, velocidade de condução nas fibras nervosas em pacientes com DM2 que apresentaram neuropatia, função endotelial bem como na manutenção da função das células-beta em pessoas portadoras de DM 2 (PAOLISSO et col, 1993; SALONEN et col, 1995; REAVEN et col. 1995; TUTUNCU et col. 1998; DEVARAJ et col. 2000; FORD, 2001; ).

MAYER-DAVES et col. (2002), no estudo caso-controle Insulin Resistance and Atherosclerosis Study (IRAS) realizado com pacientes diabéticos e não diabéticos com idades entre 53 a 57 anos, demonstraram um incremento de $22 \%$ no risco de DM2 por $1 \mu \mathrm{mol} / \mathrm{L}$ de decréscimo nos níveis plasmáticos de $a$-tocoferol $(p=$ 0.0004). Indivíduos com diabetes que não fizeram uso de vitamina $E$ apresentaram concentraç̃̃es plasmáticos de a-tocoferol $(25.7 \pm 7.5 \mu \mathrm{mol} / \mathrm{L})$ menores quando comparados àqueles que fizeram uso de suplemento de vitamina $\mathrm{E}$ e permaneceram livres da doença $(41.7 \pm 17.8 \mu \mathrm{mol} / \mathrm{L})$, sugerindo que o $a$-tocoferol apresenta um 
significante efeito protetor na redução do risco de incidência de DM2 e um efeito limitado nos pacientes que não fizeram uso de suplementos de vitamina $\mathrm{E}$, concordando com os resultados também encontrados por SALONEN et col. (1995) e NOUROOZ-ZADEH et col. (1997).

CERILLO e col. (1991), em estudos realizados com pacientes diabéticos com idade de aproximadamente 41 anos, que faziam uso de insulina relataram decréscimo na Hemoglobina Glicosilada $\left(\mathrm{HBA}_{\mathbf{l c}}\right)$ com o uso de vitamina $\mathrm{E}$. Em concordância, PAOLISSO e col. (1993a), em estudo com pacientes idosos que apresentaram DM2 sem complicações diabéticas durante 3 meses, encontraram decréscimo nos níveis sanguíneos de glicose de jejum $(P<0.05)$, decréscimo nos níveis de $\mathrm{HBA}_{1 \mathrm{c}}$ de $7.8 \%$ para $7.1 \%$ e diminuição na produção de oxigênio plasmático após a administração de vitamina $E$, observando um aumento no nível plasmático de vitamina $E$ e da razão de oxidação e redução da glutationa. No estudo com pacientes diabéticos e pacientes controle saudáveis durante 4 meses, os pacientes diabéticos que tomaram vitamina $\mathrm{E}$, tiveram diminuição de $7.9 \%$ para $7.0 \%$ nos níveis de HBAlc, aumento nos níveis séricos de vitamina $\mathrm{E}$ e melhorias na oxidação e viscosidade da membrana (PAOLISSO e col. 1993b).

No estudo de SKRHA e col. (1999) com pacientes controles e com DM2, idades entre 33 a 58 anos que fizeram uso de vitamina $E$, encontrou-se uma diminuição na disponibilidade da glicose e clearance metabólico de glicose $(P<0.01)$ e baixos níveis séricos de vitamina $\mathrm{E}(11.6 \pm 4.8 \mathrm{mg} / \mathrm{L})$ em pacientes diabéticos com fibrinólise e altos níveis de indicadores de estresse oxidativo como malonaldeído (MDA) e ativador plasminogênio nos tecidos (tPA) antes da administração da vitamina $\mathrm{E}$.

Dada a importância dos dados apresentados, a presença do DM2 caracteriza-se como responsável por alteraç̃es significativas no metabolismo estando relacionado ao aparecimento de doenças cardiovasculares e formação de ateromas. A glicotoxicidade causada pelo DM2 pode ocasionar oxidação lipídica e conseqüentemente desequilíbrio das defesas antioxidantes. 
Sabe-se que a vitamina $E$, naturalmente presente em vários alimentos, é um antioxidante que atua protegendo as membranas celulares e as lipoproteínas da oxidaça causada pelos radicais livres, apresentando uma importante função tanto em pessoas saudáveis quanto naquelas que apresentam DM2.

Assim, a determinação sanguínea das concentraçóes de $\alpha$-tocoferol e a análise da frequêencia do consumo da vitamina $E$, torna-se de vital importância, para avaliar a presença de baixas concentraçð̌es sanguíneas dessa vitamina $\mathrm{E}$ em pessoas com DM2 e em pessoas sem DM2, justificando a realização deste estudo. 
2-Objetivos 


\section{OBJETIVOS}

\subsection{Geral}

Determinar as concentrações séricas de vitamina $\mathrm{E}$ em pacientes portadores e não portadores de DM2 do município de Jundiaí- SP.

\section{2- Especfíicos}

Análise descritiva dos pacientes do grupo caso e controle;

Verificar a concentração sérica de $\alpha$ - tocoferol em pacientes com DM2;

Verificar a concentração sérica de $\alpha$ - tocoferol em pacientes sem DM2;

Avaliar em pacientes com DM2 a relação entre a concentração sérica deste antioxidante e o consumo de vitamina $\mathrm{E}$ da dieta;

Avaliar em pacientes sem DM2 a relação entre a concentração sérica deste antioxidante e o consumo de vitamina $\mathrm{E}$ da dieta; 
31

3-Casuística e Métodos 


\section{CASUÍSTICA E METOdOS}

\section{1- Delineamento, Seleção dos Grupos e População}

Este é um estudo desenvolvido juntamente com uma tese de doutorado intitulada : "O impacto da suplementação de ácido $\alpha$-lipoíco e $\alpha$-tocoferol no controle da resistência a insulina e outros componentes da Síndrome Metabólica em pacientes com diabetes mellitus do tipo $2 "$.

Trata-se de um estudo epidemiológico do tipo caso-controle envolvendo pacientes portadores e não portadores de DM2, realizado no município de Jundiaí -SP.

Jundiá está situada a 63 quilômetros da capital do estado de São Paulo e possui cerca de 340 mil habitantes, distribuídos em uma área de $432 \mathrm{~km}^{2}$, sendo $112 \mathrm{~km}^{2}$ área urbana e $228,6 \mathrm{~km}^{2}$ área rural, tendo como principais produtos agrícolas à uva o morango e o pêssego. $O$ acesso à cidade é feito pelas rodovias Anhangüera, Bandeirantes e Dom Gabriel Paulino Couto. O município faz limite com 11 municípios: Várzea Paulista, Campo Limpo Paulista, Franco da Rocha, Cajamar, Pirapora do Bom Jesus, Cabreúva, Itupeva, Louveira, Vinhedo, Itatiba e Jarinú (IBGE, 2005)

A cidade foi escolhida para o desenvolvimento do estudo devido à proximidade com São Paulo e pela facilidade no acesso ao banco de dados fornecido pela Prefeitura do Municipio de Jundiaí. Outro motivo para a escolha foi à inexistência de pesquisas sobre o problema da deficiência de vitamina E nessa cidade, com base em dados bioquímicos.

Os pacientes selecionados foram convidados a participar da pesquisa através de contato telefônico. Após apresentação do projeto e esclarecimento dos objetivos e procedimentos a serem realizados pela pesquisadora responsável solicitou-se aos 
pacientes e seus acompanhantes (controles) que comparecessem às Policlínicas do Retiro e Hortolândia para a colheita dos dados.

As Policlínicas de Saúde são assim denominadas por serem mantidas pela Prefeitura do Município e realizar o atendimento emergencial aos finais de semana quando as unidades básicas de saúde estão fechadas. Assim, a escolha das policlínicas para a realização da coleta foi baseada na facilidade para a utilização das dependências aos finais de semana, já que a maioria dos pacientes contatados relatou possuir disponibilidade em participar da pesquisa, se essa fosse realizada aos sábados. $O$ critério utilizado para a distribuição dos grupos nos locais da coleta, foi baseado na proximidade da residência do paciente com as respectivas policlínicas.

A figura 4 apresenta o mapa da cidade com a localização das Policlínicas de saúde.

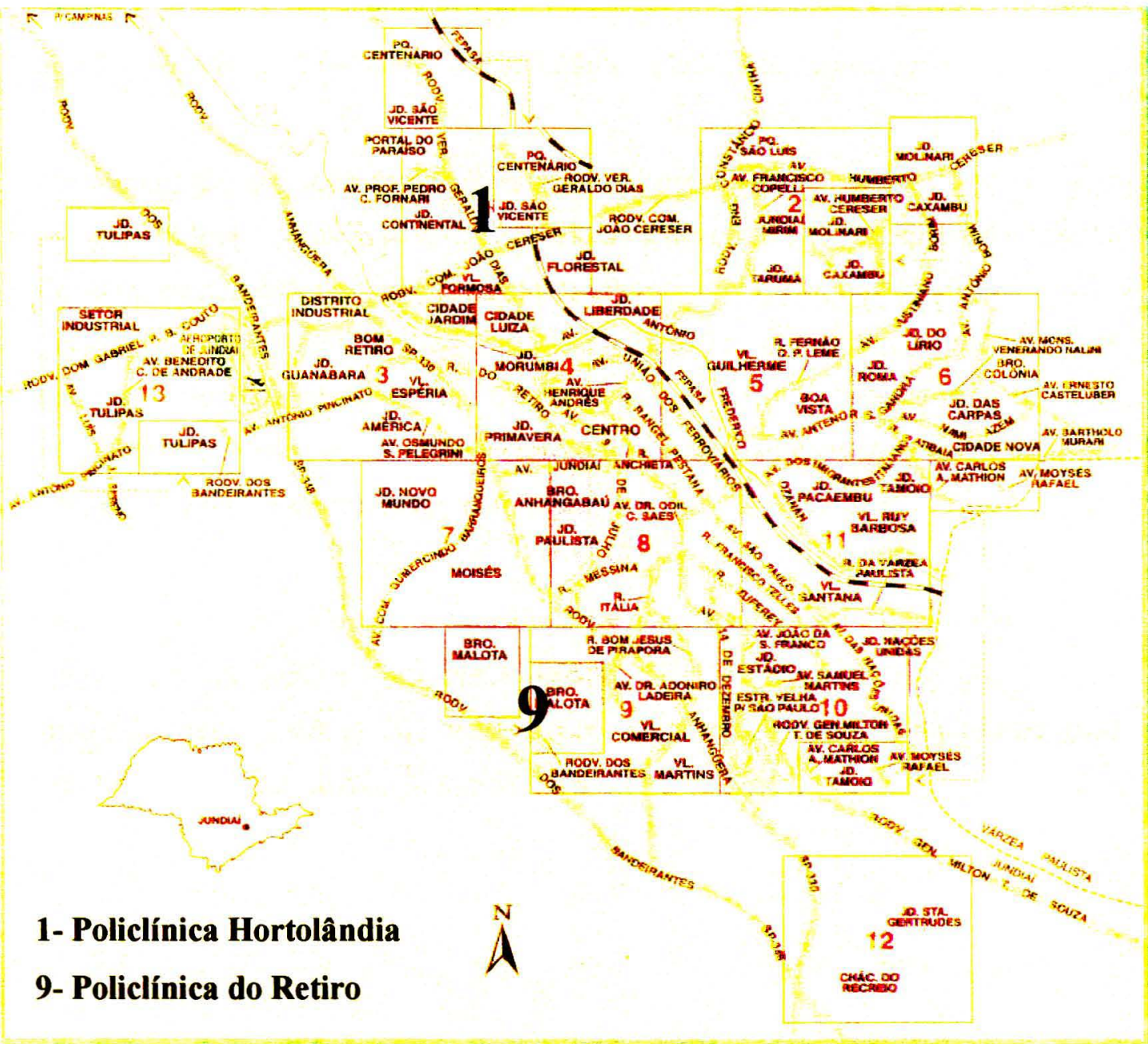


Participaram do estudo pessoas diabéticas do tipo 2 e pessoas não diabéticas. $O$ grupo de pacientes com DM2 foi selecionado através do banco de dados de pacientes diabéticos do SUS de Jundiai, fornecido pela Prefeitura.

Inicialmente o banco consistia de 3107 pessoas diabéticas do tipo 2 dos quais, foram excluidas pessoas com idade inferior a 35 anos para evitar o diabetes do tipo LADA e superior a 75 anos devido a dificuldade no transporte e locomoção. Também foram exclúdos pacientes que apresentaram valores de $\mathrm{HbA}_{1 \mathrm{c}}$ superior a $7,9 \%$ no ano de 2002 e 2004, chegando a um total de 784 pacientes.

Pacientes diabéticos que tomaram suplementos vitamínicos que incluíam vitamina $\mathrm{E}$, que fizeram uso de insulina, portadores de insuficiência renal crônica, e pacientes grávidas também foram excluídos. Assim, foram sorteados aleatoriamente através do programa Excell, 250 pacientes e destes foram recrutados as pessoas que compuseram o grupo denominado caso. Foram incluídos pacientes portadores de diabetes do tipo 2 , independentemente do tempo que possuíam a doença, inclusive aqueles que utilizavam tratamento dietoterápico e hipoglicemiantes orais.

Na composição do grupo de pacientes controle, pediu-se que cada paciente portador de diabetes levasse uma pessoa não portadora da doença e que não apresentasse grau de parentesco, sendo preferencialmente os cônjuges. No caso dos cônjuges que não puderam colaborar por também apresentarem a doença, foram recrutados para compor o grupo de pacientes controle, amigos, vizinhos ou conhecidos do paciente com DM2. Em todos os pacientes controle foram utilizados os mesmos critérios de exclusão utilizados nos pacientes com DM2.

Devido à colheita de material sanguíneo ter sido realizado no final de semana o sangue total não pôde ser enviado ao Laboratório Central do Hospital das Clínicas para a determinação de $\mathrm{HbA}_{1 \mathrm{c}}$. Neste estudo, os pacientes foram acompanhados pelo valor de $\mathrm{HbA}_{1 \mathrm{c}}$ apresentado no ano de 2004. 
Todos os pacientes que participaram da pesquisa, não foram submetidos a nenhum risco ou dano morais, físicos ou psíquicos.

\section{2- Amostragem}

Para o cálculo da amostragem foi utilizado o programa EPI INFO versão 6.0 (CDC 1990), baseando-se na menor prevalência de deficiência da vitamina $E$ no sangue de pessoas com DM2. Sendo assim, o valor considerado foi de $15,4 \%$, a menor prevalência encontrada para a deficiência de $a$ - tocoferol em estudo realizado por VANNUCCHI, (1994) com pessoas com DM2 e 0,01\% de deficiência de $a-$ tocoferol para pessoas não diabéticas em estudo realizado por DESAI e col., (1980), segundo levantamento bibliográfico através da base de dados Medline para o período de 1980 a junho de 2004. Conforme o cálculo, a amostra requerida para este estudo com um nível de confiança de $95 \%$ ( $\alpha$ ) e um poder de $80 \%(\beta)$, seria de 116 participantes, distribuídos em dois grupos de 58 pessoas cada.

Assim, 64 pacientes participaram da pesquisa sendo que 06 pacientes não puderam completar o estudo devido às exclusões relacionadas a uso de insulina e perda de material biológico na análise bioquímica no Laboratório Central do Hospital das Clínicas de São Paulo. Do grupo sem DM2, 62 pacientes participaram e 04 pacientes não completaram o estudo devido à perda de material biológico na análise bioquímica. Entretanto, não houve prejuizo no número amostral final anteriormente calculado.

\section{3- Variáveis do estudo}

3.3.1- Variáveis descritivas dos pacientes com e sem DM2: Dados pessoais, escolaridade, renda familiar.

3.3.2- Variáveis de interesse para pacientes com DM2: História de diabetes, uso de medicamentos e suplementos vitamínicos, pressão arterial $(\mathrm{mm} / \mathrm{Hg})$, glicose 
plasmática, colesterol total e fraçðes, triglicerideos de jejum, questionário de freqũência alimentar para vitamina $\mathrm{E}$, concentração de $\alpha$-tocoferol.

3.3.3- Variáveis de interesse para pacientes sem DM2: Uso de medicamentos e suplementos vitamínicos, pressão arterial $(\mathrm{mm} / \mathrm{Hg})$, glicose plasmática, colesterol total e fraçoes, triglicerideos de jejum, questionário de frequência alimentar para vitamina $E$, concentração de $\alpha$-tocoferol.

3.3.4 Variáveis antropométricas para pacientes com e sem DM2: peso $(\mathrm{Kg})$, altura $(\mathrm{cm})$, índice de massa corporal $\left(\mathrm{Kg} / \mathrm{m}^{2}\right)$ circunferência da cintura e quadril $(\mathrm{cm})$, relação circunferência-quadril $(\mathrm{cm})$.

\section{4- Freqüência alimentar}

Os hábitos alimentares foram avaliados através de questionário de frequeência alimentar. Para este propósito, considerou-se:

Alimentos ricos em vitamina E ( $\alpha$-tocoferol): queijo, requeijão, manteiga e margarina, leite, batata doce, ameixa preta seca, abacate, uva passa, peixe (fresco e enlatado), frango, figado, carne processada (presunto, salame), carne vermelha (bovina e suína), ovo, maionese, amendoim, amêndoa, avelă, castanha e óleos (girassol, soja, milho, canola, amendoim, azeite de oliva).

Os participantes foram questionados sobre o consumo de cada tipo de alimento durante o período de um ano. A freqũência do consumo alimentar foi categorizada em cinco diferentes escores: $0=$ alimento nunca consumido; $0,03=$ alimento consumido 1 vez por mês ou menos; $0,08=2$ a 3 vezes por mês; $0,22=$ alimento consumido 1 a 2 vezes por semana; $0,50=$ alimento consumido 3 a quatro vezes por semana; $0,79=5$ a 6 vezes por semana; 1 = alimento consumido todo dia (FORNES, 1989). 


\section{5- Testes estatísticos}

Para o armazenamento e análise estatística dos dados foram utilizados os programas Microsoft Excel versão XP e Software Statistical Package for the Social Sciencies (SPSS) para Windows versão 10.0 , sendo que, para todos os testes estatísticos realizados neste estudo foi considerado um nivel de significância de ( $\alpha$ ) de $5 \%$.

Para as análises estatísticas todas as variáveis foram testadas quanto à sua normalidade e simetria pelos testes de Skewness e Kurtosis.

A descrição da amostra estudada foi feita utilizando-se as frequências absolutas e relativas, médias, desvios padrão e intervalos de confiança.

Nas análises de diferenças de variáveis categóricas entre os grupos caso e controle foram utilizados o teste de qui-quadrado e o teste de Fisher.

Nas análises de diferenças de médias encontradas nas variáveis quantitativas do grupo caso e controle, foram realizados os testes $t$ de student.

Para comparação da média de $\alpha$ - tocoferol ajustada pelas variáveis de confusão foi utilizada análise de ANCOVA com o nível sérico de $\alpha$ - tocoferol como variável dependente e separado por grupo de pacientes caso e controle. As variáveis utilizadas no ajuste da média foram: sexo, renda mensal, escolaridade, hábito de fumar e ingerir bebidas alcoólicas, IMC, RCQ, glicose, colesterol total e fraç̋es, triglicérides, escore médio de ingestão de alimentos fonte em vitamina $\mathrm{E}$ e idade.

Foi realizada a análise de regressão linear múltipla stepwise e o nível sérico de $\alpha$ tocoferol foi a variável dependente. As variáveis testadas no modelo foram: sexo, renda mensal, escolaridade, hábito de fumar e ingerir bebidas alcoólicas, IMC, RCQ, glicose, colesterol total e fraçðes, triglicérides, escore médio de ingestão de alimentos fonte em vitamina $\mathrm{E}$ e idade. 
Análise de correlação de Pearson foi realizada para efeito de comparação das variáveis que apresentaram $p<0,10$ ou que apresentavam significado clínico com o modelo de regressão linear stepwise. $O$ nivel sérico de $\alpha$ - tocoferol foi a variável dependente e as variáveis contínuas testadas foram: IMC, RCQ, glicose, colesterol total e fraçðes, triglicérides, escore médio de ingestão de alimentos fonte em vitamina $E$ e idade.

\section{6- Levantamento dos dados}

\subsection{1 - Técnica de colheita de dados}

Primeiramente, os pacientes e controles assinaram um termo de consentimento de participacão no projeto assegurado-lhes o direito de recusa ou desistência em qualquer momento da pesquisa.

Os participantes responderam a um formulário elaborado especificamente para este estudo visando à obtençăo de informações demográficas, socioeconômicas, comportamentais e dados sobre antecedentes pessoais e familiares, bem como o uso de medicamentos e suplementos vitamínicos. Após a obtenção das informações do formulário foi realizada a antropometria.

Após o consentimento, os pacientes foram pesados utilizando-se balança eletrônica digital da marca Soehnle, com capacidade máxima de $150 \mathrm{Kg}$ e precisão de $100 \mathrm{~g}$. No momento da pesagem pediu-se que os selecionados retirassem os calçados e objetos dos bolsos das vestimentas que pudessem alterar a pesagem, para que a tomada do peso fosse a mais exata possível.

Na tomada da medida da estatura utilizou-se um antropômetro fixo em parede, marca Microtoise com capacidade máxima de $2 \mathrm{~m}$. Os pacientes foram medidos descalços, com os pés e os calcanhares juntos, região glútea e ombros encostados na parede. A cabeça foi posicionada de forma que a parte inferior da órbita ocular estivesse no 
mesmo plano do orificio externo do ouvido (Plano ou ângulo de Frankfort), mantendo os braços relaxados (JELLIFFE e JELLIFFE 1989).

As medidas de cintura e quadril foram tomadas conforme descrito abaixo:

circunferencia da cintura: o perímetro da cintura foi medido em centímetros, com uma fita inelástica de $150 \mathrm{~cm}$ posicionada na menor curvatura localizada no ponto médio entre a última costela e a crista ilíaca estando o paciente em posição ortostática, relaxado e sem encolher a barriga.

circunferência do quadril: o perímetro do quadril foi medido em centímetros com a fita inelástica de $150 \mathrm{~cm}$ posicionada na maior área glútea, com a pessoa em pé com as pernas unidas e os glúteos contraídos.

A determinação da relaçăo cintura-quadril (RCQ) foi obtida segundo a fórmula:

\section{$\mathrm{RCQ}=\mathrm{CC} / \mathrm{CQ}$}

onde: $\mathrm{CC}=$ circunferência da cintura expressa em centímetros $(\mathrm{cm})$

$\mathrm{CQ}=$ circunferência do quadril em centímetros $(\mathrm{cm})$

Foram considerados elevados valores $\geq 0,95$ nos homens e $\geq 0,80$ em mulheres (PEREIRA e col, 1999).

A determinação do índice de massa corporal (IMC) foi calculada por meio da fórmula:

$\mathrm{IMC}=\mathrm{P} / \mathrm{E}^{2}\left(\mathrm{Kg} / \mathrm{m}^{2}\right)$

onde : $\mathrm{P}=$ peso corporal expresso em kilogramas $(\mathrm{Kg})$ 
$E=$ estatura em metros (m)

Para classificação do índice de massa corporal (IMC) foram utilizados os parâmetros designados pela OMS (1997) definidos como:

\section{Bairo: $<18,5 \mathrm{Kg} / \mathrm{m}^{2}$}

Eutrofico: $18,5-24.9 \mathrm{Kg} / \mathrm{m}^{2}$

Sobrepeso: $25-29.9 \mathrm{Kg} / \mathrm{m}^{2}$

Obeso: $\geq 30 \mathrm{Kg} / \mathrm{m}^{2}$

$\mathrm{Na}$ aferiçăo da pressão arterial foi utilizado o método auscultatório, com um esfigmomanômetro de coluna de mercúrio marca UNITEC e um estetoscópio marca BD- Duo Sonic adulto. A medição foi realizada no braço direito de cada paciente, com os mesmos na posição sentada e obedecendo-se pelo menos cinco minutos de repouso. Optou-se por utilizar três medidas consecutivas em cada paciente, com intervalo de cinco minutos entre uma medida e outra, sendo que o valor final foi representado pela média aritmética das três medidas.

Para todos os dados antropométricos foram realizadas três medidas e foi utilizado o valor médio de todos os parâmetros.

\subsection{2- Colheita de amostras de sangue}

A colheita do sangue foi realizada através de sistema a vácuo por uma auxiliar de enfermagem recrutada no Laboratório Central do Hospital das Clínicas de São Paulo para que todo o procedimento inicial da coleta seguisse o protocolo exigido pelo laboratório responsável pelas dosagens bioquímicas. 
A colheita obedeceu a um jejum de 12 horas, requisito necessário para as dosagens bioquímicas e todo o procedimento e material utilizado para colheita, manuseio e descarte do sangue seguiram às normas de biossegurança (BRASIL, 2000). O sangue dos pacientes foi separado com o auxílio de material descartável para tubos do tipo vacutainer@ especificos para cada tipo de análise.

Para a realização das análises de glicose, colesterol total e frações lipídicas e triglicerídeos foi colhido $8 \mathrm{~mL}$ de sangue num tubo contendo gel e em até $6 \mathrm{~h}$ da colheita do sangue, os tubos foram centrifugados numa centrífuga para tubos marca Tomy, modelo IC-15 AN, o plasma foi separado, com auxilio da pipeta automática, transportado para microtubos, congelado a $-70^{\circ} \mathrm{C}$ e enviado ao Laboratório Central do Hospital das Clínicas de SP.

Para avaliação do nível plasmático de glicose foram considerados:

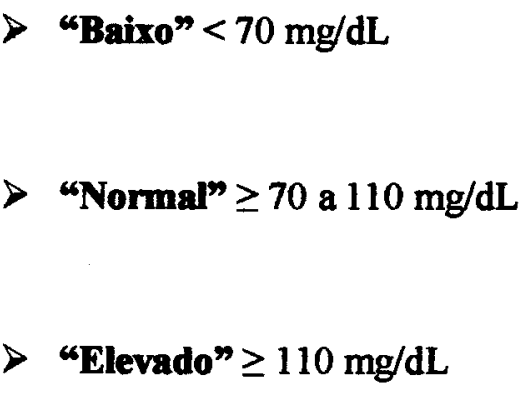

Para o colesterol total (em pessoas acima de 20 anos) foram classificados níveis plasmáticos:

“Desejável" < $200 \mathrm{mg} / \mathrm{dL}$

Limítrofe 200 a $239 \mathrm{mg} / \mathrm{dL}$

"Alto" $>240 \mathrm{mg} / \mathrm{dL}$ 
As fraç̃es do colesterol foram classificadas como:

HDL: níveis plasmáticos adequados $>40 \mathrm{mg} / \mathrm{dL}$

LDL: niveis plasmáticos adequados até $130 \mathrm{mg} / \mathrm{dL}$

VLDL níveis plasmáticos adequados até $40 \mathrm{mg} / \mathrm{dL}$

Para os triglicérides (em pessoas acima de 20) anos foram classificados níveis plasmáticos:

"Adequado" $\leq 200 \mathrm{mg} / \mathrm{dL}$

$>$ "Inadequado" $>200 \mathrm{mg} / \mathrm{dL}$

Para a dosagem de $\alpha$ - tocoferol foi retirado $5 \mathrm{~mL}$ de sangue em tubos plásticos sem anticoagulante, enrolados em papel alumínio evitando assim a exposição da vitamina E à luz. Após decorrido 30 minutos da colheita a amostra foi centrifugada a 1600g por $10 \mathrm{~min}$ e as alíquotas de plasma foram transferidas com o axxilio de uma pipeta automática para microtubos âmbar do tipo eppendorf@ e acondicionados em recipiente refrigerado (isopor) contendo gelo seco para o transporte ao laboratório de Micronutrientes na FSP, onde foi armazenado em um freezer a $-70^{\circ} \mathrm{C}$ protegido da luz até o início das dosagens no HPLC (ARNAUD e col., 1991).

\subsubsection{Antioxidantes sanguíneos}

As análises de $a$-tocoferol foram realizadas através de cromatografia líquida no laboratório de Micronutrientes do Departamento de Nutrição da Faculdade de Saúde Pública da Universidade de São Paulo. 
A avaliação dos índices glicêmicos, colesterol total e frações lipídicas e triglicérides foram realizados através de método enzimático colorimétrico automatizado no laboratório central do Hospital das Clínicas de São Paulo.

\subsection{4- Dosagem de $\alpha$ - tocoferol}

A análise do $\alpha$-tocoferol foi realizada em equipamento de Cromatografia Líquida de Alta Eficiência - HPLC (High Performance Liquid Chromatograph) da marca Shimadzu, sendo a separação realizada através de coluna Synergi Fusion $4 \mu$ - RP 80 150X4,6mm e Security Guard - HPLC Guard Cartridge System - KJO 4282 (précoluna) ambos da marca Phenomenex® mediante comando do System Controller SCL-10AVP da marca Shimadzu e software Class-vp 6.12 SP 5.

A fase móvel para separaça do $\alpha$-tocoferol foi composta por $70 \%$ Acetonitrila (Vetec), 10\% Metanol (Merck) e 20\% Diclorometano (Merck), ressaltando-se que todos os reagentes utilizados na análise foram grau HPLC. $O \alpha$-tocoferol foi bombeado a um fluxo isocrático de $1,2 \mathrm{~mL} / \mathrm{min}$ através do Solvent Delivery Module LC-10ADVP (Shimadzu) até o final da corrida que ocorreu aos $5 \mathrm{~min}$. 0 tempo de retenção do a-tocoferol ocorreu aos 3,8 min e foi identificado pelo detector UV visível SPD-10AVP (Shimadzu) com lâmpada de Deutério $\left(D_{2}\right)$ a um comprimento de onda de 292nm de absorbância (ARNAUD e col., 1991).

A interpretação dos níveis de $\alpha$-tocoferol dos pacientes diabéticos foi realizada através de comparaçð̃es com a curva de calibração (padrões de referência injetados previamente) abrangendo diferentes concentraçðes. A curva foi construída com as concentrações de $\alpha$-tocoferol entre $2-49 \mathrm{umol} / \mathrm{L}$, visto que um adulto em condições normais apresenta concentraçð̃es plasmáticas entre 11,6 - 30,8 umol/L (MEYDANI, 1995).

Para a confecção da solução padrão de $\alpha$-tocoferol $(400 \mu \mathrm{M})$, pesou-se em um balăo volumétrico de $100 \mathrm{~mL} 215,3 \mathrm{mg}$ do padråo de $\alpha$-tocoferol (Sigma/USA, T3251- 
25g) e diluiu-se em $100 \mathrm{ml}$ de etanol (Vetec). A concentração da solução padrão foi aferida com o auxilio do espectrofotômetro utilizando a absorbância específica em $292 \mathrm{~nm}$ para o $\alpha$-tocoferol $\left(\mathrm{A}^{1 \%}{ }_{1 \mathrm{~cm}}, 75,8\right)$ e após a checagem a solução foi estocada em freezer $-70^{\circ} \mathrm{C}$ abrigado de luz. A solução padrão de $a$-tocoferol foi diluída com Etanol em sete diferentes concentraçžes, sendo considerado o ponto $\underline{A}$ o de maior concentração e o $\underline{G}$ o de menor concentração, que foram posteriormente injetados no HPLC para a construção da curva.

Após as concentraçð̃es do padrão terem sido calculadas, parâmetros como tempo de retenção, concentração dos picos da curva, programação de corrida bem como integraç⿸尸es dos picos dos cromatogramas foram configuradas no ḦPLC antes do inicio da corrida da curva e das amostras.

Para a extração do $\alpha$-tocoferol da amostra, $200 \mu l$ do plasma, foi colocado em um microtubo âmbar de 2,0 mL juntamente com $200 \mu l$ da solução de etanol (Vetec) com BHT (Merck) a 0,125\%. A mistura foi agitada por $5 \mathrm{~s}$ no vórtex (Biomixer- MVS-1) e em seguida colocados $500 \mu l$ de hexano (Merck) e novamente agitado no vórtex por 2 minutos. A mistura foi centrifugada a $700 x g$ numa centrífuga eppendorf (B) (Centrifuge 5415C) por aproximadamente 5 minutos e após, $250 \mu$ l do sobrenadante foi retirado e estocado em outro microtubo de $0,5 \mathrm{~mL}$ limpo, onde o resíduo foi evaporado com auxilio de nitrogênio e reconstituido em $200 \mu 1$ de fase móvel. A amostra ficou em ambiente refrigerado até a hora de injetar.

A injeção de um volume de $50 \mu \mathrm{L}$ dos pontos da curva e das amostras foi realizada manualmente em um injetor de amostras marca Rheodyne. Antes da injeção, os microtubos foram agitados em Vórtex garantindo assim, a completa homogeneização da amostra e do padrão.

As amostras foram descongeladas à temperatura ambiente e no escuro para evitar a degradação da vitamina $\mathrm{E}$, e preparadas diariamente ou quando fossem ser analisadas, não ficando amostras para injetar no dia seguinte. Antes de iniciar a corrida das amostras, foram realizadas injeçðes de alguns pontos da curva 
previamente preparados, e corridas em branco (corrida só com fase móvel) para evitar substâncias retidas na coluna e aferir a boa repetibilidade do HPLC. Entre as amostras de soro também foram realizadas injeçðes de padrăo.

A seringa utilizada na injeção foi lavada com fase móvel para evitar a contaminação entre uma amostra e outra. Durante a corrida, não foi realizada nenhuma etapa suplementar de limpeza, pois sendo o HPLC um equipamento que trabalha com programaçőes de corrida, não existe a possibilidade de uma amostra correr sobre a outra, pois, terminado o tempo estabelecido na programação o que não foi analisado é desprezado.

O limite de detecção e de quantificação foi realizado segundo instruçð̌es técnicas da SINC do Brasil, responsável pelos equipamentos da marca Shimadzu no Brasil. O teste de deteç̧ão define a partir de onde é confiável a detecção da substância a ser analisada. Foram realizadas três corridas do ponto de menor concentração da curva de calibração (I) e analisadas quais foram as áreas onde o ruído da linha de base era mais alto. A maior altura foi multiplicada por 3. Assim, estabeleceu-se que: limite de deteç̧å $=3 \mathrm{X}>$ altura do ruído de base.

O teste do limite de quantificação revela quanto da substância a ser analisada o equipamento consegue quantificar. Foi realizada com base no ponto da curva com menor concentração (I). Se a amostra apresentasse valores menores que a menor concentração da curva estabelecia-se que a amostra estava fora do limite de quantificação.

\section{7- Aspectos éticos}

O desenvolvimento do estudo seguiu os requisitos da Resolução 196/96 do Conselho Nacional de Saúde/Ministério da Saúde do Brasil (MINISTÉRIO DA SAÚDE 1997) e as normas internas da Faculdade de Saúde Pública - USP, que regulamentam pesquisas envolvendo seres humanos. Todos os pacientes portadores ou não de DM2 
selecionados receberam informaçores a respeito do trabalho, como objetivos, metodologia e foram informadas do direito de recusa à participação em qualquer momento da pesquisa sem prejuizo ou penalidade de qualquer espécie, sendo resguardada a integridade e privacidade dos dados obtidos no estudo. (anexo 2).

Após os esclarecimentos, a pesquisadora e o paciente assinaram um termo de consentimento livre e esclarecido, elaborado em duas vias, uma para cada assinante (anexo 1).

O presente estudo foi submetido e aprovado pela Comissão Ética em Pesquisa da Faculdade de Saude Pública/USP e pelo Diretor de Açóes e Saúde da Secretaria Municipal de Saúde de Jundiaí. 
4-Resultados 


\section{4- RESULTADOS}

\section{1- Abrangência do estudo}

0 presente estudo incluiu 58 pessoas diabéticas do tipo 2 que compuseram o grupo caso e 58 pessoas não diabéticas que compuseram o grupo controle. Os dados foram colhidos nos meses de setembro e outubro de 2005 no município de Jundiai - SP.

São descritos a seguir as características gerais das amostras dos grupos caso e controle, de acordo com as variáveis propostas neste estudo. As descriçðes e análises foram feitas levando-se em conta a condição de portador e não portador de DM2.

\subsection{2- Características sócio-demográficas dos grupos caso e controle}

Observou-se que, do total de pacientes que participaram do estudo $(n=116), 60,3 \%$ eram pessoas do sexo feminino, $76,7 \%$ dos participantes do estudo eram casados ou viviam em união consensual, $63,8 \%$ referiram ter concluído até a $4^{\circ}$. série do ensino fundamental e apresentaram renda mensal familiar maior que um salário mínimo $(96,6 \%)$.

Os pacientes com DM2 (caso) apresentaram idades entre 39 e 77 anos, enquanto os pacientes sem DM2 (controle) apresentaram idades entre 35 e 78 anos. A idade média dos pacientes caso foi de 62,31 anos com um desvio padrão de 8,52 anos para - grupo e a idade média dos pacientes controle foi de 53,88 anos com um desvio padrão de 12,64 anos para o grupo. Foi encontrada diferença estatística significante ao comparar os grupos em relação à idade $(p<0,01)$. 
O grupo caso apresentou $63,8 \%$ de pacientes do sexo feminino enquanto o controle apresentou $56,9 \%$ confirmando a predominância feminina no estudo. Observou-se que a maioria dos pacientes dos dois grupos afirmou ter até cinco anos de estudo, e somente $12,1 \%$ dos pacientes do grupo caso disseram ter concluído o ensino médio e o terceiro grau enquanto que no grupo controle a freqüência foi de $32,8 \%$.

Comparando-se o nível de escolaridade segundo o sexo, $68,6 \%$ das mulheres tiveram até cinco anos de estudo, 12,9\% fizeram até o ensino médio e 18,6\% apresentaram o ensino superior completo. Quanto ao grupo masculino, 56,5\% apresentou até cinco anos de estudo, $15,2 \%$ o ensino médio e $28,3 \%$ o ensino superior.

Em relação ao estado civil, ambos grupos apresentaram maior freqüência de pessoas casadas ou vivendo em união consensual $(72,4 \%$ caso e $81,0 \%$ controle $)$.

Em relação à renda familiar, grande parte dos pacientes dos dois grupos disse possuir renda familiar entre um e dois salários minimos (R\$ 300,00 a R\$ 600,00) e somente três pacientes $(n=3)$ do grupo caso e doze $(n=12)$ do grupo controle disseram possuir renda maior que sete salários mínimos ( $R \$ 2100,00)$.

Na comparação entre os grupos caso e controle houve diferença estatística significante em relação à escolaridade $(p<0,05)$. A Tabela 4.1.1 apresenta a comparação de algumas características sócio-econômicas observadas entre o grupo de pacientes com DM2 (caso) e o grupo de pacientes que não apresentavam DM2 (controle). 
Tabela 4.1.1- Número e percentual de pacientes caso e controle, segundo sexo, escolaridade e renda mensal, Jundiaí - SP, 2005.

\begin{tabular}{|c|c|c|c|c|c|}
\hline \multirow[b]{2}{*}{ VARIÁVEIS } & \multicolumn{2}{|c|}{ CASOS } & \multicolumn{2}{|c|}{ CONTROLES } & \multirow[t]{2}{*}{$p^{(1)}$} \\
\hline & \multicolumn{2}{|l|}{$\bar{n}$} & \multicolumn{2}{|c|}{ n $\%$} & \\
\hline SEXO & & & & & \\
\hline $\begin{array}{l}\text { Feminino } \\
\text { Masculino }\end{array}$ & $\begin{array}{l}37 \\
21\end{array}$ & $\begin{array}{l}63,8 \\
36,2\end{array}$ & $\begin{array}{l}33 \\
25\end{array}$ & $\begin{array}{l}56,9 \\
43,1\end{array}$ & 0,448 \\
\hline Total & 58 & 100,0 & 58 & 100,0 & \\
\hline ESCOLARIDADE & & & & & \\
\hline $0-15$ anos de estudo & 43 & 74,1 & 31 & 53,4 & \\
\hline $5-111$ anos de estudo & 8 & 13,8 & 8 & 13,8 & \\
\hline$>11$ anos de estudo & 7 & 12,1 & 19 & 32,8 & 0,024 \\
\hline Total & 58 & 100,0 & 58 & 100,0 & \\
\hline RENDA MENSAL & & & & & \\
\hline$<1 \mathrm{SM}$ & 3 & 5,2 & 1 & 1,7 & \\
\hline$\geq 1 \mathrm{SM}$ & 55 & 94,8 & 57 & 98,3 & 0,309 \\
\hline Total & 58 & 100,0 & 58 & 100,0 & \\
\hline
\end{tabular}

(1) Teste de qui-quadrado

\subsection{3- Hábitos de fumar $e$ ingestão de bebida alcólica nos grupos caso e controle}

Quanto aos hábitos como fumo e a ingestão de bebidas alcoblicas, a maior parte dos pacientes do estudo não possuía o hábito de fumar. Entre os pacientes fumantes do grupo caso, a média de tempo de tabagismo foi de 28,6 anos com um desvio padrão de 9,4 anos e a média de tempo de tabagismo dos pacientes controle foi de 24,5 anos com um desvio padrão de 14,2 anos. Os hábitos de fumar e beber são mostrados nas figuras 4.1 e 4.2 . 
Figura 4.1- Percentual de pacientes caso e controle, segundo hábito de fumar, Jundiaí - SP, 2005.

\section{Hábito de fumar}

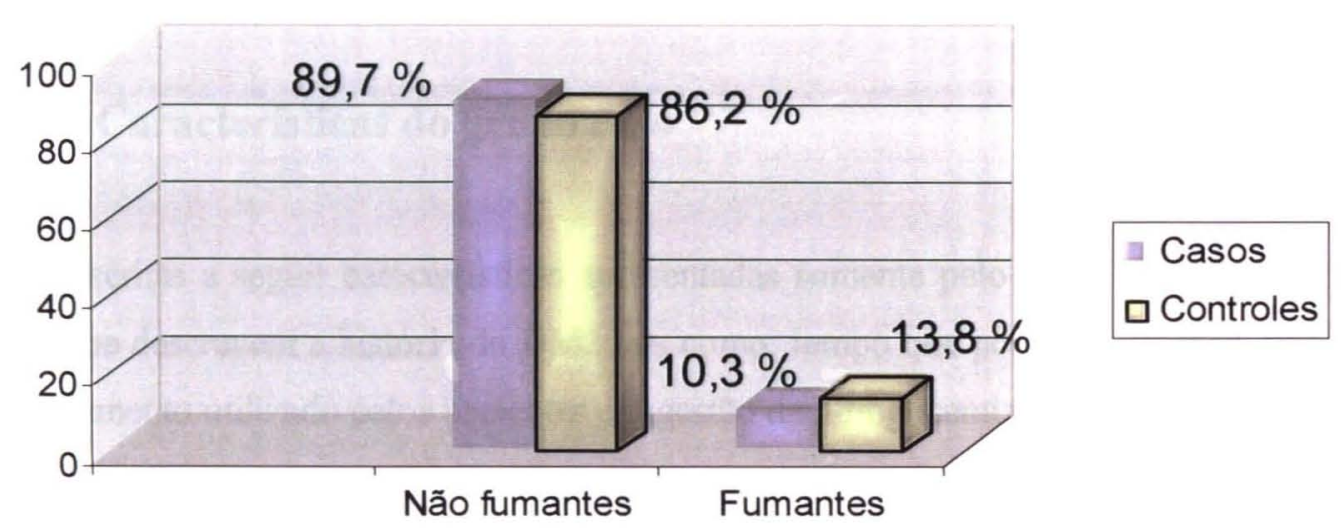

$p=0,569$

Figura 4.2- Percentual de pacientes caso e controle, segundo hábito de ingerir bebidas alcoólicas, Jundiaí SP, 2005.

\section{Hábito de ingerir bebida alcoólica}

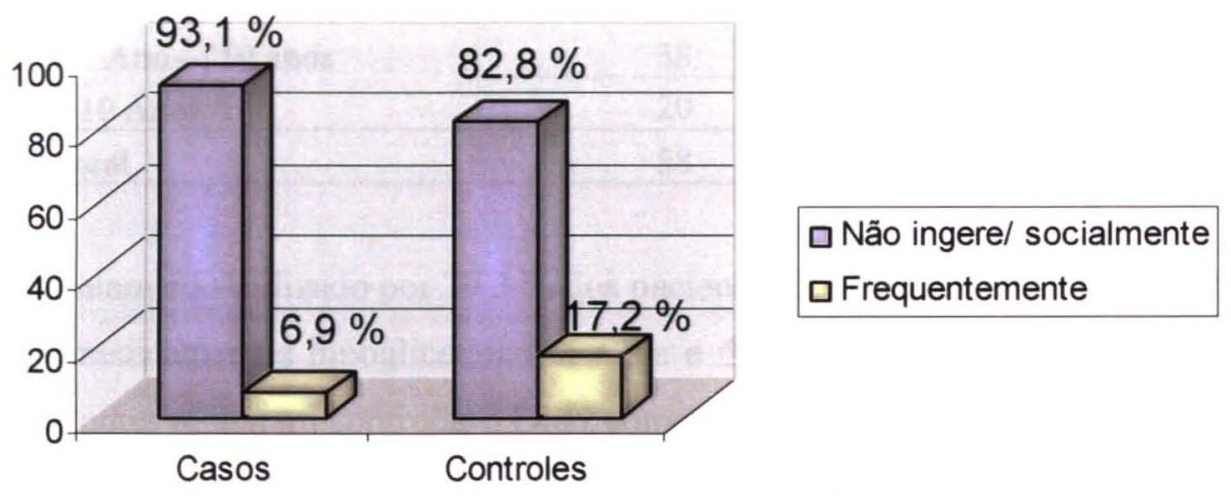

$p=0,087$ 
Com relação à quantidade de bebida alcoólica ingerida pelo grupo caso, 15,5\% referiu ingerir menos que um copo de bebida alcoólica por dia e $10,3 \%$ ingeria mais que um copo diariamente, enquanto que no grupo controle, $8,6 \%$ referiu ingerir menos que um copo por dia e $29,3 \%$ dos pacientes ingeria mais que um copo de bebida alcoolica diariamente. Houve diferença estatística significante entre os grupos quanto à quantidade de bebida alcoólica consumida $(p<0,05)$.

\subsection{4- Características do grupo caso}

São descritas a seguir caracteristicas apresentadas somente pelo grupo de pacientes caso que descrevem a história do DM2 tais como: tempo que possuía a doença, tipo de tratamento utilizado pelos pacientes e ingestão de hipoglicemiantes orais.

Com relação ao tempo de diabetes $65,5 \%$ dos pacientes são portadores do DM2 entre um a dez anos e $34,5 \%$ relataram ser portadores da doença há mais de dez anos. Quatorze pacientes $(n=14)$ possuía o DM2 entre sete a dez anos e somente três pacientes $(n=3)$ revelaram possuir o DM2 a mais de 20 anos. (Tabela 4.1.2).

Tabela 4.1.2 - Número e percentual de pacientes caso, segundo tempo de DM2, Jundiaf - SP, 2005.

\begin{tabular}{|c|c|c|}
\hline \multirow{2}{*}{ TEMPO DE DM2 } & \multicolumn{2}{|c|}{ CASOS } \\
\hline & $\mathbf{N}$ & $\%$ \\
\hline$<1$ Ano - 10 anos & 38 & 65,5 \\
\hline$>10$ Anos & 20 & 34,5 \\
\hline Total & 58 & 100,0 \\
\hline
\end{tabular}

O tratamento utilizado por $79,3 \%$ dos pacientes diabéticos baseou-se na combinação de medicamentos hipoglicemiantes orais e dieta apropriada e somente $20,7 \%$ dos pacientes relataram controlar o DM2 somente com a utilização de dietas apropriadas. Os hipogliceminantes orais mais relatados pelos pacientes diabéticos foram a Metformina e a Glibenclamida 


\subsection{5- Presença de morbidades no grupo caso e controle}

A hipertensão arterial apresentou-se como a morbidade mais freqũente tanto no grupo caso $(77,6 \%)$, quanto no controle $(20,7 \%)$ mas também foram relatados pelos pacientes diversas morbidades que incluaram:

D Caso: gastrite, sinusite, bronquite, faringite, litiase da vesícula biliar, osteoporose, litíase renal, diverticulite e labirintite .

Controle: rinite, gastrite, sinusite, esquizofrenia, litíase renal, depressão, problemas de prostata.

\subsection{6- Uso de Medicamentos e Suplementos vitamínicos pelos grupos caso e controle}

$O$ uso de medicamentos anti - hipertensivos foi referido por 77,6 \% dos pacientes do grupo caso e $20,7 \%$ dos pacientes do grupo controle. Os medicamentos antihipertensivos mais utilizados pelos dois grupos foram "Captopril" e "Capoten". Outros medicamentos muito citados pelo grupo caso foram o Ácido Acetilsalisílico (AAS) e a Hidroclorotiazida. No grupo controle medicamentos como Aldoperidol, Ranitidina e Diclofenaco Sódico foram citados.

Tanto o grupo caso quanto o controle, demonstrou que $89,7 \%$ dos participantes do estudo $(n=104)$ não faziam uso de complexos vitamínicos e apenas $10,3 \%(n=12)$ dos pacientes disseram utilizar algum tipo de vitamina.

No grupo de casos, $15,5 \%(n=9)$ e no grupo controle somente $5,2 \%(n=3)$ dos pacientes, relataram o uso de vitaminas do complexo B, vitamina C e de Sulfato Ferroso. 


\subsection{7- Características antropométricas do grupo caso e controle}

Observou-se que os pacientes dos dois grupos demonstraram uma grande heterogeneidade em relação ao peso. $\mathrm{O}$ grupo caso, foi composto de mulheres com pesos que variavam entre $41,9 \mathrm{Kg}$ e $137,5 \mathrm{Kg}$, e homens com pesos que variavam entre $49,9 \mathrm{Kg}$ a $136,9 \mathrm{Kg}$. $O$ grupo controle apresentou mulheres com pesos que variavam entre $51,3 \mathrm{Kg}$ e $113,5 \mathrm{Kg}$ e homens com pesos que variavam entre $50,5 \mathrm{Kg}$ e $95,8 \mathrm{Kg}$. $\mathrm{O}$ peso médio das mulheres do grupo caso foi de $72,8 \mathrm{Kg}$ (DP 17,2 $\mathrm{Kg}$ ) e dos homens foi de $81,8 \mathrm{Kg}$ (DP 22,8 Kg). A média de peso das mulheres no grupo controle foi de $69,0 \mathrm{Kg}$ (DP 14,1 Kg) e dos homens foi de 75,1 Kg (DP 12,2 Kg).

Em relação à altura, o grupo caso apresentou mulheres com altura média de 154,7 cm (DP $6,5 \mathrm{~cm}$ ) e homens com altura média de $167,4 \mathrm{~cm}$ (DP 7,8 cm) enquanto 0 grupo controle apresentou mulheres com média de altura de 159,1 cm (DP 5,7 cm) e homens com média de 170,1 cm (DP 8,6 cm)

Também foram avaliadas a média e desvio-padrão das variáveis circunferência da cintura, circunferência do quadril, índice de massa corpórea e a relação cintura quadril, segundo o sexo (Tabela 4.1.3).

Tabela 4.1.3- Média e desvio padrão de variáveis antropométricas de pacientes caso e controle, segundo sexo, Jundiaí - SP, 2005.

\begin{tabular}{|c|c|c|c|c|c|}
\hline \multirow{3}{*}{ VARIÁVEIS } & \multicolumn{2}{|c|}{ CASOS $(n=58)$} & \multicolumn{2}{|c|}{ CONTROLES $(n=58)$} & \multirow[b]{3}{*}{$p^{(l)}$} \\
\hline & \multicolumn{2}{|c|}{ Média (DP) } & \multicolumn{2}{|c|}{ Média (DP) } & \\
\hline & Homens & Mulheres & Homens & Mulheres & \\
\hline Peso (Kg) & $81,8(22,8)$ & $72,8(17,2)$ & $75,1(12,2)$ & $69,0(14,1)$ & 0,078 \\
\hline Altura (cm) & $167,4(7,8)$ & $154,7(6,5)$ & $170,1(8,6)$ & $159,1(5,7)$ & 0,445 \\
\hline $\mathrm{CC}(\mathrm{cm})$ & $102,11(18,2)$ & $96,5(11,6)$ & $95,6(10,5)$ & $87,9(13,4)$ & 0,347 \\
\hline $\mathrm{CQ}(\mathrm{cm})$ & $105,3(14,6)$ & $107,1(13,5)$ & $100,4(7,3)$ & $104,9(10,4)$ & 0,042 \\
\hline RCQ & $0,95(0,081)$ & $0,90(0,069)$ & $0,94(0,066)$ & $0,84(0,079)$ & 0,530 \\
\hline $\operatorname{IMC}\left(\mathrm{K} / \mathrm{m}^{2}\right)$ & $29,04(6,7)$ & $30,28(6,0)$ & $25,96(4,0)$ & $27,36(5,6)$ & 0,190 \\
\hline
\end{tabular}

Nota 2-CC- Circunferência cintura; CQ- Circunferência quadril; RCQ- Relação cinturaquadril; IMC- Índice de Massa Corpórea; (1) Teste $t$ 
$\mathrm{Na}$ comparação das variáveis antropométricas segundo sexo, houve diferença estatística significante entre os grupos na variável circunferência do quadril ( $\mathrm{p}<$ $0,05)$.

O estado nutricional foi avaliado através do Índice de Massa Corpórea (IMC), dividido conforme proposto pela OMS (1997), e representado abaixo na figura 1.

Figura 4.3 - Estado nutricional (IMC) do grupo caso e controle, segundo sexo, Jundiaí - SP, 2005.

\section{Caso- IMC Feminino}

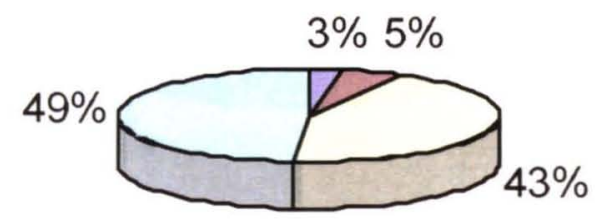

$\square$ Baixo $\square$ Eutrófico $\square$ Sobrepeso $\square$ Obesidade

\section{Caso- IMC Masculino}

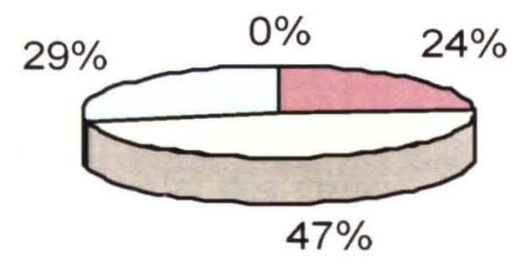

$\square$ Baixo $\square$ Eutrófico $\square$ Sobrepeso $\square$ Obesidade 


\section{Controle - IMC Feminino}

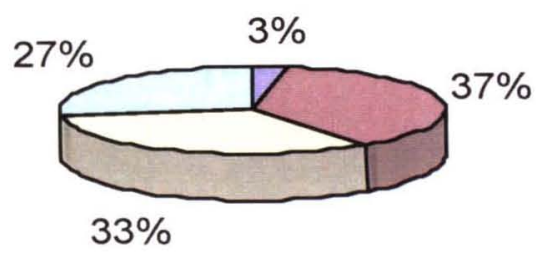

$\square$ Baixo $\square$ Eutrófico $\square$ Sobrepeso $\square$ Obesidade

\section{Controle - IMC Masculino}

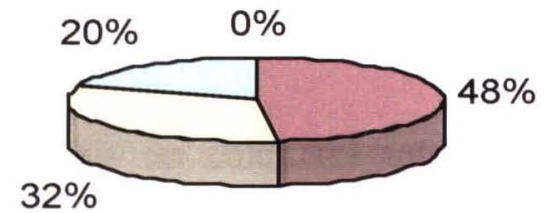

\section{$\square$ Baixo $\square$ Eutrófico $\square$ Sobrepeso $\square$ Obesidade}

A relação cintura-quadril (RCQ), foi classificada segundo o sexo. Observou-se que entre os pacientes do grupo caso, 75,7\% das mulheres apresentaram RCQ $>0,80$ $85,7 \%$ dos homens tiveram RCQ $>0,95$. No grupo controle, $60,6 \%$ das mulheres estavam acima do índice proposto enquanto $64,0 \%$ dos homens apresentaram o índice elevado.

Considerando a pressão arterial dos grupos, observou-se pressão arterial média de 150x20 mmHg nos pacientes caso com pressão mínima de $110 \times 70 \mathrm{mmHg}$ e máxima de 200x100 mmHg. e pressão arterial média de 130x40 mmHg no grupo controle e mínima de $90 \times 70 \mathrm{mmHg}$ e máxima de 200x100 mmHg. Houve diferença estatística significante entre a pressão arterial dos grupos $(\mathrm{p}<0,01)$. 
$\mathrm{Na}$ comparação das variáveis antropométricas entre os grupos houve diferença estatística significante na altura, circunferência da cintura, RCQ e no IMC $(p<0,05)$.

\subsection{8- Características bioquímicas do grupo caso e controle}

Os grupos foram avaliados segundo parâmetros bioquímicos que incluíram análises de glicose, colesterol total e frações e triglicérides.

Os resultados dos indicadores bioquímicos revelaram que o grupo de pacientes caso apresentou média de glicose plasmática maior que o grupo de pacientes controle demonstrando uma diferença estatística significante entre os grupos $(p<0,01) .0$ grupo caso apresentou pacientes com níveis de glicose elevado, mas no grupo controle nenhum paciente apresentou niveis de glicose acima de $110 \mathrm{mg} / \mathrm{dL}$.

Em relação aos níveis de colesterol total e frações de colesterol, os grupos apresentaram niveis desejáveis, fato verificado também nos triglicérides (Tabela 4.1.4). Houve diferença estatística significante na variável HDL e VLDL colesterol e triglicérides entre o grupo caso e controle $(p<0,005)$.

Tabela 4.1.4- Número, percentual, média e desvio padrão de variáveis bioquímicas, segundo grupo caso e controle, Jundiaí - SP, 2005. 


\begin{tabular}{|c|c|c|c|c|c|}
\hline \multirow[b]{2}{*}{ GLICOSE } & \multicolumn{2}{|c|}{ CASOS } & \multicolumn{2}{|c|}{ CONTROLES } & \multirow[t]{2}{*}{$p^{(1)}$} \\
\hline & $\mathbf{n}$ & $\%$ & $\mathbf{N}$ & $\%$ & \\
\hline Baixo & 7 & 12,1 & 12 & 20,7 & \\
\hline Normal & 25 & 43,1 & 46 & 79,3 & \\
\hline Elevado & 26 & 44,8 & 0 & - & 0,001 \\
\hline Total & 58 & 100,0 & 58 & 100,0 & \\
\hline Média (DP) & \multicolumn{2}{|c|}{$116,86(51,93)$} & \multicolumn{2}{|c|}{$76,06(10,58)$} & \\
\hline \multicolumn{6}{|c|}{ COL. TOTAL } \\
\hline Desejável & 30 & 51,7 & 34 & 58,6 & \\
\hline Limitrofe & 15 & 25,9 & 16 & 27,6 & \\
\hline Elevado & 13 & 22,4 & 8 & 13,8 & 0,192 \\
\hline Total & 58 & 100,0 & 58 & 100,0 & \\
\hline Média (DP) & \multicolumn{2}{|c|}{$201,98(48,73)$} & \multicolumn{2}{|c|}{$191,14(39,90)$} & \\
\hline \multicolumn{6}{|l|}{ HDL COL. } \\
\hline Adequado & 32 & 55,2 & 43 & 74,1 & \\
\hline Inadequado & 26 & 44,8 & 15 & 25,9 & 0,002 \\
\hline Total & 58 & 100,0 & 58 & 100,0 & \\
\hline Media (DP) & \multicolumn{2}{|c|}{$42,17(13,59)$} & \multicolumn{2}{|c|}{$49,71(12,47)$} & \\
\hline \multicolumn{6}{|l|}{ LDL COL. } \\
\hline Adequado & 36 & 62,1 & 36 & 62,1 & \\
\hline Inadequado & 22 & 37,9 & 22 & 37,9 & 0,213 \\
\hline Total & 58 & 100,0 & 58 & 100,0 & \\
\hline Média (DP) & \multicolumn{2}{|c|}{$127,52(40,99)$} & \multicolumn{2}{|c|}{$118,62(35,34)$} & \\
\hline \multicolumn{6}{|c|}{ VLDL COL. } \\
\hline Adequado & 49 & 84,5 & 51 & 87,9 & \\
\hline Inadequado & 9 & 15,5 & 7 & 12,1 & 0,007 \\
\hline Total & 58 & 100,0 & 58 & 100,0 & \\
\hline Média (DP) & \multicolumn{2}{|c|}{$31,36(20,73)$} & \multicolumn{2}{|c|}{$22,81(11,45)$} & \\
\hline \multicolumn{6}{|c|}{ TRIGLICÉRIDES } \\
\hline Adequado & 47 & 81,0 & 50 & 86,2 & \\
\hline Inadequado & 11 & 19,0 & 8 & 13,8 & 0,007 \\
\hline Total & 58 & 100,0 & 58 & 100,0 & \\
\hline Média (DP) & \multicolumn{2}{|c|}{$161,34(99,65)$} & \multicolumn{2}{|c|}{$117,69(66,88)$} & \\
\hline
\end{tabular}

Unidades de variáveis bioquímicas: $\mathrm{mg} / \mathrm{dL}$;

(1) Teste $t$ 


\subsection{9- Concentração de $\alpha$-tocoferol sérico no grupo caso e controle}

A avaliação do estado nutricional da vitamina $E$, demonstrou a ocorrência de defíciência (concentrações séricas de $\alpha$-tocoferol $\leq 11,6 \mu \mathrm{mol} / \mathrm{L}$ ) no grupo caso e no controle demonstrada na figura 4.4 .

Figura 4.4 - Distribuição percentual de paciente caso e controle, segundo concentrações séricas de $\alpha$-tocoferol, São Paulo, 2005.

\section{Prevalência de deficiência de alfa tocoferol nos grupos caso e controle}

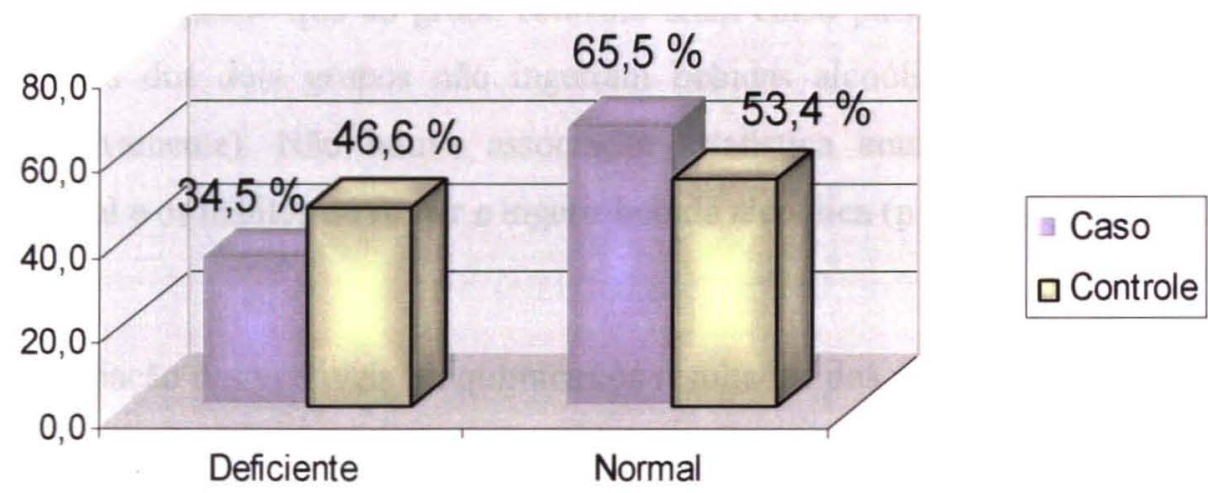

As concentrações de $\alpha$ - tocoferol séricas dos grupos foram analisadas através de análise de covariância e ajustadas segundo as variáveis de confusão. As médias das concentrações séricas de $\alpha$-tocoferol são demonstradas na tabela 4.1.5. 
Tabela 4.1.5: Módias estimadas, desvio padrăo e intervalo de confiança as concentraçóes séricas de $\alpha$ - tocoferol, segundo grupo caso e controle, Jundiai - SP, 2005.

\begin{tabular}{lcccc}
\hline & \multicolumn{3}{c}{$\alpha$-tocoferol sérico (pmol/L) } \\
\cline { 2 - 5 } STATUS & Média & DP & \multicolumn{2}{c}{ IC (95\%) } \\
\hline CASOS & 13,20 & 0,522 & 12,16 & 14,23 \\
CONTROLES & 13,52 & 0,522 & 12,48 & 14,56 \\
\hline
\end{tabular}

Não houve diferença estatística significante nas concentraçőes séricas de $\alpha-$ tocoferol entre os grupos $(p>0,05 ; p=0,698)$.

$\mathrm{Na}$ avaliação da associação do hábito de fumar e ingestão de bebidas alcoólicas com a deficiência de $\alpha$ - tocoferol, observou-se que no grupo caso três pacientes eram fumantes enquanto que no grupo controle eram cinco pacientes a maior parte dos pacientes dos dois grupos não ingeriam bebidas alcoólicas $(n=20$ e $n=20$, respectivamente). Não houve associação estatística entre a deficiência de $\alpha$ tocoferol e os hábitos de fumar e ingerir bebida alcoólica $(p>0,05)$.

$\mathrm{Na}$ avaliação das variáveis bioquímicas os resultados dos pacientes que apresentaram deficiência de a-tocoferol, foram estatisticamente semelhantes e demonstraram que tanto o grupo caso quanto o controle tiveram a maior parte de seus pacientes com níveis de glicose normais, colesterol total, LDL,VLDL e triglicérides em níveis desejáveis. A única variável bioquímica em que o grupo caso apresentou mais pacientes com níveis inadequados, foi o colesterol $\mathrm{HDL}$, diferentemente dos níveis de colesterol HDL apresentados pelos pacientes deficientes em $\alpha$-tocoferol do grupo controle.

Em relação ao tempo de DM2 apresentado pelos pacientes do grupo caso, observouse que concentrações séricas deficientes em $\alpha$-tocoferol $(<11,6 \mu \mathrm{mol} / \mathrm{L})$ foram mais freqüentes em pessoas que apresentavam a doença entre três a quatro anos, mas não 
houve associação estatística significante entre tempo de DM2 e deficiência de $\alpha-$ tocoferol $(p>0,05)$.

A análise de correlação foi realizada para verificar a correlação das concentraçð̃es séricas de $\alpha$-tocoferol com o IMC a RCQ e a idade. Os resultados são demonstrados na tabela 4.1.6.

Tabela 4.1.6: Coeficiente de correlação de Pearson entre $\alpha$ - tocoferol e variáveis de interesse clínico, Jundiaí - SP, 2005.

VARIÁVEIS DE INTERESSE CLÍNICO

\begin{tabular}{l|ccc}
\hline & IMC & RCQ & IDADE \\
\hline $\boldsymbol{a}$ - tocoferol (Ca) & $0,327^{*}$ & 0,299 & 0,039 \\
$\boldsymbol{a}$ - tocoferol (Co) & $0,319^{*}$ & 0,036 & 0,067 \\
\hline
\end{tabular}

${ }^{*} p<0,05 ;{ }^{* *} p<0,01$

A correlação das fraçðes lipídicas com as concentraçðes séricas de $\alpha$ - tocoferol é demonstrada na figura 4.1.7.

Tabela 4.1.7: Coeficiente de correlaçăo de Pearson entre $\alpha$ - tocoferol e fraçðes lipídicas nos grupos caso e controle, Jundial - SP, 2005.

\begin{tabular}{l|ccccc}
\hline \multicolumn{6}{c}{ FRACOES LIPIDICAS } \\
\hline & COL TOT. & HDL & LDL & VLDL & TRIGLIC. \\
\hline $\boldsymbol{a}$ - tocoferol (Ca) & $0,525^{* *}$ & $-0,041$ & $0,410^{* *}$ & $0,498^{* *}$ & $0,559^{* *}$ \\
$\boldsymbol{a}-$ tocoferol (Co) & $0,400^{* *}$ & 0,042 & $0,323^{*}$ & $0,349^{* *}$ & $0,337^{* *}$ \\
\hline
\end{tabular}

* $p<0,05 ;{ }^{* *} p<0,01$

A investigação da relação entre o $\alpha$ - tocoferol sérico e variáveis de confusão no modelo de regressão linear multivariada stepwise para o grupo caso é demonstrada na tabela 4.1.8. 
Tabela 4.1.8: Modelo de regressão linear para as concentraçðes séricas de $\alpha-$ tocoferol dos pacientes do grupo caso, Jundiai- SP, 2005.

\begin{tabular}{lcc}
\hline \multicolumn{1}{c}{ Variável Independente } & \multicolumn{2}{c}{ CASO } \\
\hline & $\boldsymbol{\beta}$ & $\boldsymbol{p}$ \\
Col. Total & 0,028 & 0,003 \\
Triglicérides & 0,018 & 0,001 \\
\hline
\end{tabular}

A investigação da relação entre o $\alpha$ - tocoferol sérico e variáveis de confusão no modelo de regressão linear multivariada stepwise para o grupo controle é demonstrada na tabela 4.1.9.

Tabela 4.1.9: Modelo de regressão linear para as concentrações séricas de $\alpha-$ tocoferol dos pacientes do grupo controle, Jundiaí- SP, 2005.

\begin{tabular}{lcc}
\hline Variável Independente & \multicolumn{2}{c}{ CONTROLE } \\
\hline & $\boldsymbol{\beta}$ & $\boldsymbol{p}$ \\
Colesterol total & 0,040 & 0,002 \\
IMC & 0,248 & 0,016 \\
\hline
\end{tabular}

Observou-se que no modelo final de regressão linear stepwise para o grupo caso, o colesterol total e o triglicérides tiveram correlação significativa com a variável dependente nível sérico de $\alpha$ - tocoferol e a variável IMC não teve correlação estatística significante. No grupo controle observou-se que o colesterol total e o IMC tiveram associação significativa com a variável dependente concentração sérica de a - tocoferol. Portanto, neste estudo, o fator independente correlacionado com as concentraç̃es de $a$ - tocoferol sérico no grupo caso, foram o colesterol total e o triglicérides e no grupo controle foram o colesterol total e o IMC.

4.2- Freqüência do consumo de alimentos fonte de $a$ - tocoferol 
Com relação aos alimentos fonte de $a$ - tocoferol, na tabela 4.2 apresenta-se a distribuição percentual dos pacientes do grupo caso e controle nas categorias de consumo correspondente.

Observa-se que entre os alimentos listados, os que tiveram maior freqüência de consumo diário no grupo caso foram: manteiga ou margarina $(25,9 \%)$, leite $(55,2$ $\%)$, óleo de soja (84,5\%) e azeite de oliva (34,5\%). O grupo controle relatou um consumo diário semelhante ao do grupo caso.

Dentre os alimentos não consumidos pelos grupos foram citados com maior frequiência requeijão, abacate, batata doce, ameixa preta seca, abacate, peixe, figado, carne processada (presunto, salame, mortadela, salsicha, lingüiça), maionese, amendoim, amêndoa, avelã, castanha, óleo de girassol, milho, canola e amendoim.

Tabela 4.2: Freqüência de consumo de alimentos ricos em vitamina $E$, segundo grupo caso e controle, Jundiaí - SP.

\begin{tabular}{|c|c|c|c|c|c|c|c|}
\hline \multicolumn{8}{|c|}{ Frequência de Consumo \% } \\
\hline ALIMENTO & $\begin{array}{c}\text { Diário } \\
1\end{array}$ & $\begin{array}{l}5-6 \\
\text { vezes } \\
\text { Sem. }\end{array}$ & $\begin{array}{c}3-4 \\
\text { veres } \\
\text { sem. }\end{array}$ & $\begin{array}{l}1 \text { - } 2 \\
\text { vezes } \\
\text { sem. }\end{array}$ & $\begin{array}{c}2-3 \\
\text { vezes } \\
\text { mês }\end{array}$ & $\begin{array}{l}1 \text { vez / } \\
\text { mês ou } \\
\text { menos }\end{array}$ & Nunca \\
\hline $\begin{array}{l}\text { Queijo (Ca) } \\
\text { Queijo (Co) }\end{array}$ & $\begin{array}{l}8,2 \\
5,2\end{array}$ & $\begin{array}{l}1,7 \\
5,2 \\
\end{array}$ & $\begin{array}{l}10,3 \\
18,9 \\
\end{array}$ & $\begin{array}{l}17,2 \\
24,1\end{array}$ & $\begin{array}{l}8,6 \\
5,2 \\
\end{array}$ & $\begin{array}{l}12,1 \\
19,0 \\
\end{array}$ & $\begin{array}{l}42,6 \\
22,4\end{array}$ \\
\hline $\begin{array}{l}\text { Requeijaso (Ca) } \\
\text { Requeijlo (Co) }\end{array}$ & $\begin{array}{c}8,6 \\
13,8\end{array}$ & $\begin{array}{l}3,4 \\
5,2\end{array}$ & $\begin{array}{l}0,0 \\
0,0\end{array}$ & $\begin{array}{l}6,9 \\
6,9\end{array}$ & $\begin{array}{l}1,7 \\
6,9\end{array}$ & $\begin{array}{l}10,3 \\
12,1\end{array}$ & $\begin{array}{l}69,0 \\
55,2\end{array}$ \\
\hline $\begin{array}{l}\text { Mant/Margarina (Ca) } \\
\text { Mant/Margarina (Co) }\end{array}$ & & $\begin{array}{l}1,7 \\
5,2\end{array}$ & $\begin{array}{c}10,3 \\
6,9\end{array}$ & $\begin{array}{l}24,1 \\
8,6\end{array}$ & $\begin{array}{l}3,4 \\
1,7\end{array}$ & $\begin{array}{l}0,0 \\
5,2\end{array}$ & $\begin{array}{l}34,5 \\
13,8\end{array}$ \\
\hline $\begin{array}{l}\text { Leite (Ca) } \\
\text { Leite (Co) }\end{array}$ & $\begin{array}{l}55,2 \\
65,5\end{array}$ & $\begin{array}{l}0,0 \\
1,7\end{array}$ & $\begin{array}{l}8,6 \\
1,7\end{array}$ & $\begin{array}{l}10,3 \\
15,5\end{array}$ & $\begin{array}{l}3,4 \\
0,0\end{array}$ & $\begin{array}{l}1,7 \\
3,4 \\
\end{array}$ & $\begin{array}{l}20,7 \\
12,1 \\
\end{array}$ \\
\hline Batata doce $(\mathrm{Ca})$ & 1,7 & 0,0 & 0,0 & 1,7 & 5,2 & 5,2 & 86,2 \\
\hline Batata doce (Co) & 1,7 & 0,0 & 0,0 & 8,6 & 1,7 & 8 & 79,3 \\
\hline $\begin{array}{l}\text { Ameixa preta seca (Ca) } \\
\text { Ameixa preta seca (Co) }\end{array}$ & 1.7 & $\begin{array}{l}0,0 \\
0,0\end{array}$ & $\begin{array}{l}0,0 \\
0,0\end{array}$ & $\begin{array}{l}0,0 \\
3,4\end{array}$ & $\begin{array}{l}0,0 \\
3,4\end{array}$ & $\begin{array}{l}6,7 \\
6,9\end{array}$ & $\begin{array}{l}96,6 \\
81,0\end{array}$ \\
\hline $\begin{array}{l}\text { Abacate (Ca) } \\
\text { Abacate (Co) }\end{array}$ & $\begin{array}{l}0,0 \\
3,4\end{array}$ & $\begin{array}{l}0,0 \\
0,0\end{array}$ & $\begin{array}{l}0,0 \\
0,0\end{array}$ & $\begin{array}{l}5,2 \\
5,2\end{array}$ & $\begin{array}{l}1,7 \\
3,4\end{array}$ & $\begin{array}{l}10,3 \\
17,2\end{array}$ & $\begin{array}{l}82,8 \\
70,7\end{array}$ \\
\hline $\begin{array}{l}\text { Uva passa (Ca) } \\
\text { Uva passa (Co) }\end{array}$ & $\begin{array}{l}0,0 \\
8,6\end{array}$ & $\begin{array}{l}0,0 \\
0,0\end{array}$ & $\begin{array}{l}0,0 \\
1,7\end{array}$ & $\begin{array}{l}5,2 \\
3,4\end{array}$ & $\begin{array}{l}3,4 \\
0,0\end{array}$ & $\begin{array}{l}1,7 \\
5,2\end{array}$ & $\begin{array}{l}89,7 \\
81,0\end{array}$ \\
\hline Peire (Ca) & 0,0 & 0,0 & 1,7 & 27,6 & 17,2 & 19,0 & 34,5 \\
\hline
\end{tabular}




\begin{tabular}{|c|c|c|c|c|c|c|c|}
\hline Peixe (Co) & $\mathbf{0 , 0}$ & 0,0 & 6,9 & 25,9 & 10,3 & 22,4 & 34,5 \\
\hline Frango (Ca) & 6,9 & 1,7 & 17,2 & 53,4 & 10,3 & 1,7 & 8,6 \\
\hline Frango (Co) & 3,4 & 5,2 & 19,0 & 55,2 & 6,9 & 1,7 & 8,6 \\
\hline Fígado (Ca) & 0,0 & 0,0 & 1,7 & 17,2 & 3,4 & 24,1 & 53,4 \\
\hline Figado (Co) & 3,4 & 0,0 & 3,4 & 6,9 & 1,7 & 17,2 & 67,2 \\
\hline Presunto/salame (Ca) & 1,7 & 0,0 & 1,7 & 36,2 & 12,1 & 6,9 & 41,4 \\
\hline Presunto/salame (Co) & 5,2 & 0,0 & 17,2 & 29,3 & 8,6 & 13,8 & 25,9 \\
\hline Carne vermelha (Ca) & 6,9 & 5,2 & 22,4 & 41,4 & 6,9 & 3,4 & 13,8 \\
\hline Carne vermelha (Co) & 17,2 & 8,6 & 25,9 & 31,0 & 1,7 & 3,4 & 12,1 \\
\hline Ovo (Ca) & 0,0 & 0,0 & 10,3 & 34,5 & 6,9 & 13,8 & 34,5 \\
\hline Ovo (Co) & 1,7 & 0,0 & 10,3 & 44,8 & 8,6 & 13,8 & 20,7 \\
\hline Maionese (Ca) & 1,7 & 0,0 & 0,0 & 6,9 & 6,9 & 6,9 & 77,6 \\
\hline Maionese (Co) & 5,2 & 1,7 & 1,7 & 3,4 & 10,3 & 20,7 & 56,9 \\
\hline Amendoim (Ca) & 0,0 & 0,0 & 0,0 & 3,4 & 1,7 & 6,9 & 87,9 \\
\hline Amendoim (Co) & 0,0 & 0,0 & $\mathbf{0 , 0}$ & 5,2 & 3,4 & 22,4 & 69,0 \\
\hline Amêndoa (Ca) & 3,4 & 0,0 & 0,0 & 0,0 & 0,0 & 0,0 & 96,6 \\
\hline Amêndoa (Co) & 0,0 & 0,0 & 0,0 & 1,7 & 0,0 & 6,9 & 91,4 \\
\hline Avelã (Ca) & 3,4 & 0,0 & 0,0 & 0,0 & 0,0 & 0,0 & 96,6 \\
\hline Avelä (Co) & 1,7 & 0,0 & 0,0 & 0,0 & 0,0 & 5,2 & 93,1 \\
\hline Castanha (Ca) & 1,7 & 0,0 & 0,0 & 0,0 & 1,7 & 0,0 & 96,6 \\
\hline Castanha (Co) & 1,7 & 0,0 & 0,0 & 0,0 & 0,0 & 5,2 & 93,1 \\
\hline Girassol (Ca) & 3,4 & 0,0 & 0,0 & 1,7 & 0,0 & 0,0 & 94,8 \\
\hline Girassol (Co) & 3,4 & 0,0 & 0,0 & 1,7 & 0,0 & 0,0 & 94,8 \\
\hline Soja (Ca) & 84,5 & 1,7 & 1,7 & 1,7 & 0,0 & 0,0 & 10,3 \\
\hline Soja (Co) & 89,7 & 0,0 & 0,0 & 3,4 & 0,0 & 0,0 & 6,9 \\
\hline Milho (Ca) & 3,4 & 0,0 & 0,0 & 0,0 & 0,0 & 0,0 & 96,6 \\
\hline Milho (Co) & 3,4 & 0,0 & 0,0 & 0,0 & 1,7 & 0,0 & 94,8 \\
\hline Canola (Ca) & 5,2 & 0,0 & 0,0 & 1,7 & 3,4 & 0,0 & 89,7 \\
\hline Canola (Co) & 5,2 & 0,0 & 1,7 & 0,0 & 1,7 & 1,7 & 89,7 \\
\hline Amendoim (Ca) & 1,7 & 0,0 & 0,0 & 0,0 & 0,0 & 0,0 & 98,3 \\
\hline Amendoim (Co) & 0,0 & 0,0 & 0,0 & 0,0 & 0,0 & 0,0 & 100,0 \\
\hline Azeite de oliva (Ca) & 34,5 & 0,0 & 10,3 & 10,3 & 0,0 & 0,0 & 44,8 \\
\hline Azeite de oliva (Co) & 56,9 & 0,0 & 10,3 & 10,3 & 0,0 & 0,0 & 22,4 \\
\hline
\end{tabular}

Entre os alimentos que apresentaram diferença estatística significante no consumo entre os grupos estão:

Queijo $(\mathrm{p}<0,05)$;

Manteiga/ Margarina $(\mathrm{p}<0,01)$;

Ameixa preta seca $(p<0,05)$ 
Uva passa $(p<0,05)$

Carne processada $(\mathrm{p}<0,05)$;

Azeite $(\mathrm{p}<0,05)$;

Na tabela 4.2.1 apresenta-se a estatística descritiva dos escores de frequêencia de consumo dos alimentos fontes de vitamina $\mathrm{E}$, onde o consumo de cada alimento foi medido através de freqüência de consumo simples. Não houve diferença estatística significante entre os escores médios de consumo entre o grupo caso e controle.

Tabela 4.2.1: Estatística descritiva dos escores de freqüência de consumo de alimentos fontes de vitamina E, segundo grupos caso e controle, Jundiai-SP, 2005.

\begin{tabular}{lcc}
\hline & CASOS $(\boldsymbol{n}=\mathbf{5 8})$ & CONTROLES $(\boldsymbol{n}=\mathbf{5 8})$ \\
\cline { 3 - 3 } PARÂMETROS & & \\
\hline Média & 0,26 & 0,24 \\
Desvio Padrão & 0,22 & 0,14 \\
Mínimo & 0,10 & 0,10 \\
Máximo & 0,90 & 0,90 \\
\hline
\end{tabular}

$(p>0,05 ; p=0,682)$

A correlação entre o nível sérico de $a$ - tocoferol e o consumo deste antioxidante pela dieta nos grupos caso e controle pode ser observado na figura 4.5. 
Figura 4.5 - Concentrações séricas de $\alpha$-tocoferol nos grupos caso e controle, segundo escores médios de consumo de alimentos ricos em vitamina E, Jundiaí - SP, 2005.

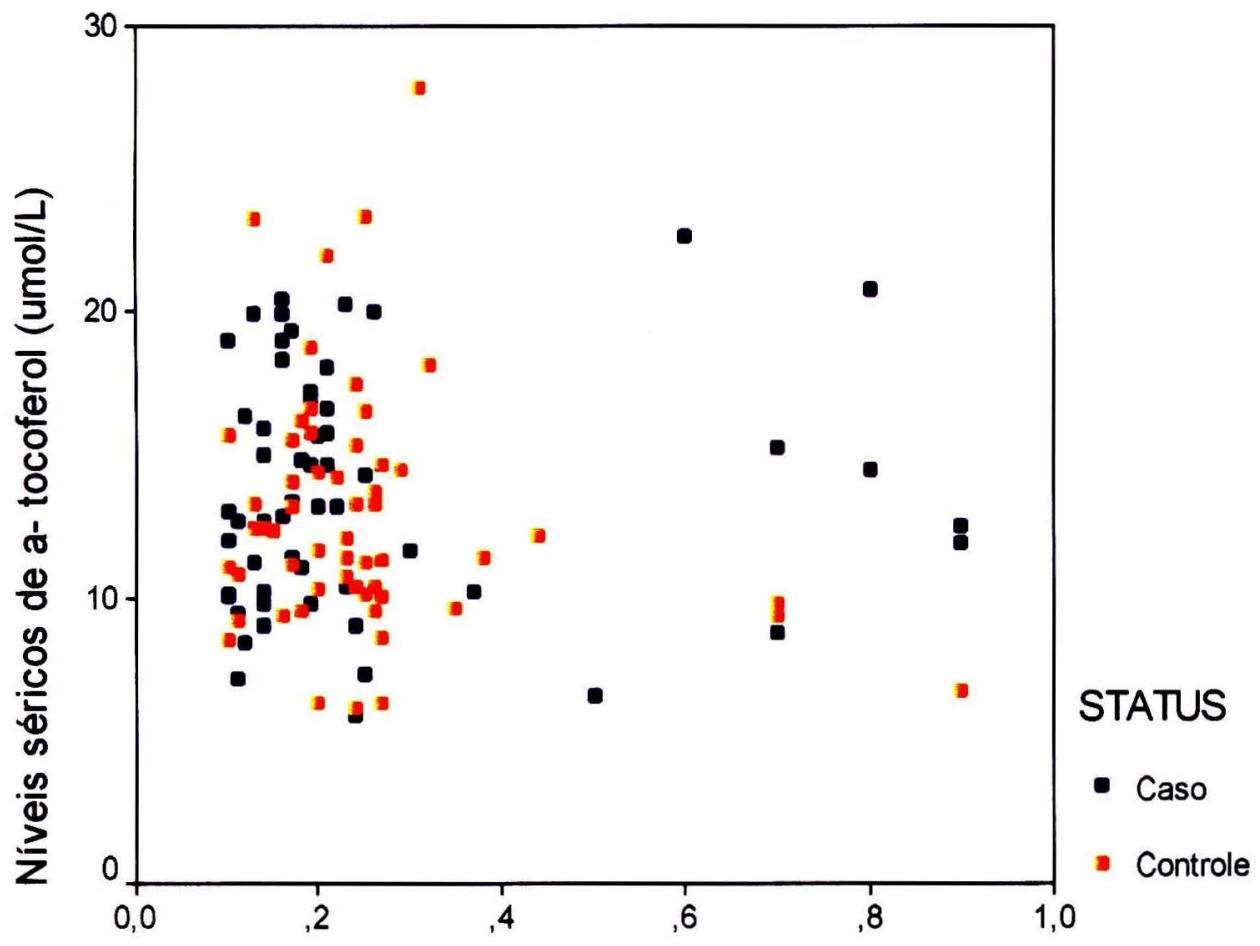

Média de escores de consumo de vitamina $\mathrm{E}$

Ao investigarmos a correlação das concentrações séricas de $\alpha$ - tocoferol do grupo caso e controle com a média de escores de consumo de alimentos fonte de vitamina E, observou-se que não houve correlação estatisticamente significativa ( $p>0,05 ; r=$ $0,662)$. 
5-DISCUSSÃO 


\section{0 - DISCUSSÃO}

A vitamina $\mathbf{E}$ é o principal antioxidante da membrana celular, capaz de inibir a ação dos radicais livres e prevenir a propagação da peroxidação lipídica. É um nutriente de importância reconhecida na manutenção da saúde dos indivíduos, independentemente de sua faixa etária, sexo e etnia.

A deficiência de vitamina $\mathrm{E}$, destaca-se como uma grande preocupação em saúde pública, face ao aumento mundial na prevalência de indivíduos com DM2 ocasionada pela obesidade, especialmente em países em desenvolvimento e em transição nutricional (SOUZA e col. 2003),

Embora a importância da vitamina $\mathrm{E}$ como antioxidante da membrana celular seja reconhecida há várias décadas, estudos com esse micronutriente antioxidante ainda estão sendo realizados com o intuito de trazer mais esclarecimentos e beneficios em pacientes com e sem DM2.

\section{1 - Validade do estudo}

Uma importante limitação nos estudos clínicos é a ocorrência de perdas na população em estudo, sobretudo quando existe a necessidade de deslocamento dos participantes da pesquisa de seu domicílio para o local onde são coletados os dados.

No presente estudo, este fato foi vivenciado e muitos dos pacientes que foram sorteados e convidados a fazer parte da pesquisa, alegaram não querer participar devido à distância de seus domicilios do local da coleta de dados e principalmente por serem pessoas idosas com dificuldades na locomoção e transporte e não terem quem as acompanhasse. 


\section{2- Características gerais dos grupos caso e controle}

Neste estudo, os participantes apresentaram características sócio-econômicas compativeis com as de populações de baixo poder aquisitivo, uma vez que a renda familiar mensal variou entre um e dois salários mínimos e os pacientes apresentaram até cinco anos de estudo. Estes resultados refletem o perfil de renda familiar mensal apresentados na Pesquisa Nacional por amostras de Domićlios (PNAD) realizada no país nos anos de 2002 e 2003 pelo IBGE (2004) onde 29,2 \% da população do estado de São Paulo apresentou de 1 a 2 salários mínimos como renda familiar mensal.

Sendo a escolaridade e a renda familiar indicadores sócio-econômicos e de qualidade de vida, as características observadas colocam os pacientes estudados em um grupo populacional mais vulnerável, tanto no que se refere à falta de recursos econômicos e hábitos alimentares como também às condiçơes de desinformação e falta de educação alimentar que ocasionam estados nutricionais deficientes em vitaminas e micronutrientes.

Considerando que o hábito de fumar e a ingestăo de bebidas alcoólicas relaciona-se com uma grande variedade de efeitos adversos à saúde humana, estes hábitos foram pouco relatados entre os pacientes do estudo sendo mais freqüentes no grupo controle do que no caso. Apesar de alguns estudos reportarem uma significante associação entre níveis séricos de $\alpha$ - tocoferol com o hábito de fumar (BOLTONSMTTH e col,1991; FERNANDEZ-BANARES e col, 1994), neste não houve associaçőes, e a concentração sérica de $\alpha$ - tocoferol foi normal entre fumantes e não fumantes dos dois grupos.

Quanto a ingestão de bebida alcoólica, a ausência de associaçð̃es entre a concentração do $a$ - tocoferol sérico e a ingestão de bebidas alcoólicas nos dois grupos pode ser explicada pelo fato do álcool exercer um efeito direto sobre o 
metabolismo da glicose e insulina sendo então mais restrito seu consumo por pessoas diabéticas.

Abordando às variáveis antropométricas, o IMC e a RCQ foram importantes na avaliação da gordura corporal. Neste estudo, a média de IMC no grupo caso foi maior que a do grupo controle $\left(29,83 \mathrm{Kg} / \mathrm{m}^{2}\right.$ e $26,75 \mathrm{Kg} / \mathrm{m}^{2}$, respectivamente) e ambos grupos encontravam-se em sobrepeso. Estes achados são condizentes com a literatura onde a elevação do IMC é um importante fator de risco para a progressão ao DM2 já que o excesso de peso, principalmente a obesidade visceral resulta na menor extração de insulina pelo figado, maior produção hepática de glicose e diminuição de captação de glicose pelo tecido muscular (MACHADO e col., 2002 CORREA e col, 2003).

$\mathrm{Na}$ abordagem do IMC em relaçåo ao sexo, as mulheres com DM2 tiveram maior prevalência de sobrepeso e obesidade do que as mulheres sem DM2, fato também verificado para os homens sem DM2 quando comparados aos homens com DM2, concordando com o estudo de CORREA e col, (2003).

A análise bioquímica, realizada com o intuito de controlar e servir como parâmetro de comparação entre os grupos, detectou a presença de maiores níveis de glicose nos paciente do grupo caso, devido obviamente a presença de DM2. Em relação ao perfil lipídico demonstrado pelos grupos, foi possível aferir que o grupo caso demonstrou maior freqüência de pacientes com níveis elevados de colesterol total/fraçðes e triglicérides do que o referido no grupo controle, embora somente a fração HDL do colesterol tenha apresentado diferença estatística entre os grupos. 


\section{3- Concentrações séricas de $\alpha$ - tocoferol nos grupos caso controle}

Neste estudo, foram encontrados baixas concentraçðes séricas de $\alpha$ - tocoferol em pacientes com e sem DM2. Demonstrou-se a prevalência de deficiência de $\alpha-$ tocoferol em $34,5 \%$ de pacientes com DM2, maior do que a prevalência encontrada no estudo de VANNUCHI e col. (1994), que demonstrou 15,4\% de deficiência de $\alpha$ - tocoferol em idosos com DM2, realizado em Ribeirão Preto.

A prevalência de deficiência de $\alpha$ - tocoferol para pacientes sem DM2 neste estudo foi de 46,6\%. Este resultado é condizente com estudos de prevalência de deficiência de vitamina E em pessoas sem DM2 em várias partes do mundo. HALLER e col. (1991) avaliando a população de 11 paises europeus encontraram de 0,5 a $25 \%$ de deficiência de $\alpha$ - tocoferol em pessoas idosas de 07 países. GOUADO e col,. (1998) encontraram $66 \%$ de deficiência de $\alpha$ - tocoferol em pessoas com idades de até 75 anos em oito vilarejos de Norte de Camarões. SHAHAR e col. (1999) encontraram $27 \%$ de prevalência de deficiência de $\alpha$ - tocoferol em idosos na costa oeste da Malásia. LEOTSINIDIS e col. (2000), demonstraram que 68,3\% dos homens idosos e $62 \%$ das mulheres idosas da área urbana na Grécia apresentaram deficiência de $\alpha$ tocoferol.

De acordo com FARREL e col. (1994), concentrações de $\alpha$ - tocoferol abaixo de 11,63 $\mu \mathrm{mol} / \mathrm{L}$ associados com baixo tocoferol/razão lipídico ou com a ocorrência de hemólise eritrocitária em $2 \%$ peróxido de hidrogênio, são necessárias para classificação de deficiência de vitamina $\mathrm{E}$. Valores séricos isolados de $\alpha$-tocoferol $<$ 11,63 $\mu \mathrm{mol} / \mathrm{L}$, são uma indicação de deficiência subclínica ou bioquímica, e não necessariamente evidências de deficiência de vitamina $\mathrm{E}$.

$\mathrm{Na}$ análise univariada observou-se baixas concentraçzes de $\alpha$ - tocoferol no grupo de pacientes controle. Quando realizado ajuste dos niveis séricos de $\alpha-$ tocoferol, 
segundo as variáveis que tiveram significado clínico ou foram significativas na análise de correlação, a média de $\alpha$ - tocoferol no grupo controle foi discretamente maior do que no grupo caso, sugerindo que algumas covariáveis podem explicar a diferença de concentração sérica de $\alpha$ - tocoferol nos grupos.

Ao investigarmos a correlação dos níveis séricos de $\alpha$ - tocoferol do grupo caso e controle com as variáveis de interesse clínico como o IMC a RCQ e a idade, observou-se que o IMC nos grupos caso e controle teve uma fraca correlação estatisticamente significativa e que as variáveis relação cintura-quadril e idade embora importantes do ponto de vista clínico, não apresentaram correlação estatística significante com os níveis séricos de $\alpha$ - tocoferol. Estes achados são condizentes com o relatado na literatura que descreve a associação dos níveis séricos de $\alpha-$ tocoferol com o IMC (RIEMERSMA e col. 1990, BOLTON - SMITH e col, 1991, SINHA e col., 1993) e com outros estudos que não encontraram associação significativa entre níveis séricos de $a$ - tocoferol, RCQ, idade e sexo (STRYKER e col. 1988; ASHERIO e col.,1992; OLIVIERI e col., 1994; SINGH e col, 1995; KITAMURA E COL., 1997).

A associação do $a$ - tocoferol com a concentração lipídica tem sido muito discutida Nesse estudo, observou-se uma forte correlação entre $\alpha$ - tocoferol com o colesterol total e fraç̋es e o triglicérides em ambos grupos, concordando com inúmeros estudos da literatura (KNEKT e col., 1988; HERBETH e col., 1989; RIEMERSMA e col. 1990, SINGH e col, 1995). Essa relação pode ser explicada quando se considera o importante papel das lipoproteínas como transportadoras de $\alpha$ - tocoferol dentro do organismo. Assim, sendo a vitamina E lipossolúvel, depende exclusivamente dos níveis plasmáticos dessas lipoproteínas para seu adequado nível sérico. Havendo elevaçð̃es nas concentrações de VLDL, redução nas concentraçð̃es de HDL, e modificaçø̃es no tamanho das partículas de LDL, conseqüentemente a concentração de $\alpha$ - tocoferol sérica sofrerá alterações (BEHRENS e col. 1982, YOSHIDA, 1997). 
A menor concentração de $\alpha$ - tocoferol no soro dos pacientes de ambos grupos, ainda não encontra esclarecimento objetivo, embora algumas das razð̃es para explicar esse fato sejam a interação com drogas medicamentosas, diminuição nas reservas de nutriente, menor conversão de vitaminas para suas formas ativas a má-absorção e a ingestão alimentar insuficiente (FISHER e col.,1978).

Dentre os pacientes do grupo controle, evidências sugerem que a deficiência de $\alpha-$ tocoferol pode estar relacionada ao consumo inadequado de alimentos fonte de vitamina $\mathrm{E}$, uma vez que na avaliação individual de vinte dois pacientes com baixa concentração de $\alpha$ - tocoferol não foram relatadas morbidades nem ingestão de medicamentos que pudessem interferir na concentraça sérica do $a$ - tocoferol. Em quatro pacientes observou-se a presença de hipertensão arterial com ingestão de medicamentos e uma paciente relatou a ingestão de medicamento para osteoporose. Desta forma, pode-se inferir que a presença da morbidade associada a ingestão de medicamentos e ao consumo alimentar inadequado de alimentos fonte em vitamina $E$ podem ter sido a razão da baixa concentração sérica de $\alpha$ - tocoferol nestes pacientes.

Já na avaliação individual dos pacientes do grupo caso, evidências sugerem que a deficiência de $\alpha$ - tocoferol pode estar relacionada a vários fatores conjuntos, uma vez que observou-se o consumo inadequado de alimentos fonte de vitamina $\mathrm{E}$, presença de morbidades e ingestão de vários medicamentos concomitantes que podem ter interferido nos níveis séricos de $\alpha$-tocoferol.

A avaliação das concentraçðes séricas de $\alpha$ - tocoferol em pessoas com e sem DM2 é muito complexa e inúmeros fatores podem contribuir para o desenvolvimento de deficiências desse micronutriente. Cabe ressaltar que, o presente estudo determinou as concentraçðes séricas de $\alpha$ - tocoferol nesses grupos e fez a correlação com a vitamina $\mathrm{E}$ consumida pela dieta. 
Assim, estudos mais detalhados ainda são necessários, com a utilização de marcadores para estresse oxidativo em pacientes com e sem DM2 e avaliação do consumo alimentar com questionários de frequêencia alimentar mais complexos para estabelecer com maior precisão a razão das baixas concentraç̃os séricas de $\alpha$ tocoferol nesses pacientes.

Ao correlacionarmos as concentraçбes séricas de $\alpha$ - tocoferol com os alimentos fonte em vitamina $E$, não houve associą̧̃o estatística significativa, pois o consumo pelos grupos foi baixo, com ingestão relatada de uma a duas vezes por semana

Esses achados são condizentes com os achados por MARSHAL e col., (1997) que também não encontraram correlação entre as concentrações séricas de $\alpha$ - tocoferol com a dieta, devido a pobre ingestão de alimentos fonte em vitamina $E$.

No presente estudo, o baixo consumo de alimentos ricos em vitamina $E$, pode estar relacionado à falta de recursos econômicos para a compra de alimentos adequados, a desinformação e a falta de educação alimentar, além da pequena motivação para alimentar-se, que geralmente as pessoas idosas demonstram.

Embora a ingestão insuficiente de alimentos ricos em vitamina $\mathrm{E}$ por si só não possa explicar as baixas concentrações séricas de $\alpha$ - tocoferol encontradas nos grupos, vários estudos conseguiram correlacionar a ingesta de vitamina $\mathrm{E}$ da dieta com os níveis sanguíneos desse antioxidante (KNEKT e col., 1988; STRYKER e col. 1988; HERBETH e col., 1989; ROMIEU e col., 1990; BOLTON - SMITH e col, 1991; ASHERIO e col.,1992).

Nesse estudo, o questionário usado para a avaliação da freqüência de ingestão de alimentos fonte de vitamina $\mathrm{E}$, não teve informaçðes detalhadas necessárias como a ingestão de alimentos ricos em fibras ou o tamanho das porçoses consumidas pelos 
grupos, o que pode ter interferido na associação da vitamina $\mathrm{E}$ com as concentraçð̃es sanguineas desses micronutriente. 
6-CONCLUSÕES 


\section{0- CONCLUSÕES}

Os resultados do presente estudo mostram que tanto no grupo de pacientes portadores de DM2 quanto no grupo de pacientes não portadores de DM2 observouse concentrações séricas deficientes em $\alpha$ - tocoferol. Cabe ressaltar as seguintes conclusóes:

Ambos grupos apresentaram grande parte de seus pacientes com estado nutricional avaliado através do IMC e RCQ acima dos valores recomendados na literatura.

A prevalência de baixas concentraçð̃es séricas de $\alpha$ - tocoferol $(<11,6$ $\mu \mathrm{mol} / \mathrm{L}$ ) no grupo de pacientes caso foi de $34,5 \%$ e no grupo controle de $46,6 \%$, caracterizando um problema sério de saúde pública.

Após ajuste por variáveis de confusão a média de $\alpha$ - tocoferol no grupo controle foi discretamente maior do que no grupo de pacientes caso (13,52 [ (IC 95\%) : 12,48 - 14,56 ; 13,20 (IC 95\%) : 12,16 - 14,23] ), mas não houve diferença estatística significante entre os grupos.

$\mathrm{Na}$ análise multivariada as variáveis independentes IMC, colesterol total/ frações e triglicérides apresentaram correlação estatística significativa $(p<$ $0,05)$ com a variável dependente concentração sérica de $\alpha$ - tocoferol em ambos grupos.

Embora importante do ponto de vista clínico, na análise multivariada a idade e a RCQ não tiveram correlação estatística significativa com as concentraçð̃es séricas de $\alpha$ - tocoferol nos grupos estudados.

Ao colocar as variáveis independentes na análise de regressão linear, o melhor modelo de predição para o grupo de pacientes caso envolveu as 
concentraçðes séricas de $\alpha$ - tocoferol, colesterol total e triglicérides e para o grupo controle as concentraçð̃es séricas de $\alpha$-tocoferol, colesterol total e o IMC.

$>$ A presença do DM2 não foi conclusiva para explicar a deficiência de $\alpha$ tocoferol;

A média de ingestão de alimentos fontes em vitamina $E$ foi baixa e não houve diferença estatística entre os grupos.

As concentrações séricas de $\alpha$ - tocoferol não tiveram correlação com a vitamina $E$ da dieta em nenhum dos grupos $(p>0,05)$. 
7-CONSIDERACÕES FINAIS 


\section{0 - CONSIDERAÇÕES}

As mudanças tecnológicas ocorridas nos meios de transporte, de produção e de transformação de alimentos e na área de comunicação, influenciaram intensamente 0 comportamento humano nos países industrializados, aumentaram o consumo e levaram grande parte das populaçóes à exposição a uma série de fatores de risco.

Estando estes fatores, muitas vezes presentes concomitantemente nos mesmos individuos e em geral associados ao desenvolvimento de hábitos alimentares inadequados, sedentarismo, tabagismo e etilismo, as açőes de prevenç̃̃o, preferencialmente, não devem se limitar a um único fator. $\mathrm{O}$ controle dos fatores de risco depende do nível de informação dos indivíduos sobre saúde e da disponibilidade e de facilidades para a prevenção e para as mudanças.

O DM2 destaca-se por sua importância enquanto problema de Saúde Pública, com impacto epidemiologico crescente nas taxas de morbidade e mortalidade e nas conseqüentes seqüelas de incapacidade.

A vitamina $E$ apresenta importância significativa na proteção de células e tecidos devido a sua atividade antioxidante tanto em individuos saudáveis quanto naqueles que apresentam doenças crônicas. A baixa concentração sérica de vitamina $\mathrm{E}$ decorrente de atividade de radicais livres, problemas de absorção e alimentação inadequada é bastante preocupante.

A preocupação torna-se ainda maior quando a deficiência está aliada à ocorrência de uma doença crónica como o DM2 elevando o risco de complicaçðes e sequelas debilitantes que afetam a qualidade de vida.

Essa pesquisa detectou uma diminuição das concentrações séricas de $\alpha$ - tocoferol não somente em pessoas com DM2 mas também em pessoas sem DM2, evidenciando a problemática da questão. 
O presente estudo alerta para a necessidade do aumento do consumo de alimentos fonte de vitamina E, através da educação em saúde, importante influência para mudança de hábitos nutricionais e de vida. 
8-REFERÊNCLAS BIBLIOGRÁFICAS 


\section{8- REFERÊNCIAS}

Abdalla DSP. Estresse oxidativo e alimentação. In: Tirapegui J. Nutrição: Fundamentos e aspectos atuais. São Paulo: Atheneu, p. 179-200, 2000

ADA- American Diabetes Association. Report of the Expert Committee on the diagnosis and classification of diabetes mellitus. Diabetes Care, 20: 1183-1197, 1997.

Ahmad M; Khan M.A.; Khan A.S. Naturally occurring antioxidant vitamin levels in patientes with type-II diabetes mellitus. J Ayub Med Coll Abbottabad 15(1): 54-7, 2003.

Andrew R; Skyrme-Jones P, O'Brien RC, Berry KL; Meredith IT. Vitamin E supplementation improves endothelial function in type 1 diabetes mellitus: a randomized, placebo-controlled study. J Am Coll Cardiol 36: 94-102, 2000.

Arnaud J., Fortis I., blachier S., Kia D., Favier A. Simultaneous determination of retinol, $\alpha$-tocopherol and B-carotene in serum by isocratic high-performance liquid chromatograph. J Chromatogr B Biomed Appl 572: 103-116, 1991.

Asherio A., Stampfer M.J., Colditz G.A. Correlations of vitamin A and E intakes with the plasma concentrations of carotenoids and tocopherols among American men and women. J Nutr, 122: 1792-801, 1992.

Barceló A. \& Rajpathak S. Incidence and prevalence of diabetes mellitus in the Americas. Rev Panam Salud Publica 10:300-308, 2001.

Behme MT; Dupre J; Harris SB; Hramiak IM; Mahon JL. Insulin resistance in latent autoimmune diabetes of adulthood. Ann N Y Acad Sci 1005: 374-377, 2003. 
Behrens WA; Thompson JN; Madère R. Distribution of $\alpha$-tocopherol in human plasma lipoproteins. Am J Clin Nutr 35: 691-696, 1982.

Bast A; Haenen G.R; Doelman C.J. Oxidants and antioxidants: state of the art. Am J Med 91 (3C): 2S-13S, 1991.

Brasil. Ministério da Saúde. Estudo multicêntrico sobre a prevalência do diabetes mellitus no Brasil. Inf Epidemiol SUS V.1, no. 3, p. 47-73, 1992.

Bolton-Smith C., Casey C.E, Gey K.F. Antioxidant vitamin intakes assessed using a food frequency questionnaire: correlation with biochemical status in smokers and nonsmokers. Br J Nutr. 65: 337-46, 1991.

Bouche C. \& Goldfine A.B. Prevention of type 2 diabetes: are we ready? Minerva Med 94(1): 9-18, 2003.

Bursell SE; Clermont AC; Aiello LO; Aiello LM; Schlossman DK; Feener EP; Laffel L; King GL. High-dose vitamin E supplementation normalizes retinal blood flow and creatine clearance in patients with type 1 diabetes. Diabetes Care 22: 1245-1251, 1999.

Cerillo A; Giugliano D; Quataro A; Donzella C; Dipalo G; Lefebrve PJ; Vitamin E reduction of protein glycosylation in diabetes. Diabetes Care 14: 68-72, 1991.

Ceriello B.; Crescentini M. L; Russo E.; Tonutti \& Taboga Antioxidant defences are reduced during the oral glucose tolerance test in normal and non-insulindependent diabetic subjects. Eur J Clin Invest 28(4):329, 1998.

Christ M; Klima T; Maisch B. Arterial hypertension and metabolic syndrome. Herz. 28 (8): 674-85, 2003 
Colditz GA; Willet WC; Rotnitzky A; Mason JE. Weight gain as a risk factor for clinical diabetes mellitus in women. Ann Intern Med 122: 481-486, 1995.

Dabelea D; Hanson RL; Lindsay RS; Pettitt DJ; Imperatore G; Gabir MM; Roumain J; Bennett PH; Knowler WC. Intrauterine exposure to diabetes conveys risks for type 2 diabetes and obesity. Diabetes 49: 2208-2211, 2000.

Davidson M.B. Clinical Implications of Insulin Resistance Syndromes. Am J Med 99(4): 420-426, 1995.

Deedwania PC. Metabolic syndrome and vascular disease. is nature or nurture leading the new epidemic of cardiovascular disease? Circulation Jan 6; 109(1):2-4, 2004

Desai I.D.; Swann M.A.; Garcia Tavares M.L.; Dutra de Oliveira B.S.; Duarte F.A.M.; Dutra de liveira J.E. Vitamin E status of agricultural migrant workers in Southern Brazil. Am J Clin Nutr 33(12): 2669-2673, 1980.

Devaraj S; Jialal I. Low-density lipoprotein postsecretory modification, monocyte function, and circulating adhesion molecules in type 2 diabetic patients with and without macrovascular complications. Circulation 102: 191-196, 2000.

Diamond M.P.; Chauhan S.; Kruger M.; Subramanian M. Values of fasting glucose levels, glucose tolerance tests and glucose - insulin ratios as predictors of glucose tolerance. Fertil Steril 80(4): 1022-1025. 2003.

Dierckx H. Oxidative stress status in patients with diabetes mellitus: relationship to diet. Eur J Clin Nutr 57(8): 999-1008, 2003.

Drevon C.A. Vitamin E - Its usefulness in health and curing diseases (Mino, M. et.al, eds). Japan Sci Soc Press Tokyo/ S. Karger, Basel: 65-83, 1993. 
Dornhorst A; Rossi M. Risk and prevention of type 2 diabetes in women with gestational diabetes. Diabetes Care Aug 21 Suppl 2: B 43-9, 1998.

EPI INFO 6 - Version 6.04. Centers for Disease Control \& Prevention (CDC), USA; World Health Organization (WHO), Geneva, Switzerland, January 2001.

Erhardt JG, Mack H, Sobeck U, Biesalski HK. $\beta$-Carotene and $\alpha$-tocopherol concentration and antioxidant status in buccal mucosal cells and plasma after oral supplementation. Br J Nutr 87: 471-5, 2002.

Falorni A. Immunologic and genetic aspects of latent autoimmune diabetes in the adult. Minerva Endocrinol Dec; 28 (4): 297-312, 2003.

Farrel P.M, Robert R.J. In. Modern Nutrition in Health and Disease (Shils. M.E., Olson J.A, and Shike M., eds) 8 th ed., pp. 326-339, Lea \& Febiger, New York, 1994.

Farvid MS; Siassi F; Jalali M; Hosseini M; Saadat N. The impact of vitamin and/or mineral supplementation on lipid profiles in type 2 diabetes. Diabetes Res Clin Pract 65: 21-28, 2004.

Feki M.; Souissi M.; Mebazaa A. Vitamin E deficiency : risk factor in human disease ? Ann Med Interne 152(6): 398-406, 2001.

Felber JP; Haesler E; Jéquier E. Metabolic origin of insulin resistance in obesity with and without type 2 (non-insulin-dependent) diabetes mellitus. Diabetologia 36: 1221 - 1229,1993

Ferreira A.L.A; Matsubara L.S. Radicais livres: conceitos, doenças relacionadas, sistema de defesa e estresse oxidativo. Rev Assoc Med Brasil 43(1): 61-8, 1997. 
Fernandez-Banares F., Gine J.J., Cabre E. Factors associates with low values of biochemical vitamin parameters in healthy subjects. Int J Vitam Res, 64: 68-74.

Ford E.S. Vitamin supplement use and Diabetes Mellitus Incidence among adults in the United States. Am J Epidemiol 153(9):892-897, 2001.

Fornés NS. Padróes alimentares e suas relaçóes com os lipídios séricos em população da área metropolitana de São Paulo. São Paulo; 1998. (Tese de Doutorado - Faculdade de Saúde Pública da USP).

Gardes-Albert M; Jore D; Ferradini C. Membrane lipid peroxidation: pulse and $\boldsymbol{\gamma}$ radiolysis in oxyradical research. In Vigo-Pelfrey $\mathbf{C}$ (ed): Membrane lipid oxidation. 1th ed. Santa Clara, CRC Press, 2-30, 1991.

Gimeno SG; Ferreira SR; Cardoso MA; Franco LJ; Iune SM. Weight gain in adulthood and risk of developing glucose tolerance disturbance: a study of a Japabese-Brazilian population. Japanese-Brazilian Diabetes Study Group. J Epidemiol 10: 103-110, 2000.

Gouado I., Mbiapo T.F., Moundipa F.P, Teugwa M.C. Vitamin A and E status of some rural populations in the north of Cameroon. Int J Vitam Nutr Res, 68 (1): 21-5, 1998.

Gorden P. Non-insulin dependent diabetes - the past, present and future. Ann Acad Med Singapore 26(3):326-30, 1997.

Gurruchaga AM. Consecuencias patológicas de la obesidad: hipertension arterial, diabetes mellitus y dislipidemia. Bol Esc Méd Chile 26: 18-21, 1997.

Guyton A.C, Hall J.E. Fisiologia Humana e mecanismos das doenças. $6^{a}$. Ed. Rio de Janeiro: Guanabara Koogan, 1998. 
Haffiner SM; D'Agostino Jr. R; Mykkanen L; Tracy R; Howard B; Rewers M; Selby J; Savage PJ; Saad MF. Insulin sensitivity in subjects with type 2 diabetes. Diabetes Care 22: 562-568, 1999.

Haller J., Lowik M.R, Ferry M, Ferro-Luzzi A. Nutritional status: blood vitamins A, E, B6, B12, folic acid and carotene. Euronut SENECA investigators. Eur J Clin Nutr, 45 (Suppl) 3: 63-82, 1991.

Halliwell B, Gutteridge JMC. Free radicals in biology and medicine. $3^{\text {th }} \mathrm{ed}$. Oxford: New York; 1999.

Halliwell B. Vitamin E and treatment and prevention of diabetes: a case for a controlled clinical trial. Singapore Med J 43(9): 479-484, 2002.

Handelman GJ; Packer L; Cross CE. Destruction of tocopherols, carotenoids, and retinol in human plasma by cigarrete smoke. Am J Clin Nutr 63: 559-565, 1996.

Hasanain B.; Mooradian A.D. Antioxidant vitamins and their influence in diabetes mellitus. Curr Diab Rep 2(5): 448-456, 2002.

Hebert J.R, Hurley T.G, Hsieh J. Determinants of plasma vitamins and lipids: the Working Well Study. Am J Epidemiol, 140: 132-47, 1994.

Herbeth B., Chavance M, Musse N. Dietary intake and other determinants of blood vitamins in an elderly population. Eur J Clin Nutr, 43: 175-86, 1989.

Henry RR; Wallace P.; Olefsky JM. Effects of weight loss on mechanisms of hiperglycemia in obese non-insuline dependent diabetes mellitus. Diabetes 35: 990-998, 1986.

Hershko C. Mechanism of iron toxicity and its possible role in red cell membrane damage. Semim Hematol 26: 277-85, 1989. 
Hirai A; Hirai A.T; Brunieri D.M; Harima H.A; Osiro K; Wakisaka K. Franco L.J.; Matsumura L.K; Kikuchi M.Y.; Cardoso M.A.; Junior N.B.; Tomita N.E.; Moisés R.C.S.; Freire R.D.; Chaim R.C.; Ferreira S.R.G.; Gimeno S.G.A. Diabetes mellitus e doenças associadas em Nipo-Brasileiros. Depto Med Prev UNIFESP, 2004.

Hu FB; Leitzmann MF; Stampfer MJ; Colditz GA; Willet WC; Rimm EB. Physical activity and television watching in relation to risk for type 2 diabetes mellitus in men. Arch Intern Med 161: 1542-1548, 2001.

Hu FB; LI TH; Colditz GA; Willet WC; Manson JE. Television watching and other sedentary behaviors in relation to risk of obesity and type 2 diabetes mellitus in women. JAMA april 9, 289 (14): 1785-1791, 2003.

Hubert HB; Feinleib M; McNamara PM; Castelli VP. Obesity as na independent risk factor for cardiovascular disease: a 26-year follow-up of participants in the Framinghan heart study. Circulation 67: 968-977,1983.

IBGE - Instituto Brasileiro de Geografia e Estatística. Pesquisa Nacional por Amostras de Domicílio 2003: Indicadores Sociais. Rio de Janeiro; IBGE, 2004

Ives T.J; Dunn P.F. Pharmacotherapy of Diabetes Mellitus. Lippincotts Prim Care Pract (5):537-549, 1997.

Jarret R.J. Epidemiology and public health aspects of non-insulin-dependent diabetes mellitus. Epidemiol Rev 11: 151-171, 1989.

Jelliffe DB.; Jelliffe EFP. Community nutritional assessment, with special reference to less technically developed countries. $2^{\text {nd }}$ ed. London: Oxford University Press, 1989. 
Kim JK; Wi JK; Youn JH. Metabolic impairment precedes insulin resistance in skeletal muscle during high-fat feeding in rats. Diabetes 45: 651-658, 1996.

Knekt P, Seppanen R., Aaran R.K. Determinants of serum alpha-tocopherol in Finnish adults. Prev Med, 17: 725-35, 1988.

Kip KE, Marroquin OC, Kelley DE, Johnson BD, Kelsey SF, Shaw LJ, Rogers WJ, Reis SE. Clinical importance of obesity versus the metabolic syndrome in cardiovascular risk in women: a report from the Women's Ischemia Syndrome Evaluation (WISE) study. Circulation Feb 17; 109(6):706-13, 2004.

Kitamura Y., Tanaka K, Kiyohara C. Relationship of alcohol use, physical activity and dietary habits with serum carotenoids, retinol and alpha-tocopherol among male japonese smokers. Int J Epidemiol, 26: 307-14.

Landvik S.V., Diplock A.T., Packer L. Efficacy of vitamin E in human health and disease. Handbook of antioxidants New York, Marcel Dekker, 2002.

Landin-Olsson M. Latent autoimmune diabetes in adults. Ann N Y Acad Sci, Apr; 958:112-6, 2002.

Leotsinidis M., Alexopoulos A., Schinas V., Kardara M, Kondakis X. Plasma retinol and tocopherol levels in greek elderly population from na urban and a rural área: associations with the dietary habits. Eur J Epidemiol, 16 (11): 1009-16, 2000.

Li X; Zhou ZG; Yang L; Huang G; Yan X. Metabolic syndrome and latent autoimmune diabetes in adults. Zhongguo Yi Xue Ke Xue Yuan Xue Bao 25(6): 676-679, 2003.

Machlin LJ. Handbook of vitamins. $2^{\circ}$. Ed. - New York, Marcel Dekker, 99-144, 1991. 
Mahan L.K, Arlin M.T. Krause: alimentos, nutriçăo \& dietoterapia. $10^{\circ}$ ed. - São Paulo, ROCA, 77-79, 2002.

Marshall J.R, Lanza E., Bloch A. Indexes of food and nutrient intakes as predictors of serum concentrations of nutrients: the problem of inadequate discriminant validity. Am J Clin Nutr, 65 (Suppl): 1269S-74S, 1997.

Marroquin OC; Kp KE; Kelley DE; Johnson BD; Shaw LJ; Bairey Merz CN; Sharaf BL; Pepine CJ; Sopko G; Reis SE; Women's Ischemia Syndrome Evaluation Investigators. Metabolic syndrome modifies the cardiovascular risk associated with angiographic coronary artery disease in women: A report from the Women's Ischemia Syndrome Evaluation. Circulation; Feb 17; 109(6): 714-21, 2004

Mayer-Daves EJ; Costacou T; King I; Zaccaro DJ; Bell RA. Plasma and dietary vitamin $\mathrm{E}$ in relation to incidence of type 2 diabetes. The Insulin Resistance and Atherosclerosis Study (IRAS). Diabetes Care 25 (12): 2172-2177, 2002.

Meydani M. Vitamin E. Lancet, 345: 170-5, 1995

Millen A.E.; Gruber M.; Klein R., Klein B.E.K.; Palta M.; Mares J.A. Relations of serum Ascorbic acid and $\alpha$ - tocopherol to diabetic retinopathy in the third national health and nutrition examination survey. Am J Epidemiol 158(3):225, 2003.

Ministério da Saúde. Conselho Nacional de Saúde. Brasil. Resolução 196 de 10 de outubro de 1996; Diário Oficial 1997.

Moncada S; Higgs A. The L-arginine-nitic oxide pathway. N Engl J Med 329 (27): 2002-12, 1993. 
Monteiro C. A; Mondini L. Costa R. Mudanças na composição e adequaçăo nutricional da dieta alimentar nas áreas metropolitanas do Brasil (1988-1996). Rev Saude Publica 34: 251-258.

Montonen J., Knekt K., Jărvinen R., Reunanen A. Dietary antioxidants intake and risk of type 2 diabetes. Diabetes Care 27: 362-366, 2004.

Ninomiya JK, L'Italien G, Criqui MH, Whyte J, Gamst A, Chen RS. Association of the metabolic syndrome with history of myocardial infarction and stroke in the Third National Health and Nutrition Examination Survey. Circulation Jan 6; 109(1): 42-6, 2004.

Nourooz-Zadeh J.; Rahimi A.; Tajaddini-Sarmadi.; Tritschler H.; Rosen P.; Halliwell B.; Betteridge D.J. Relationships between plasma measures of oxidative stress and metabolic control in NIDDM. Diabetologia 40: 647-653, 1997.

O'Connell BS. Select vitamins and minerals in the management of diabetes. Diabetes Spectrum Volume 14, number 3, 2001.

Olivieri O., Stanzial A.M., Girelli D. Selenium status, fatty acids, vitamins A and E, and aging: The Nove Study. Am J Clin Nutr, 60: 510-17, 1994.

Opara E.C. Oxidative stress, micronutrients, diabetes mellitus and its complications. J R Soc Health 122(1): 28-34, 2002.

Palanduz S.; Ademoglu E.; Gokkusu C.; Tamer S. Plasma antioxidants and type 2 diabetes mellitus. Res Commun Mol Pathol Pharmacol 109(5-6): 309-18, 2001.

Paolisso G; Dámore A; Galzerano D; Balbi V; Giugliano D; Varriccho M; D’Onofrio F. Daily vitamin E supplements improve metabolic control but not insulin 
secretion in elderly type 2 diabetic patients. Diabetes Care 16: 1433-1437, 1993 (a).

Paolisso G; D'Amore A; Giugliano D; Ceriello A; Varricchio M; D'Onofrio. Pharmacologic doses of vitamin $\mathrm{E}$ improve insulin action in healthy subjects and non-insulin-dependent diabetic patients. Am J Clin Nutr 57: 650-656, 1993 (b).

Pereira RA, Sichieri R, Marins VMR. Razão cintura / quadril como preditor de hipertensão arterial. Cad. Saúde Pública,15: 333-4, 1999.

Pereira LO, Francischi RP, Lancha Jr. AH. Obesidade: hábitos nutricionais, sedentarismo e resistência à insulina. Arq Bras Endocrinol Metab vol. 47, no. 2, São Paulo, Apr. 2003.

Póvoa F. Radicais livres em Patologia Humana. Rio de Janeiro. Imago, 1995.

Reaven PD; Herold DA; Barnett J; Edelman S. Effects of vitamin E on susceptibility of low-density lipoprotein and low-density lipoprotein subfractions to oxidation and on protein glycation in NIDDM. Diabetes Care 18: 807-816, 1995.

Riemersma R.A., Oliver M., Elton R.A. Plasma antioxidants and coronary heart disease: vitamins $\mathrm{C}$ and $\mathrm{E}$ and selenium. Eur J Clin Nutr, 44: 143-50, 1990.

Romieu I., Stampfer M.J., Stryker W.S. Food predctors of plasma beta- carotene and alpha - tocopherol: validation of a food frequency questionnaire. Am J Epidemiol, 131: 864-76, 1990.

Ruhe R.C.; Mcdonald R.B. Use of antioxidant nutrients in the prevention and treatment of type 2 diabetes. J Am Coll Nutr 20 (5 Suppl): 363S-369S; discussion 381S-383S, 2001. 
Salles G.F, Bloch K.V., Cardoso C.R.L. Mortality and predictors of mortality in a cohort of Brazilian type 2 diabetic patients. Diabetes Care 27: 1299-1305, 2004

Salonen JT; Nyyssonen K; Tuomainen TP; Kaplan GA; Lynch J; Helmrich SP. Increased risk of non-insulin dependent diabetes mellitus at low plasma follow up study in men. BMJ 311: 1124-1127, 1995.

Sartorelli D.S; Franco L.J. Tendências do diabetes mellitus no Brasil: o papel da transição nutricional. Cad Saude Publica Rio de janeiro 19(Sup. 1): S29 -S36, 2003.

Sarubin A. The Health Professional's Guide to Popular Dietary Supplements. Chicago, The American Dietetic Association, 2000.

Schwedhelm E.; Maas R.; Troost R.; Boger R.H. Clinical Pharmacokinetics of Antioxidants and their Impact on Systemic Oxidative Stress. Clin Pharmacokinet 42(5): 437-459, 2003.

Seghrouchni I., Drai J., Bannier E., Rivière J., Calmard P., Garcia I., Orgiazzi J., Revol A Oxidative stress parameters in type I, tipe II and insulin-treated type 2 diabetes mellitus; insulin treatment efficiency. Clin Chim Acta 321: 89-96, 2002.

Sentinelli F; Romeo S; Arca M; Filippi E; Leonetti F; Banchieri M; Dimario U; Baroni MG. Human resistin gene, obesity and type 2 diabetes. Diabetes 51: 860$862,2002$.

Shahar S., Earland J., owers H.J., Rahman S.A. Nutritional status of rural elderly Malays: dietary and biochemical findings. Int J Vitam Res, 69 (4): 277-84, 1999.

Sinha R., Patterson B.H., Mangels A.R. Determinants of plasma vitamin E in healthy males. Cancer Epidemiol Biomarkers Prev, 2: 473-9, 1993. 
Singh RB; Ghosh S; Niaz MA; Singh R; Beegum R; Chibo H; Shoumin Z; Postiglione A. Dietary intake, plasma levels of antioxidant vitamins, and oxidative stress in relation to coronary artery disease in elderly subjects. Am J Cardiol 76: $1233-1238,1995$.

Skrha J; Sindelka G; Kvasnicka J; Hilgertová J. Insulin action ans fibrinolysis influenced by vitamin $\mathbf{E}$ in obese type 2 diabetes mellitus. Diabetes Res Clin Pract 44: 27-33,1999.

Smith SR; De Jonge L; Zachwieja JJ; Roy H; Nguyen T; Rood JC. Fat and carbohydrate balances during adaptation to a high-fat. Am J Clin Nutr 71: 450$457,2000$.

Soriguer-Escofet. Prevalence of latent autoimmune diabetes of adults (LADA) in Southem Spain. Diabetes Res Clin Pract 56: 213-220, 2002.

Souza L.J; Chalita F.E.B; Reis A.F.F; Teixeira C.L; Neto C.G; Bastos D.A; Filho J.T.D.S; Souza T.F; Côrtes V.A; . Prevalência de Diabetes Mellitus e fatores de risco em Campos dos Goytacazes, RJ. Arq Bras Endocrinol Metabol 47/1:6974, 2003.

Stryker W.S., Kaplan L.A, Stein E.A. The relation of diet, cigarrette smoking, and alcohol consuption to plasma betacarotene an alpha-tocopherol levels. Am J Epidemiol, 127: 283-96, 1988.

Tan HH; Lim SC. Latent autoimmune diabetes in adults (LADA): a case series. Singapore Med J, 42(11): 513-516, 2001.

Traber M.G. Vitamin E Bioavailability, biokinetics, and metabolism. Handbook of antioxidants New York, Marcel Dekker, 2002. 
Tutuncu N.B, Bayraktar M, Varli K. Reversal of defective nerve conduction with vitamin E supplementation in type 2 diabetes: A preliminary study. Diabetes Care 21: 1995-1918, 1998.

Vannucchi H.; Cunha D.F.; Bernardes M.M.; Unamuno M.R.D.L. Avaliação dos níveis séricos das vitaminas $A, E, C$ e $B_{2}$, de carotenóides e zinco, em idosos hospitalizados. Rev Saude Publica 28(2):121-6, 1994

Wannamethee SG; Shaper AG. Weight change and duration of overweight and obesity in the incidence of type 2 diabetes. Diabetes care 22: 1266-1272, 1999.

Wing RR; Koeske R; Epstein LH; Nowalk MP; Gooding W; Becker D. Long term effects of modest weight loss in type II diabetic patients. Arch Intern Med 147: 1749-1753, 1987

World Health Organization Obesity: Preventing and Managing the global epidemic. Report of a WHO consultation on obesity Geneva: WHO, 1997

World Health Organization Expert Consultation on diet, nutrition and the prevention of chronic diseases, Geneva, 2002.

Wiernsperger N.F. Oxidative stress as a therapeutic target in diabetes: revisiting the controversy. Diabetes Metab 29: 579-85, 2003.

Yoshida $\mathrm{H}$; Ishikawa $\mathrm{T}$; Nakamura $\mathrm{H}$. Vitamin E/lipid peroxide ratio and susceptibility of LDL to oxidative modification in Non-Insulin-Dependent Diabetes Mellitus. Arterioscler Thromb Vasc Biol 17(7): 1438-1446, 1997.

Yun-Zhong F.; Yang S.; Wu G. Free radicals, antioxidants and nutrition. Nutrition 18 (10): 872-879, 2002. 
Zhou Z.G, Li X. Latent autoimmune diabetes in adults: an update. Yuan Yi Xue Bao Oct; 25 (5): 630-4, 2003. 
$\underline{\text { Anexos }}$ 


\section{FACULDADE DE SAÚdE PÚBLICA- USP- ANEXO 1}

\section{Termo de Consentimento Livre e Esclarecido}

Declaro, para os devidos fins, que concordo em participar da pesquisa "Determinação das concentraçбes séricas de $\alpha$ - tocoferol em pacientes portadores e não portadores de diabetes mellitus do tipo 2", que tem o objetivo de determinar as concentraçôes do antioxidante vitamina $E$ no sangue. Fui esclarecido(a) sobre os procedimentos a serem realizados, e me submeterei a uma entrevista para fornecer dados importantes para a pesquisa, estando ciente que informaç⿸̃es adicionais, como por exemplo complicaçðes diabéticas, poderæ̃o ser adquiridas diretamente do prontuário ambulatorial, ficando garantida a minha pivacidade. Permito a coleta de 8 $\mathrm{mL}$ de sangue, sendo que fui esclarecido(a) de que as técnicas utilizadas para os procedimentos de coleta serão feitas tomando-se os cuidados cabíveis, garantindo a minha seguranca.

Para a colaboração na pesquisa registro meu consentimento, assinando logo abaixo.

NOME:

ASSINATURA:

IMPORTANTE: Todas as informações formecidas pelo $\operatorname{Sr}(a)$ são confidenciais e a sua participação ou recusa, em nada interfere no seu atendimento por este ambulatório, sendo assegurado que em qualquer momento do estudo o consentimento de participação poderá ser retirado sem qualquer constrangimento ou prejuízo.

A sua contribuição é muito importante! Obrigada por participar!

Såo Paulo, de de 2005.

\section{ASSINATURA PESQUISADORA:}

Dúvidas ou informaçōes, procurar: Vanessa Kristinne Illison. Tel: 8265-9686 ou Patricia Helen de Carvalho Rond6. Faculdade de Saúde Pública da Universidade de Sro Paulo - Av. Dr. Arnaldo, 715. Sao Poulo/SP. Tel: (011) 3066-7705 ou 3066-7701. 


\section{FACULDADE DE SAÚdE PÚBLICA- USP- ANEXO 2}

\section{DETERMINAÇÃO DAS CONCENTRAÇOEES SERICAS DE $\alpha$ - TOCOFEROL EM PACIENTES PORTADORES E NAO PORTADORES DE DIABETES MELLITUS DO TIPO 2 DO MUNICIPIO DE JUNDIAI- SP.}

\section{FORMULÁRIO DE ENTREVISTA}

ENTREVISTADO $\mathbf{N}^{\circ} \bigsqcup 」$

Data:

$N^{\circ}$ Prontuário:

\section{A. IDENTIFICAÇÃo}

1. Nome completo:

2. Sexo:

(0)F (1)M

3. Data de nascimento:

4. Endereço: $\mathbf{N}^{\circ}$

5. Cidade: 6. Bairro:

7. CEP: 8. Telefone: ( )

9. E.Civil: (0)Solteiro (1)Casado (2)C/companheiro (3)Viúvo (4)Separado

\section{B. DADOS SÓcIOECONÔMICOS}

10. Ocupaça: (0)Desempregado (1)Trabalha (2)Aposentado

11. Renda familiar mensal: $\mathbf{R} \$$
$(0) \leq 1$ SM
(1)1-2 SM
(3) $3-4$ SM
(4)5-7 SM (5)>7 SM

12. Quantas pessoas residem na casa?
13. Escolaridade: (0)Nenhuma
(1) primário incompleto
(2) primário completo

(3) gin incompleto

(4) gin. completo

(5) $2^{\circ}$ grau incompleto

(6) $2^{\circ}$ grau completo

(7) $3^{\circ}$ grau incompleto (8) $3^{\circ}$ grau completo

C. HÁBITOS
14. O Sr.(a) fuma?
(0) Não
(1) Sim

15. Caso positivo, quantos cigarros em média por dia?
(0) Até 5
(1) 6-11
(2) 12 ou mais

16. Há quanto tempo o Sr.(a) fuma? (em meses)

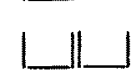


17. Se parou de fumar, há quanto tempo? (em meses)

18. O Sr.(a) costuma ingerir bebidas alcoólicas?
(0) Não
(1) Às vezes
(2) Freqüentemente

19. Quantidade (copo) (0)<1 (1)2-5 (2) $>7$
Tipo:
(0) Fermentada
(1) Destilada

20. O Sr.(a) costuma tomar café?
(0) Não
(1) Às vezes
(2) Freqüentemente

21. Quantidade (copo) (0)<1 (1)2-5 (2) $>7$

\section{ATIVIDADE FISICA}

22. Quanto à sua atividade fisica:

\begin{tabular}{|c|c|c|c|}
\hline & TIPO & DURAÇÅO & FREQUENCIA \\
\hline LABORATIVA & & & \\
\hline 18.2 & & & \\
RECREATIVALAZER & & & \\
\hline 18.3 & & & \\
TERAPEUTICA & & & \\
\hline
\end{tabular}
(0)=Sedentária;
(1)=Leve;
(2) $=$ Moderada

\section{E. HISTORIA DO DLABETES}

23. Há quanto tempo o $\mathrm{Sr}$.(a) tem diabetes? (anos)
$(0) \leq 1(1) 1-2$
(2) 3-4 (3)5-7
(4) 7-10
$(5)$

24. Como descobriu que tinha diabetes?

25. Tem casos de diabetes na família? (0)Não

(1)Sim

26. Qual era o seu peso na época da descoberta do diabetes?

Kg

27. Qual era o seu peso antes do diabetes se manifestar? $\mathrm{Kg}$

28. Qual foi o tratamento utilizado, na época do diagnóstico?

29. O Sr.(a) já apresentou alguma complicação decorrente do diabetes?
(0) Não
(1) (Sim)

30. Se positivo. Qual? 
31. Que tipo de tratamento o Sr.(a) faz atualmente?
(0) Dieta
(1) Hipoglicemiante oral
(2) Os dois juntos

32. Se utiliza hipoglicemiante oral, qual?
(0) Nð̃o toma
(1) 1
(2) 2
(3)3
(4)4 (5)mais

33. Se utiliza anti-hipertensivo, qual?
(0) Não toma (1)1
(2)2
(3) 3
(4)4 (5)mais

34. O Sr.(a) toma algum tipo de vitamina? Qual?
(0)Não toma
(1) 1
(2)2
(3)3
(4)4
(5)mais

35. Quantas refeiçðes o Sr.(a) faz por dia?
(0)1 (1)2
(2)3
(3) 4
(4)5
$(5) 6$
(6)mais

F. SINTOMAS DE HIPOGLICEMIA E HIPERGLICEMIA (Freqüência)

\begin{tabular}{|l|l|l|l|l|}
\hline HIPERGLICEMIA & MUTTAS VEZES (3) & ALGUMAS VEZES (2) & RARAMENTE (1) & NUNCA(0) \\
\hline Polifagia (muita fome) & & & & \\
\hline Polidipsia (muita sede) & & & & \\
\hline Poliúria (urinar muito) & & & & \\
\hline Nictúria (urinar à noite) & & & & \\
\hline Sonoléncia & & & & \\
\hline Cansaço fisico & & & & \\
\hline Visåo turva & & & & \\
\hline
\end{tabular}

\begin{tabular}{|l|l|l|l|l|}
\hline HIPOGLICEMIA & MUTTAS VEZES (3) & ALGUMAS VEZES (2) & RARAMENTE (1) & NUNCA(0) \\
\hline Fraqueza & & & & \\
\hline Tontura & & & & \\
\hline Dor de cabeca & & & & \\
\hline Fome súbita & & & & \\
\hline Sudorese & & & & \\
\hline Tremores & & & & \\
\hline Taquicardia (batedeira) & & & & \\
\hline
\end{tabular}




\section{FACULdADE DE SAÚdE PÚbliCA-USP - ANEXO 3}

FICHA DE AVALIAÇÃO (inicial I e final II)

ANTROPOMETRIA, BIOQUIMICA E ANTIOXIDANTES

Entrevistado $N^{\circ} \perp \perp$ Data: ___ _ _ $\quad N^{\circ}$ Prontuário:

Nome Completo:

\section{G. DADOS ANTROPOMÉTRICOS}

\begin{tabular}{|l|l|l|l|l|}
\hline & PESO & ALTURA & CIRC. CINTURA & CIRC. QUADRIL \\
\hline Medida 1 & & & & \\
\hline Medida 2 & & & & \\
\hline Medida 3 & & & & \\
\hline Média & & & & \\
\hline
\end{tabular}

37. IMC:

$\mathrm{Kg} / \mathrm{m}^{2}$.

38. Razão cintura/quadril: cm.

39- Circunferência do Pescoço: cm.

H. PRESSÃO ARTERIAL

\begin{tabular}{|l|l|l|}
\hline & SISTOLICA & DIASTÓLICA \\
\hline Medida 1 & & \\
\hline Medida 2 & & \\
\hline Medida 3 & & \\
\hline Média & & \\
\hline
\end{tabular}


FACULDADE DE SAÚdE PÚBLICA- USP ANEXO 4 QUESTINARIO DE FREQUÊNCIA DE CONSUMO ALIMENTAR

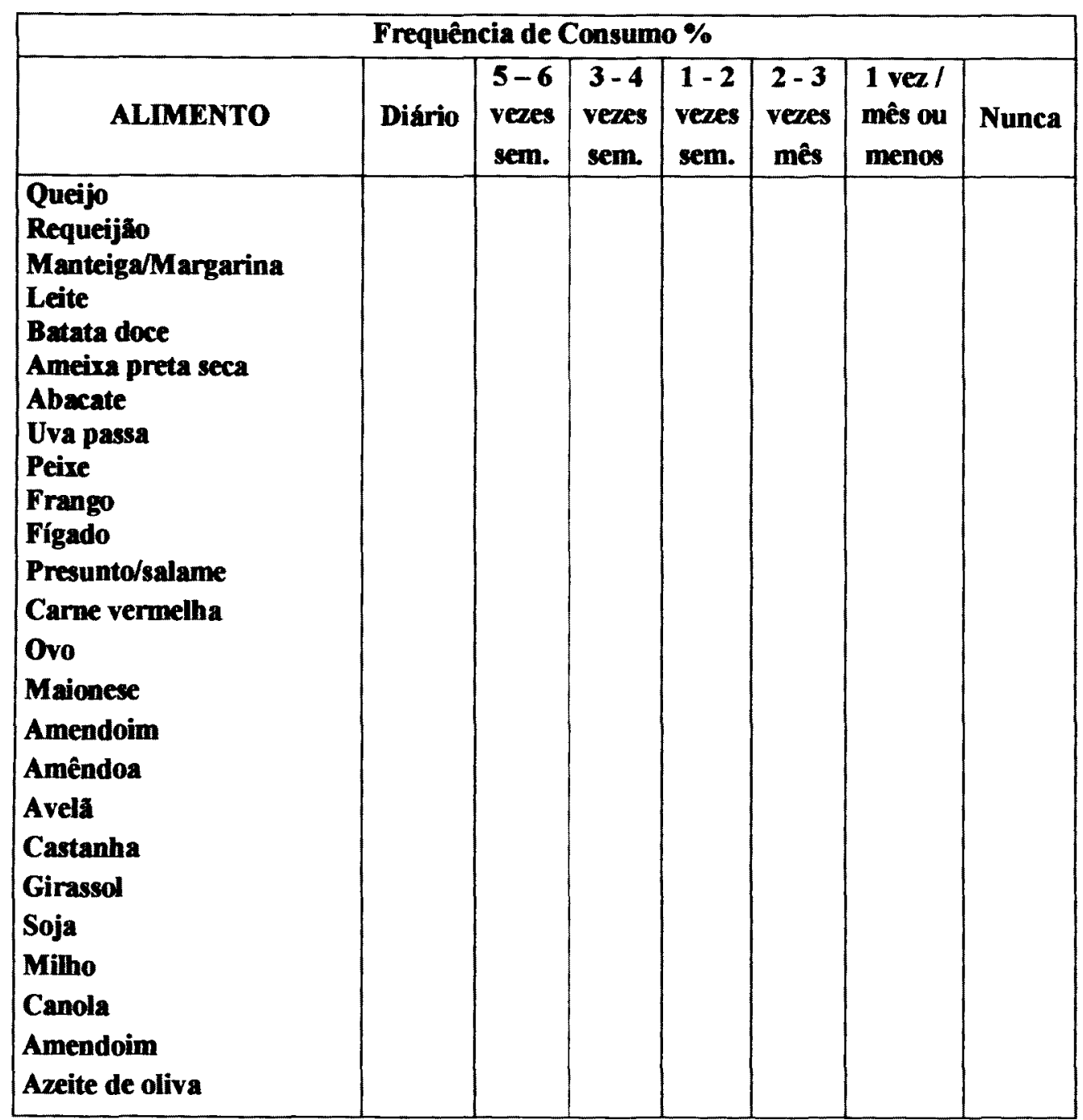




\section{FACULDADE DE SAÚDE PÚBLICA- USP- ANEXO 5 COMITE DE ÉTICA}

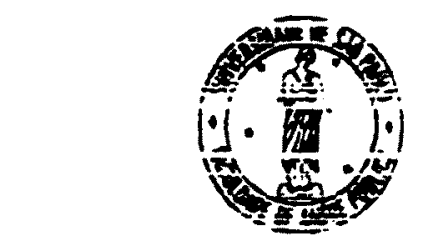

\section{Universidade de São Paulo}

Faculdade de Saúde Pública

COMITE DE ÉTICA-COEP

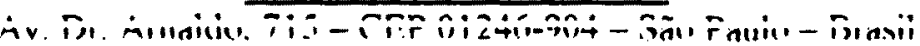

Telefones: (55-11) 306n-7770_foneifax (55-11)3064_7314-e-mail: mdgracas@usp.br

\section{Or.COEP/182/04}

25 de novembro de 2004

Pelo presente, informo que o Comitê de Ética em Pesquisa da Faculdade de Saúde Pública da Universidade de São Paulo-COEP, analisou e aprovou, de acordo com os requisitos da Resolução CNS/196/96, o Protocolo de Pesquisa n. 1174 , intitulado: "DETERMINAÇÃO DOS NIVEIS DE $\alpha$-TOCOFEROL E ÁCIDO $\alpha$ - LIPÓICO EM PACIENTES DIABÉTICOS DO TIPO 2", apresentado pela pesquisadora Vanessa Kristinne Illison.

Atenciosamente,

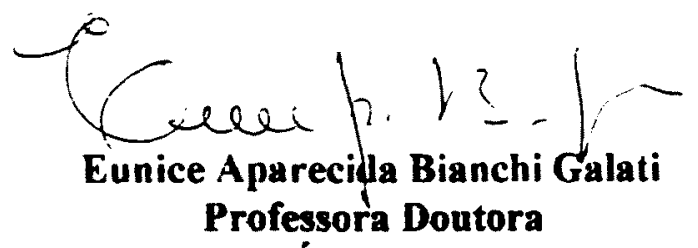

Coordenadora do Comitê de Ética em Pesquisa da FSP-COEP 